Check for updates

Cite this: RSC Adv., 2019, 9, 2673

Received 30th October 2018 Accepted 23rd December 2018

DOI: $10.1039 / c 8 r a 08982 e$

rsc.li/rsc-advances

\section{Green synthesis of silver nanoparticles: biomolecule-nanoparticle organizations targeting antimicrobial activity $\dagger$}

\author{
Anupam Roy, $t^{\mathrm{a}}$ Onur Bulut, $t^{\text {bcd }}$ Sudip Some, ${ }^{\mathrm{e}}$ Amit Kumar Mandal ${ }^{\star \mathrm{e}}$ \\ and M. Deniz Yilmaz iD *df
}

Since discovery of the first antibiotic drug, penicillin, in 1928, a variety of antibiotic and antimicrobial agents have been developed and used for both human therapy and industrial applications. However, excess and uncontrolled use of antibiotic agents has caused a significant growth in the number of drug resistant pathogens. Novel therapeutic approaches replacing the inefficient antibiotics are in high demand to overcome increasing microbial multidrug resistance. In the recent years, ongoing research has focused on development of nano-scale objects as efficient antimicrobial therapies. Among the various nanoparticles, silver nanoparticles have gained much attention due to their unique antimicrobial properties. However, concerns about the synthesis of these materials such as use of precursor chemicals and toxic solvents, and generation of toxic byproducts have led to a new alternative approach, green synthesis. This eco-friendly technique incorporates use of biological agents, plants or microbial agents as reducing and capping agents. Silver nanoparticles synthesized by green chemistry offer a novel and potential alternative to chemically synthesized nanoparticles. In this review, we discuss the recent advances in green synthesis of silver nanoparticles, their application as antimicrobial agents and mechanism of antimicrobial mode of action.
aLaboratory of Food Chemistry and Technology, Department of Chemical Engineering, Birla Institute of Technology, Mesra, Ranchi-835215, India

${ }^{b}$ Department of Molecular Biology and Genetics, Faculty of Agriculture and Natural Sciences, Konya Food and Agriculture University, 42080 Konya, Turkey

'Department of Biological Sciences, Middle East Technical University, 06800 Ankara, Turkey

${ }^{d}$ Research and Development Center for Diagnostic Kits (KIT-ARGEM), Konya Food and Agriculture University, 42080 Konya, Turkey. E-mail: deniz.yilmaz@ gidatarim.edu.tr
${ }^{e}$ Chemical Biology Laboratory, Department of Sericulture, Raiganj University, Uttar Dinajpur-733134, India. E-mail: amitmandalos@gmail.com

${ }^{f}$ Department of Bioengineering, Faculty of Engineering and Architecture, Konya Food and Agriculture University, 42080 Konya, Turkey

$\dagger$ Dedicated to Prof. Anil Bhuimali, Hon'ble Vice-Chancellor Raiganj University on the occasion of his $59^{\text {th }}$ birthday.

$\$$ These authors contributed equally to this work.

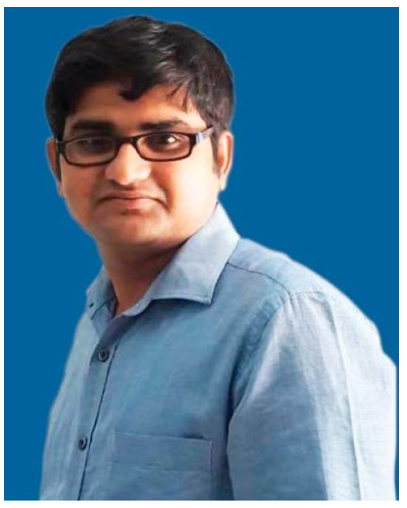

molecules for food applications.
Dr Anupam Roy obtained his PhD degree (2017) from Agricultural and Food Engineering Department, Indian Institute of Technology Kharagpur, India. At present he is working as an Assistant Professor in the Department of Chemical Engineering, Birla Institute of Technology Mesra, Jharkhand, India. His research is focused on the application of nanotechnology in developing advanced bio-

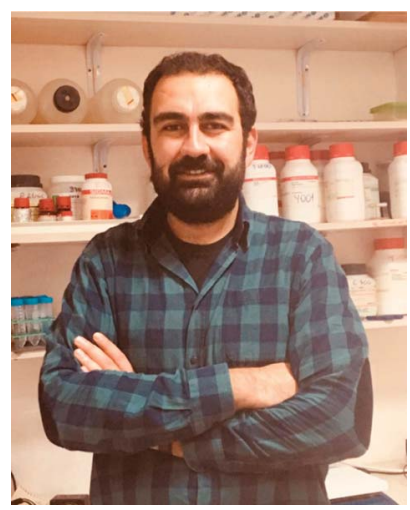

Onur Bulut was born in Turkey in 1989; he obtained his BSc degree in Molecular Biology and Genetics from Istanbul University in 2012 and his MS degree in Biology from Middle East Technical University (METU) in 2014. Currently, he is pursuing PhD in Biochemistry at METU and also working as a research assistant at Konya Food \& Agriculture University. His research interests are nanomaterials, biosensing and antimicrobial agents. 


\section{Introduction}

The increasing tendency of microbial infections, rapid emergence of drug-resistance to recent antibiotics and quick evolution through mutation necessitate development or modification of antimicrobial compounds and alternative treatments. ${ }^{1-4}$ Advanced research in nanotechnology recently comes with the development of nano-scale objects with prominent antimicrobial actions against multidrug resistant pathogens suggesting a platform to fight against bacterial mutation arch. ${ }^{5,6}$ Among the most advanced nanotechnological applications, metal nanoparticles provide the most effective results with their unique mode of actions. ${ }^{7}$

Based upon the evidence of microcidal lethal effects of essential metals (indispensible for the biochemistry of life in all organism fulfilling cellular functions) in excess dose and nonessential metals even at very minute doses, the use of metals as antimicrobial agents has proved to have strong scientific evidences since antiquity. ${ }^{8-10}$ In some cases metal ion being

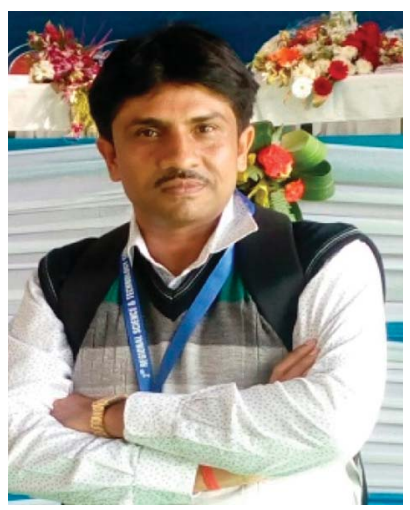

Sudip Some was born in India in 1975; he received his MSc in Botany with specialization in Microbiology from the University of North Bengal, India, in 1998. He was awarded MPhil in Environmental Sciences from University of Burdwan, India, in 2002. He moved to Raiganj University, India for his PhD studies in 2017 under the supervision of Dr Amit Kumar Mandal. He is working on plant extract mediated green synthesis of silver nanoparticles and study of its antimicrobial activity.

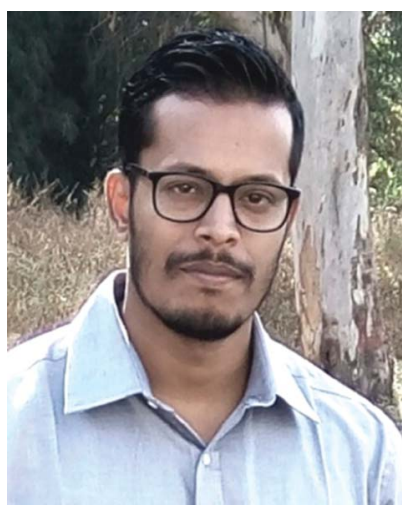

Dr Amit Kumar Mandal was born in India in 1984, he received his $B S c$ degree from Chaudhary Charan Singh University, India, in 2005, his MSc from University of North Bengal, India, in 2007, and his PhD degree from University of North Bengal, India, in 2017. He started his career as an Assistant Professor at Vidyasagar University, India, in 2014; he then moved to Raiganj University,

India, in 2017, as a full time Assistant Professor. He received prestigious Young Scientist award-2017 and Green Technology Innovation award -2018 by NESA, India. His research interests focus on nanomaterials, antimicrobials chemotherapy, and hostmicrobe interactions. tightly bound to antibiotic structure (e.g. bacitracin, bleomycin, streptonigrin, and albomycin) regulates the biocidal action, ${ }^{11}$ they have been attached to the antibiotic molecule (e.g. tetracyclines, aureolic acids, and quinolones) without causing a major change in antibiotic structure but enhancing the activity. ${ }^{12}$ Based on the microcidal nature, the synthesis of metal nanoparticles elicited high interest among the researchers and nanotechnologists. Efforts are made to prepare green synthesized nanoscale objects with different metals like copper, ${ }^{13,14}$ zinc, $^{15}$ titanium, ${ }^{16}$ magnesium, ${ }^{17}$ gold ${ }^{18}$ and silver. $^{19}$ Other green synthesized metals like gold with their low-dimensional structure $^{20}$ finds several other application in varying fields of engineering and technology; whereas, synthesis of silver nanoparticle by green method finds its possible application in biomedical field specially in antimicrobial development (AgNPs). ${ }^{21}$

Nanoscale silver particles with high surface-area-to-volume ratio (size below $100 \mathrm{~nm}$ ) are of prime interest due to high antimicrobial actions against both Gram-positive and Gramnegative bacteria, ${ }^{19,22}$ viruses and other eukaryotic microorganism $s^{23}$ as compared to other metals in their nano form. It also offers potential effects against multidrug susceptible as well as multidrug resistant strains like Pseudomonas aeruginosa, ampicillin-resistant Escherichia coli, erythromycin-resistant Streptococcus pyogenes, methicillin-resistant Staphylococcus aureus (MRSA) and vancomycin-resistant Staphylococcus aureus (VRSA). ${ }^{7}$ Due to their biocidal actions, several physical and chemical routes have been applied to synthesize AgNPs, and AgNPs have been tried to be applied in modifying surfaces, coating, fibre grafting, gel preparations etc. ${ }^{24-27}$ But the drawbacks including use of toxic precursor chemicals (such as sodium borohydride, potassium bitartrate, methoxypolyethylene glycol, and hydrazine), use of toxic solvents (such as sodium dodecyl benzyl sulphate and polyvinyl pyrrolidone), and generation of toxic by-products arise via traditional roots (physical and chemical methods) of silver nanoparticle synthesis. With the advancement of science, the synthesis of

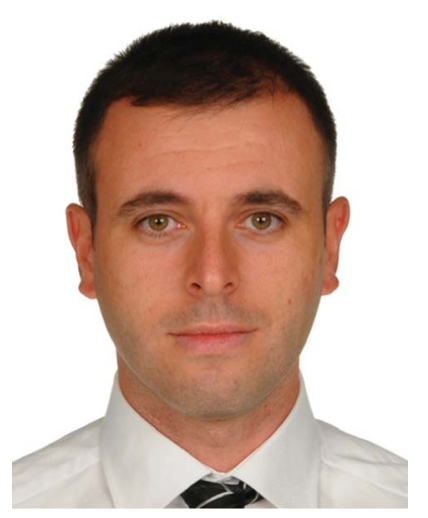

M. Deniz Yilmaz obtained his PhD with Prof. Dr Jurriaan Huskens from University of Twente, The Netherlands. After postdoctoral stay with Prof. Dr Fraser Stoddart at Northwestern University, USA, he became an Assistant Professor at Konya Food and Agriculture University, Turkey. Since April 2016 he has been Associate Professor at the same university. His research is focused on nanomaterials and supramolecular chemistry with molecular recognition and fluorescent sensing. 
metal nanoparticles finds alternative eco-friendly routes. Here, a variety of biological agents (plant extracts, bacterial and fungal derived compounds) are used to convert metal salts to nanoparticles. These agents act as in vitro reducing and capping agents. These strategies are used for the synthesis of different metal nanoparticles like silver, copper, iron, etc. $^{28,29}$

\section{Metal nanoparticle structure and surface modification: clue to enhance the antimicrobial activity}

Nanotechnology offers production, manipulation and the use of materials below $100 \mathrm{~nm}$ range. Due to large surface area to volume ratio, nanoparticles offer novel properties leading to widespread use in different field of applications. But this high surface area often brings various drawbacks associated with the surface phenomena. ${ }^{30}$ When reducing the overall surface energy, individual nanoparticles interact with each other via chemical bonds and physical attraction forces at interfaces, resulting in agglomeration. This agglomeration strictly depends on the individual nanostructure size, less the dimension of nanostructures strong the van der Waals attraction forces between nano-structured materials. So to obtain the stable nanoparticle dispersions, this huge surface energy arises from the individual nanostructure should be taken care of. Here comes the concept of stabilizing agents. If a stabilizing agent acts as antimicrobial agent, coining antimicrobial effect can be achieved effectively.

To get the effective engineered nanoparticles, better understanding of nanoparticle structure is necessary. In general sense, nanoparticle structures consist of three layers: (i) core, (ii) shell, and (iii) surface. ${ }^{31}$ The core of the nanoparticle can be synthesized using various methods, reaction conditions and precursors whereas shell is added if necessary. But during the preparation of one dimensional nanoparticle from single salt, the shell is generally composed of the same material with the core. And last, but not at least, most important is surface, which can be functionalized depending upon the need. The need is either to prevent the agglomeration or to give specific function to nanoparticles. The surface functionalization of nanoparticles is due to transient van der Waals interactions of used compounds with the nanoparticle surface.

\section{Green synthesis: biomolecule- nanoparticle organization}

Reduction of metal complexes in dilute solutions is the general method in the synthesis of metal colloidal dispersions. Generally accepted reducing agents such as hydrazine hydrate and sodium borohydride are not preferred due to their tendency in in situ reducing and capping, resulting in additional effects of undesired toxicity impregnated with nanoparticles. Thus the use of green materials like plant extracts, microbial extracts, and algal extracts as reducing agents possesses great advantages (Fig. 1). In general, biological extracts are mixed with the metal salt solutions. ${ }^{32}$ Effect of nature and concentration of the plant extract and salt, temperature, $\mathrm{pH}$, time, radiation, and hypothermia are also studied. ${ }^{33}$ Besides the most often used metal is silver, gold, copper, and iron are also used. ${ }^{30}$ Bio compounds (including alkaloids, phenolic compounds, terpenoids, enzymes, co-enzymes, proteins, and sugars etc.) reduce metal salts from positive oxidation state to zero oxidation state. Size and size distribution of metallic nanoparticles strongly depend on the bio compounds present in the extract. The presence of a strong reductant in the extract promotes a fast reaction rate and favours the formation of smaller nanoparticles. If the biomolecules rapidly reduce the salt leading to continuous formation of new nuclei or secondary nuclei, a narrow size distribution can be observed. However, a slow reaction may also occur if the secondary nucleation is suppressed over primary one. Bio molecules serve a secondary option to form a monolayer on the surface of nanoparticles to prevent the agglomeration. But recent studies on antibiotic mediated synthesis of nanoparticles confirm the surface functionalization of nanoparticles with antibiotics enhancing biocidal activity. ${ }^{34,35}$ Thus, enhanced antimicrobial activity of extract mediated nanoparticles are due to the biomolecules attached on the surface of nanoparticles.

\section{Role of biological molecules in green nanoparticle synthesis and improving antimicrobial action}

Bio molecules produced by living organisms (large macromolecules such as proteins, polysaccharides, lipids, and nucleic acids, as well as small molecules such as primary and secondary metabolites, and natural products) pose specific functions for the growth, development and sustaining in the environment. Biological molecules extracted from living systems show potential role and have become preferred choice in the synthesis of AgNPs, which are summarized in Table 1.

Most frequently used bio molecules originate from plant extracts. ${ }^{32,106,107}$ Apart from the plant extract, bio molecules from microbial (bacteria, fungi, yeasts and actinomycetes), algal and cyanobacterial origin have also been successfully utilized for the synthesis of nanoparticles..$^{33,34,108,109}$ These biological molecules extracted from different sources are externally added to metal salts to form nanoparticles. To synthesize AgNPs, biological extract in situ reduces silver salts $\left(\mathrm{Ag}^{+}\right)$to metallic silver, $\mathrm{Ag}^{0}$. In the process of nanoparticle synthesis in a green way, biological molecules not only reduce the metal salts but also cover the formed nanoparticles or acts as in situ reducing and capping agent. This capping is advantageous over as it acts as multifunctional way; (i) prevents the agglomeration of the nanoparticles, (ii) reduces the toxicity, ${ }^{\mathbf{3 5 , 1 1 0}}$ and (iii) improves antimicrobial action. ${ }^{3-5,106}$ If these coating agents themselves show antimicrobial action, a synergistic effect of metal nanoparticles and the capped bio molecules may be found. Here AgNPs offer action due to its size and bio molecule attached over nanoparticle surface for its own antimicrobial action. This is the possible explanation of low antimicrobial action of biologically synthesized nanoparticles in many cases. So, for 
synthesizing silver nanoparticles in a greenway, research is focusing to synthesize AgNPs using bio molecules which have antimicrobial action of their own.

\section{Synthesis of silver nanoparticles by microbes}

Microbes are being used as a promising biological source for synthesizing metal nanoparticles. But all the organisms do not show ability to convert metals to its nano forms. Microbial synthesis of silver nanoparticles can be achieved either by intracellular scheme or extracellular scheme. ${ }^{\mathbf{1 1 1}}$ In intracellular scheme, an accumulation of silver inside the cell nucleates the silver nanoparticle synthesis and proceeds with the microbial growth. Nanoparticles with live cells are harvested after optimum time of bacterial growth. The harvested cells, thus, require special treatment to release the synthesized nanoparticles. In extracellular synthesis process, extracellular
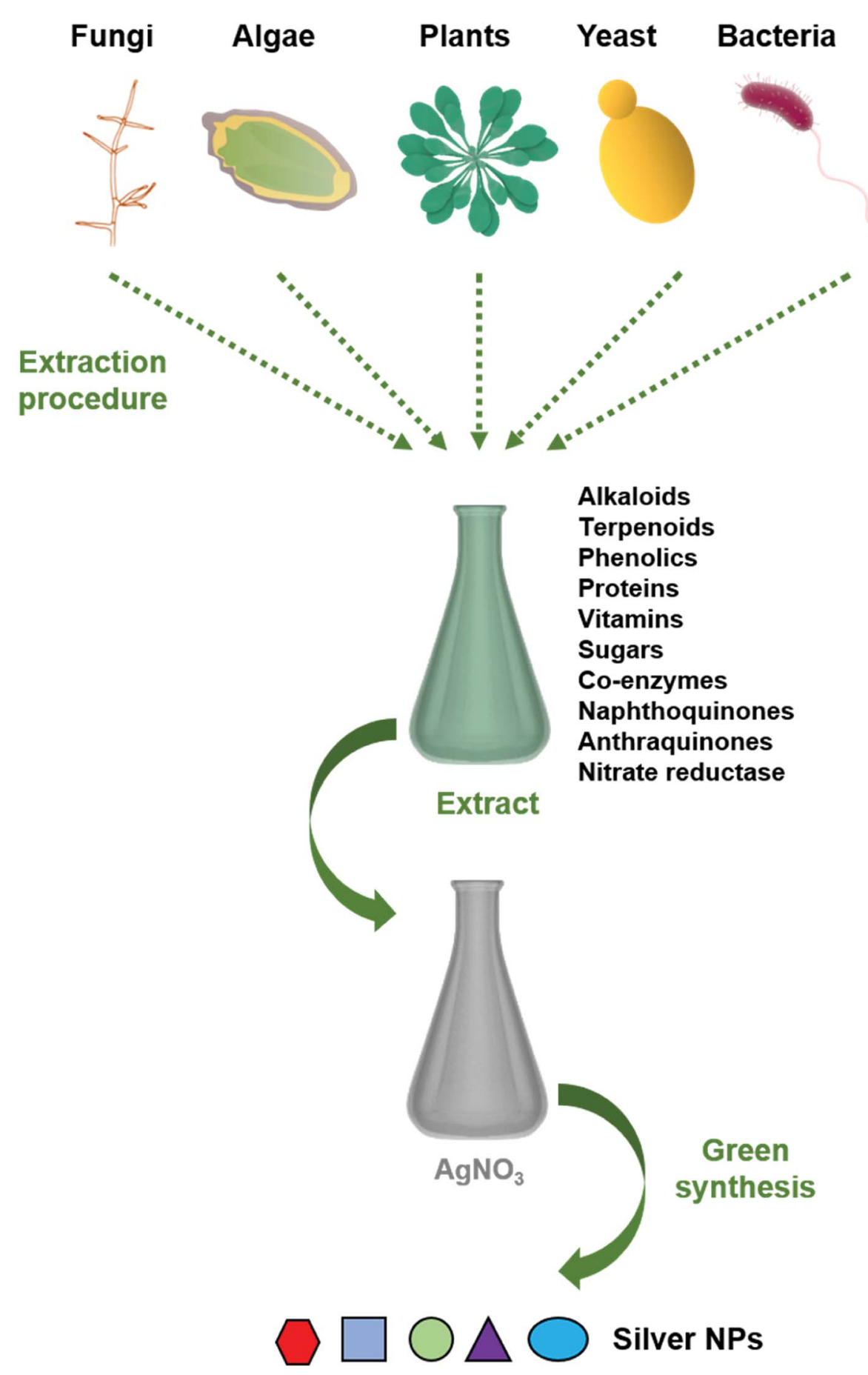

Fig. 1 Schematic representation of the procedure for green synthesis of silver nanoparticles using various biological entities. 
$\stackrel{\infty}{\infty} \stackrel{\infty}{m}$

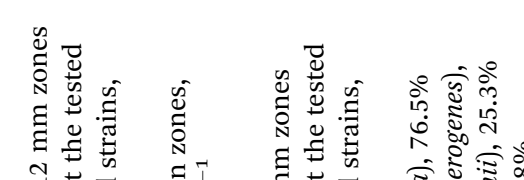

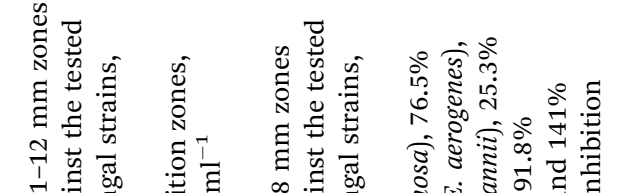

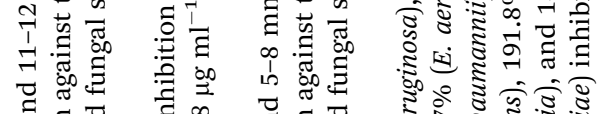

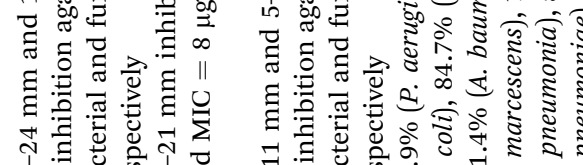

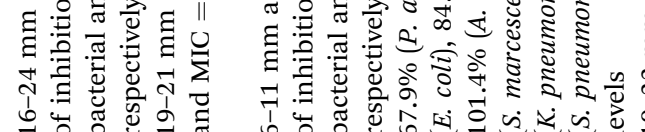

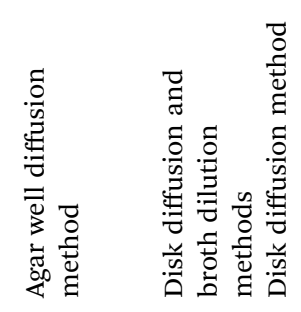

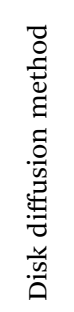

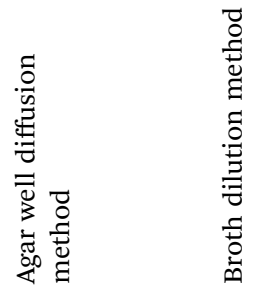

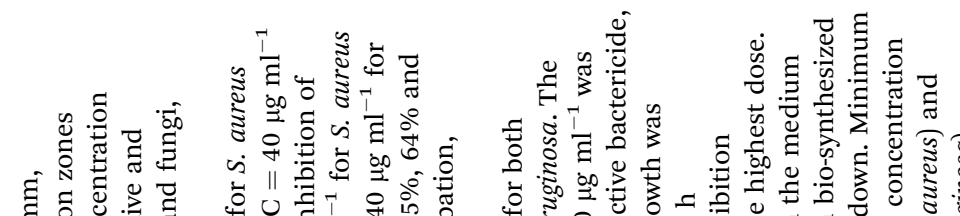

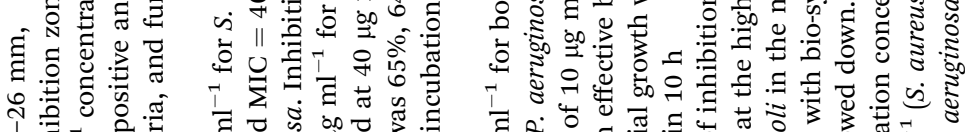

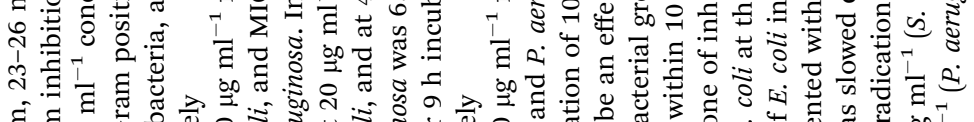

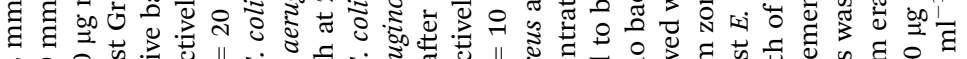

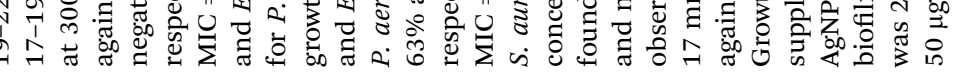
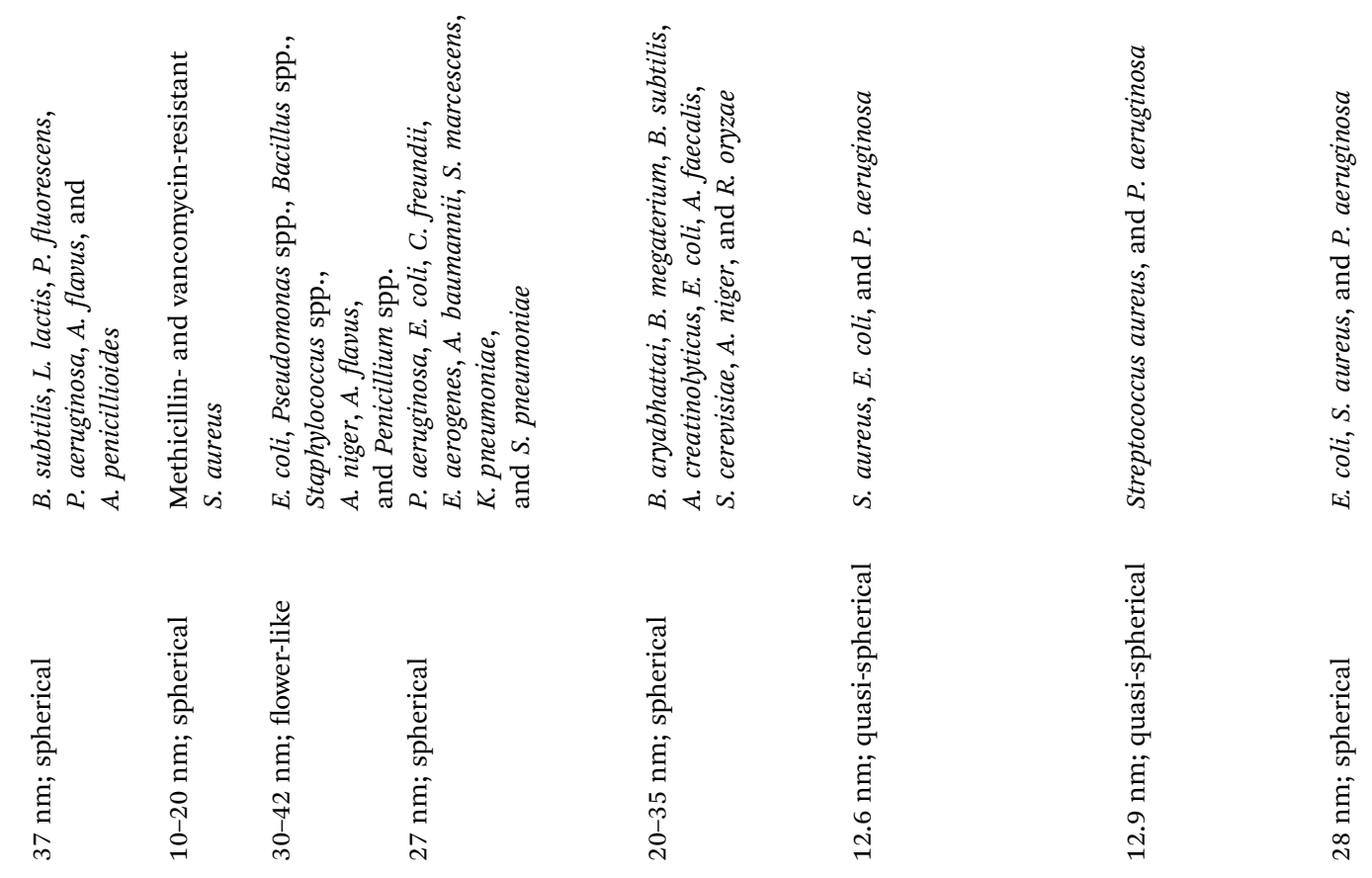

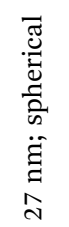
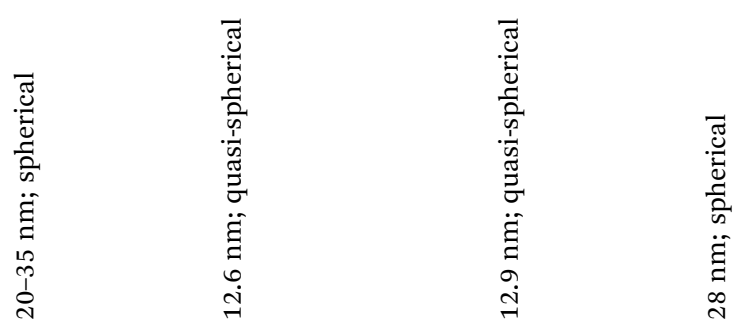

节|
$\stackrel{8}{4}$
\&
f $\stackrel{\infty}{+} \stackrel{9}{7}$
in
ह5

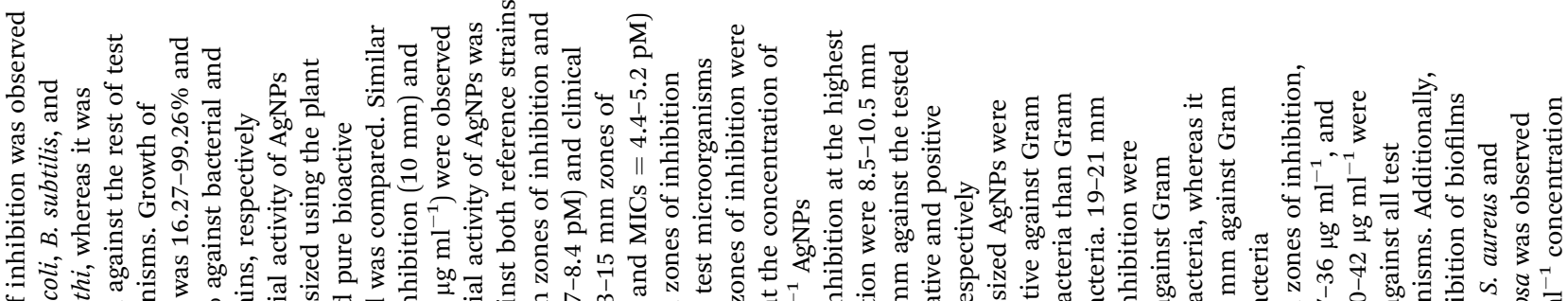

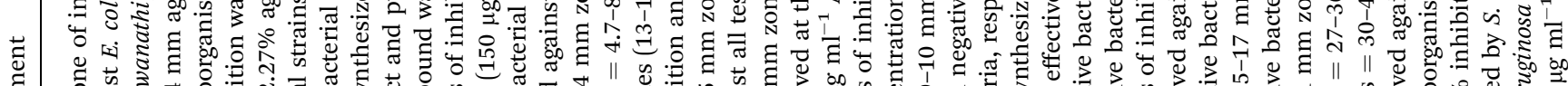

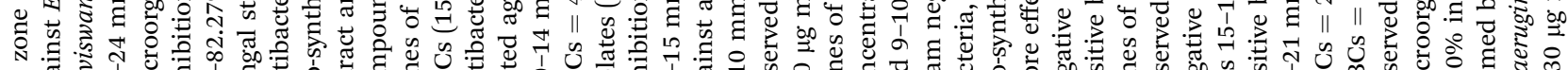

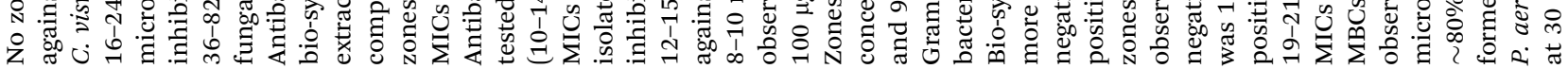
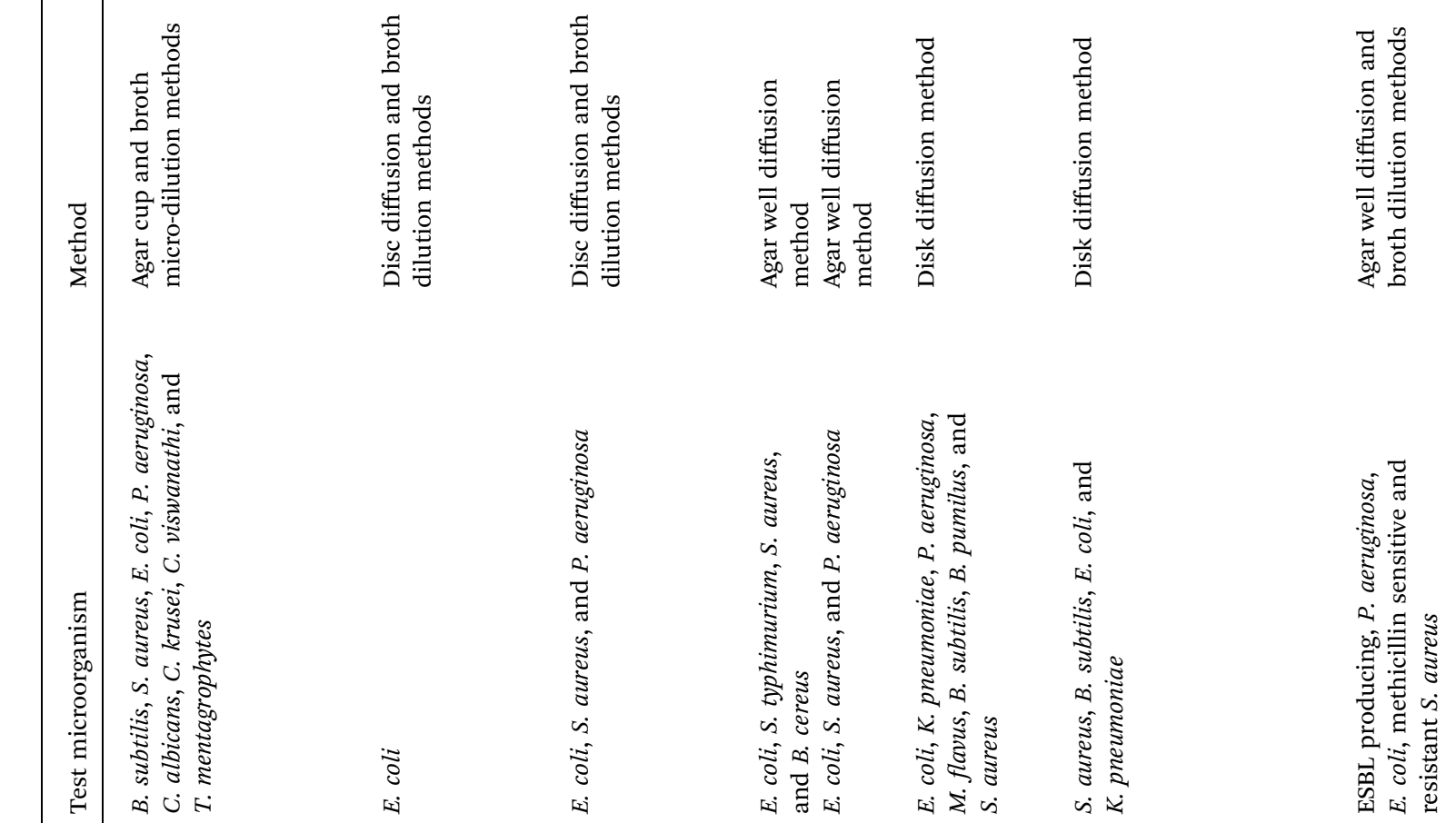

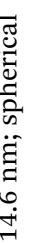
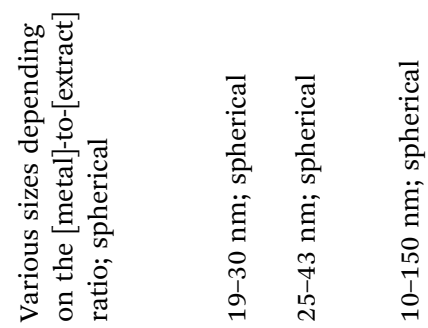

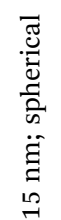

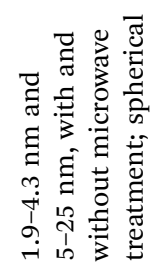

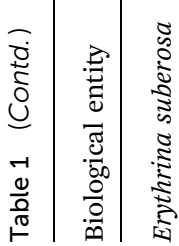

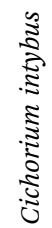<smiles>CC1[C@@H](C)C[C@@H]1C</smiles>

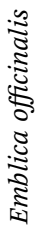

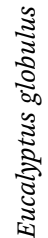


ก ถ⿱⺈

$\stackrel{\circ}{\llcorner}$

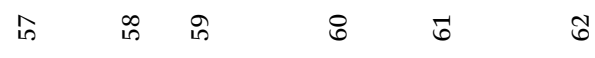

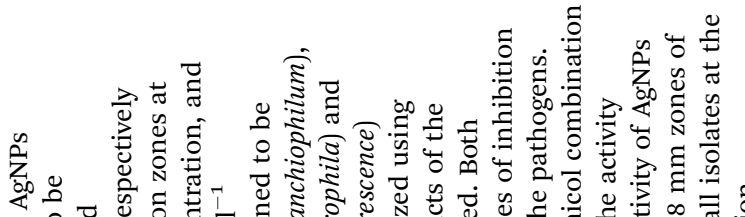

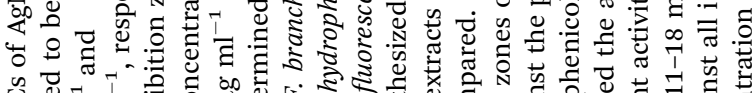

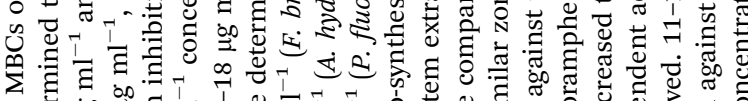

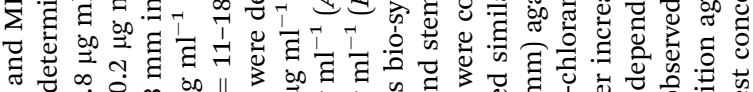

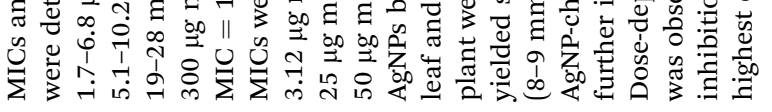

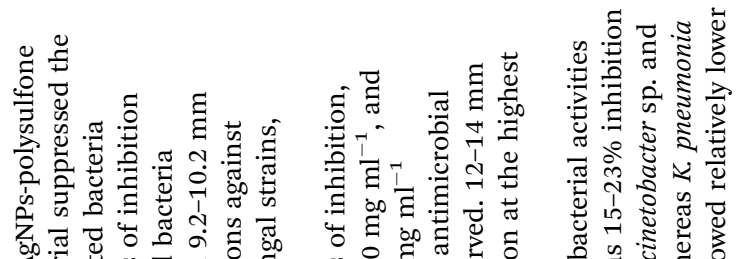

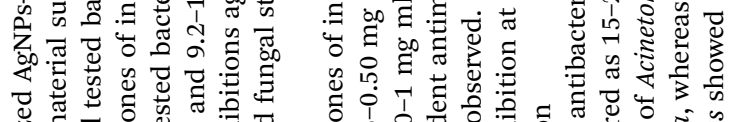

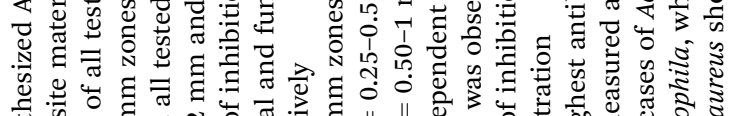

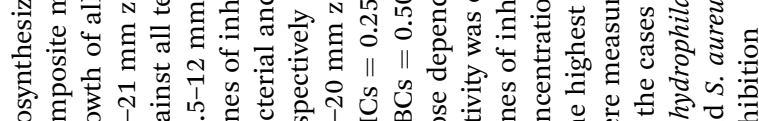

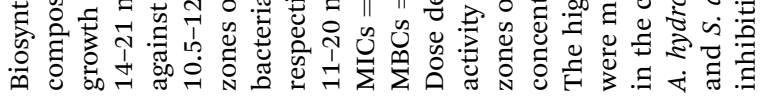

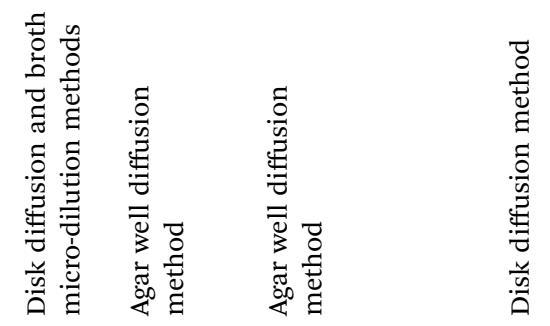

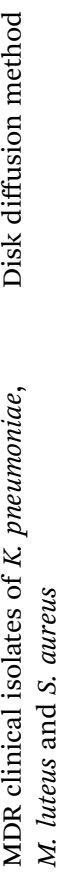
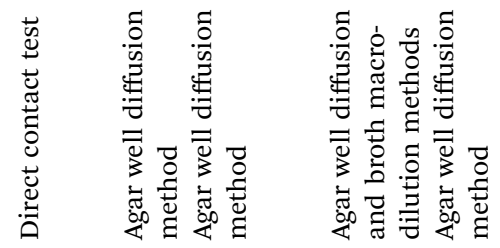

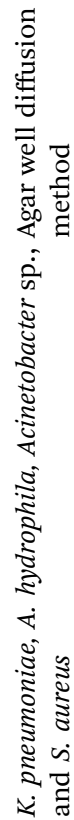

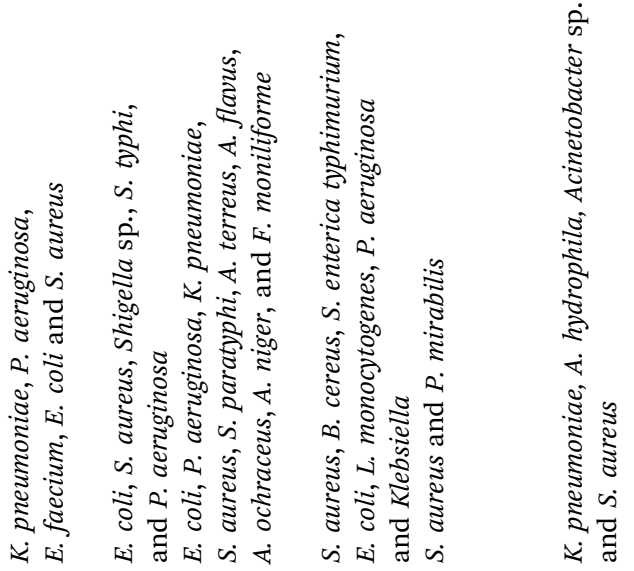

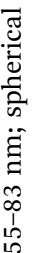
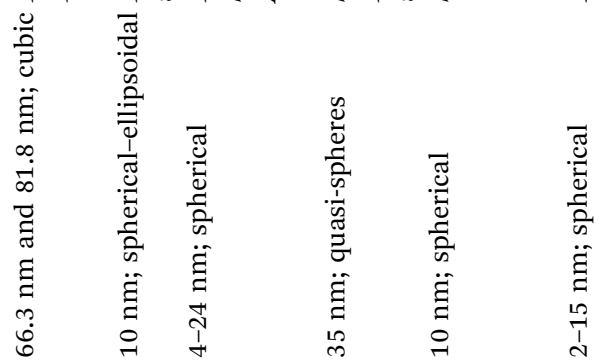

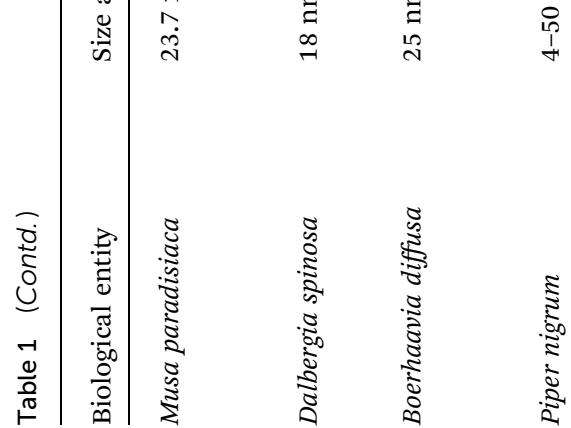

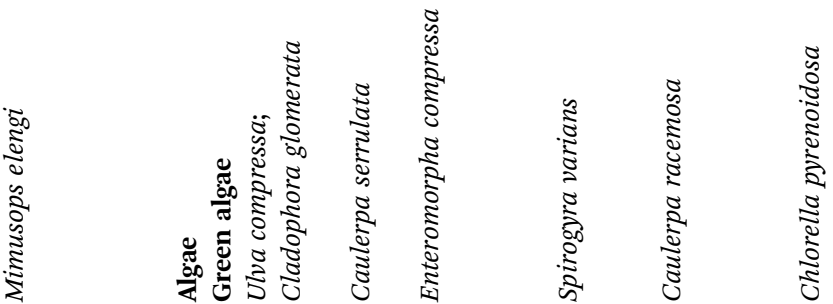




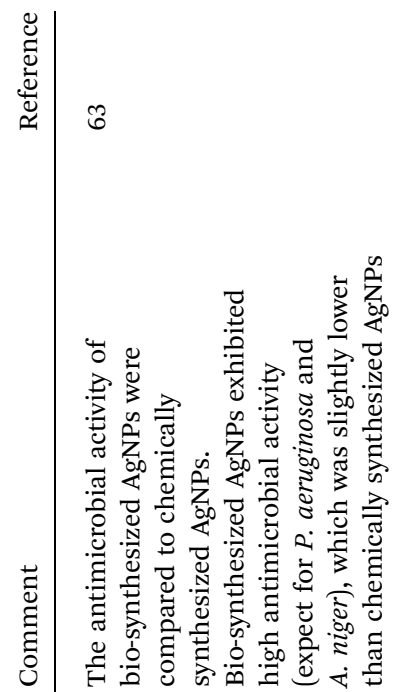

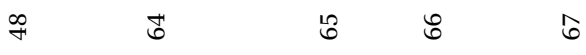

$\infty$

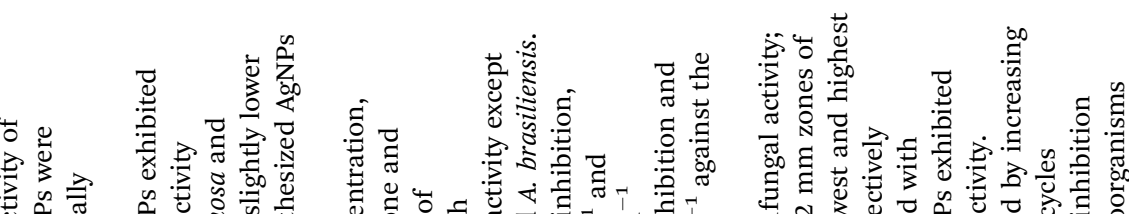

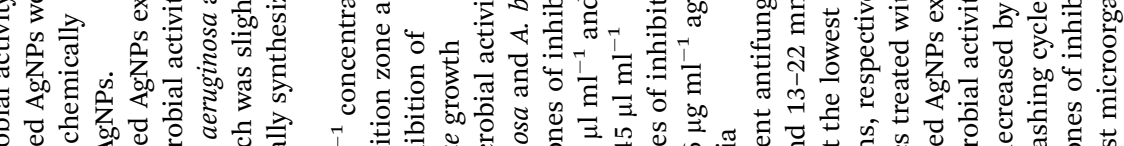

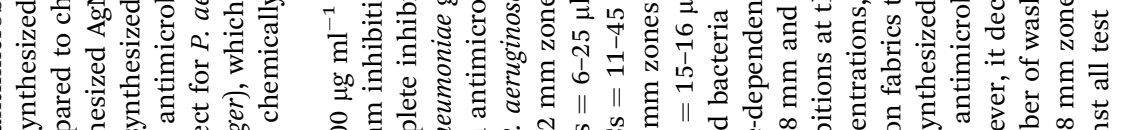

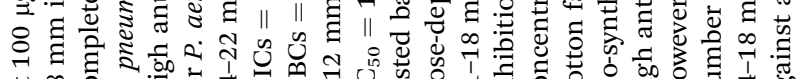

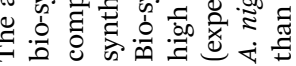

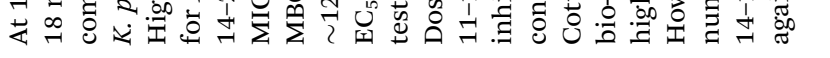

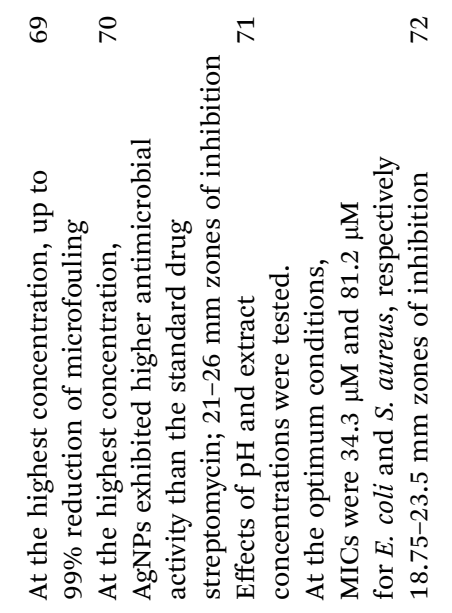

푤

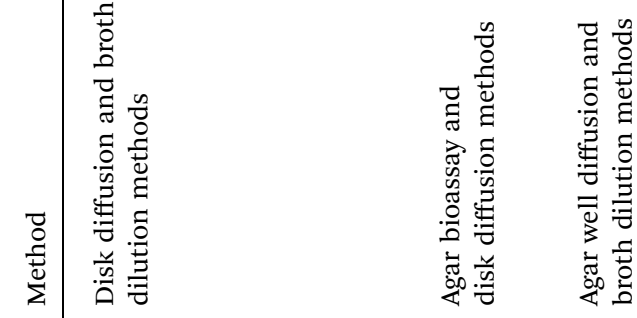

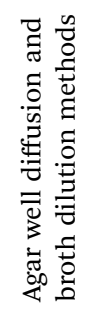
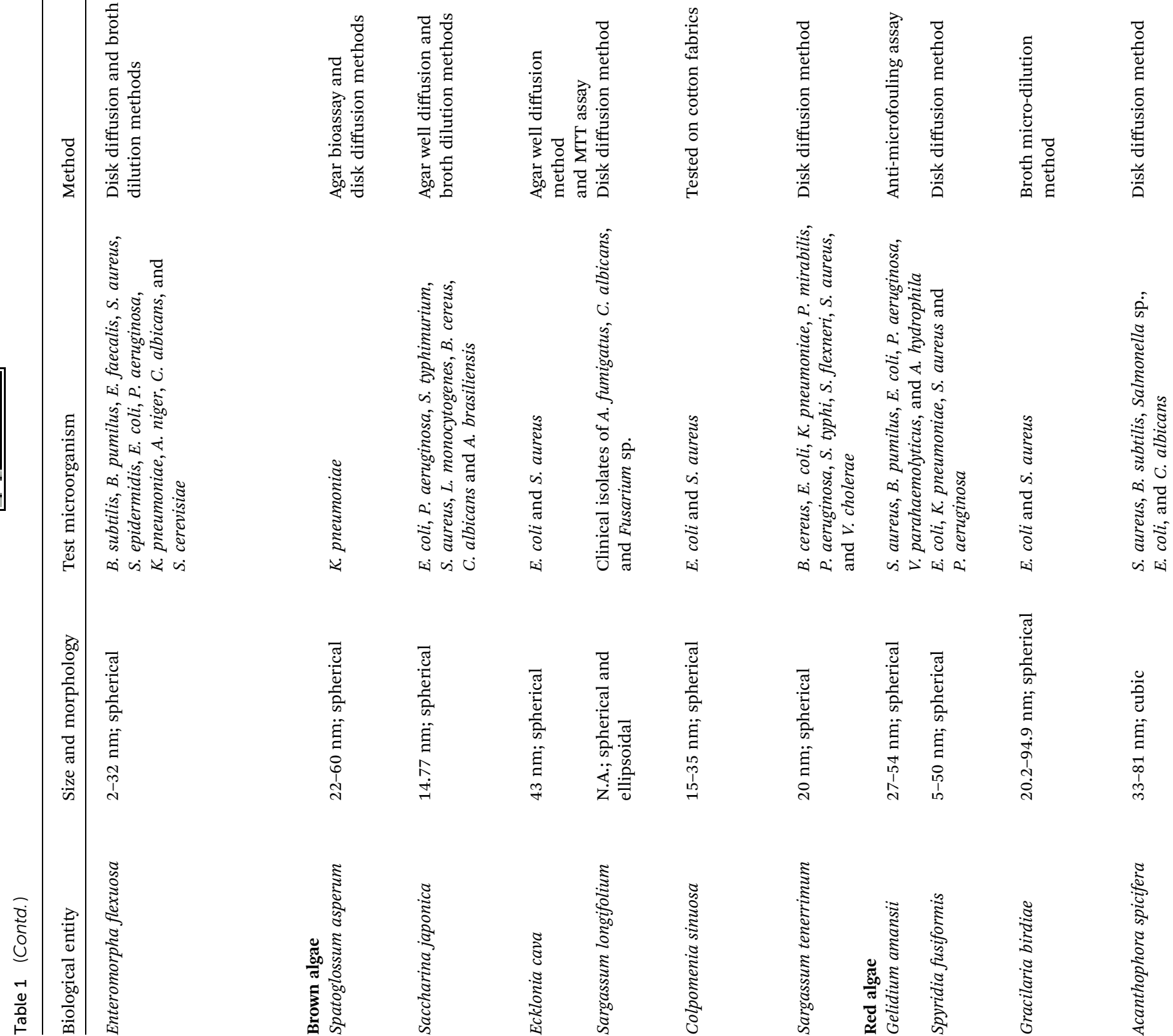

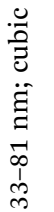




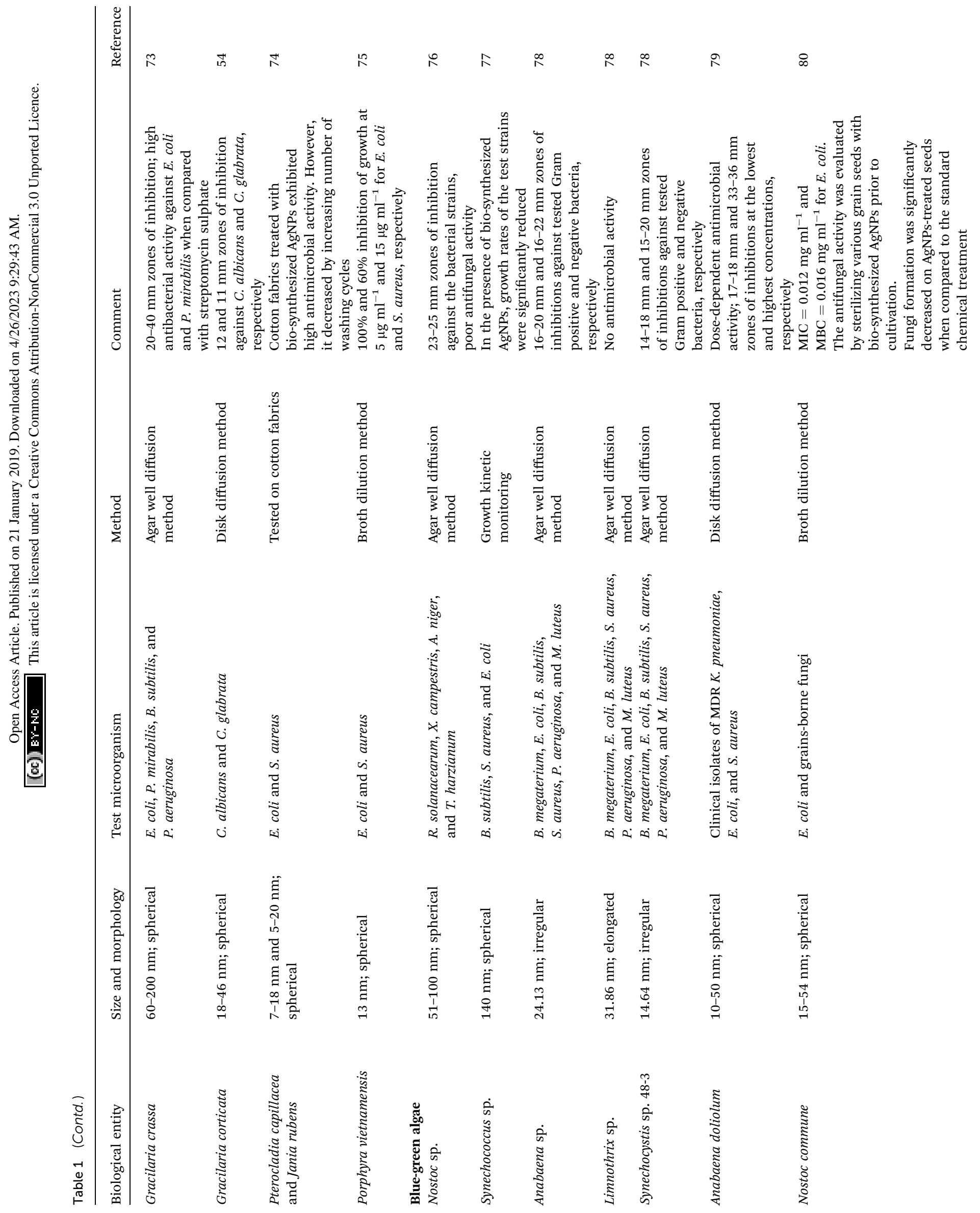


$\bar{\infty} \quad \infty$

$\infty$

$\stackrel{\infty}{\infty} \quad \stackrel{\infty}{\infty} \quad \stackrel{\infty}{\infty}$

$\infty \quad \infty \quad \&$

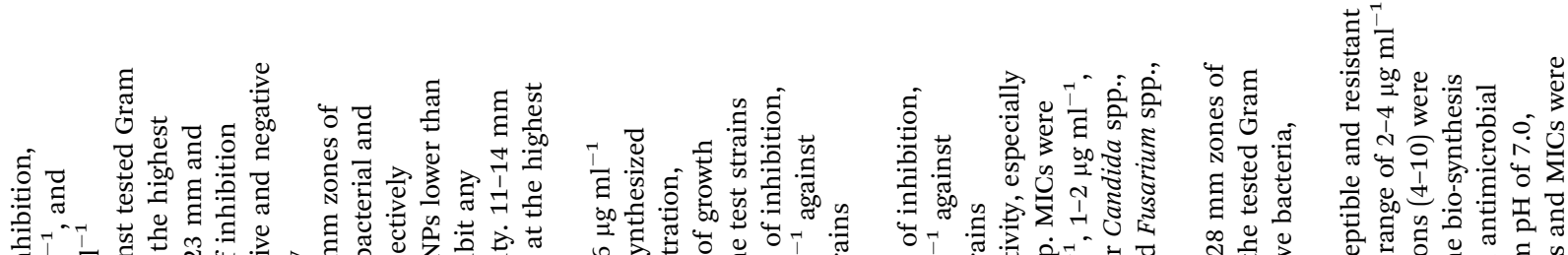

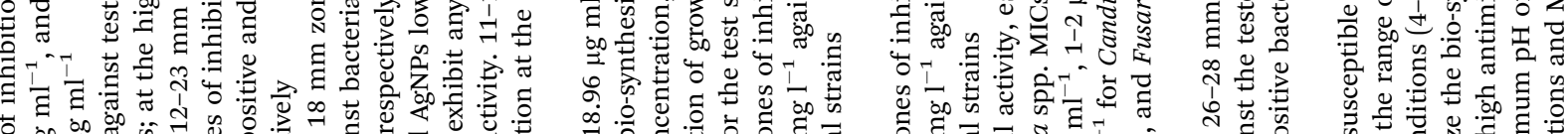

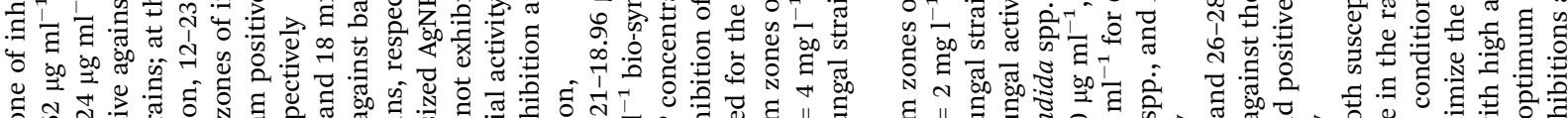

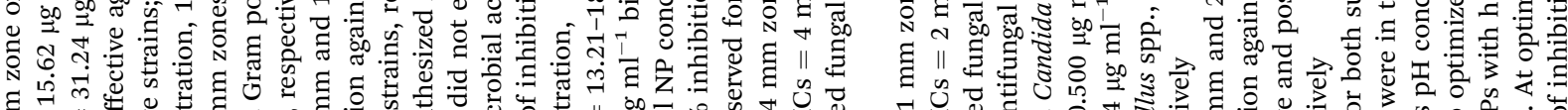

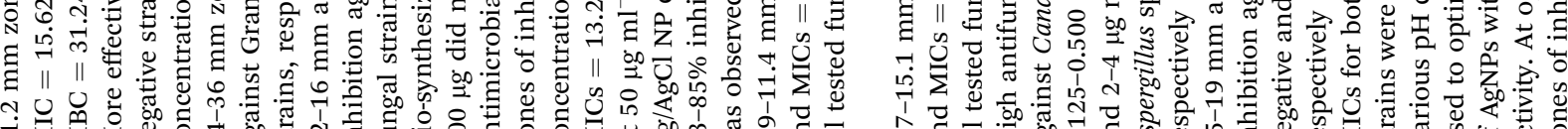

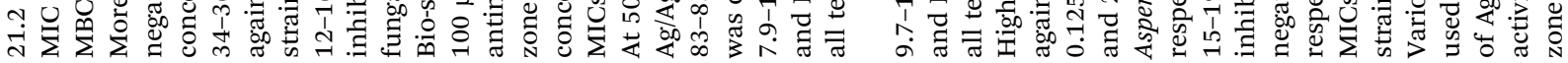
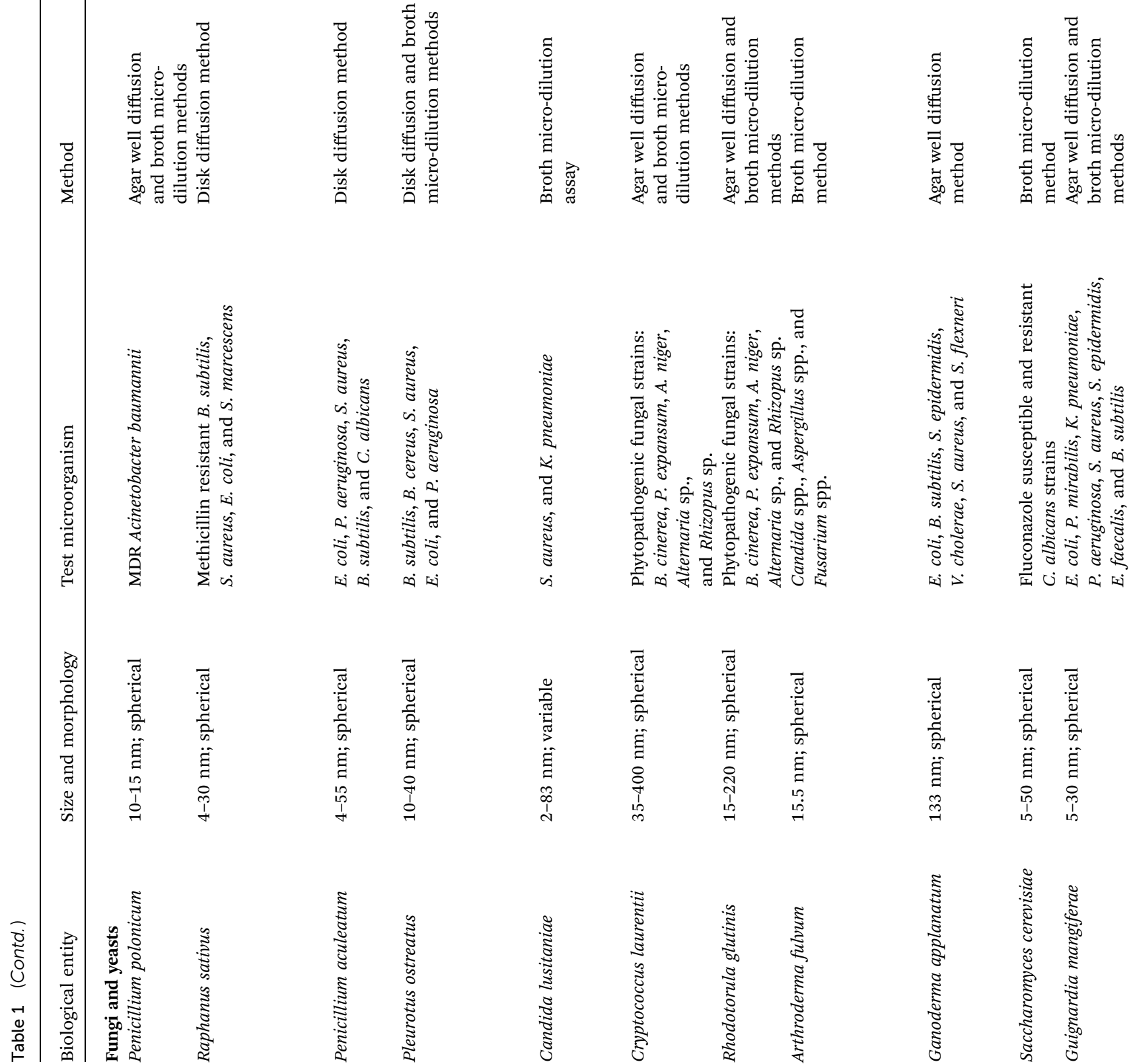


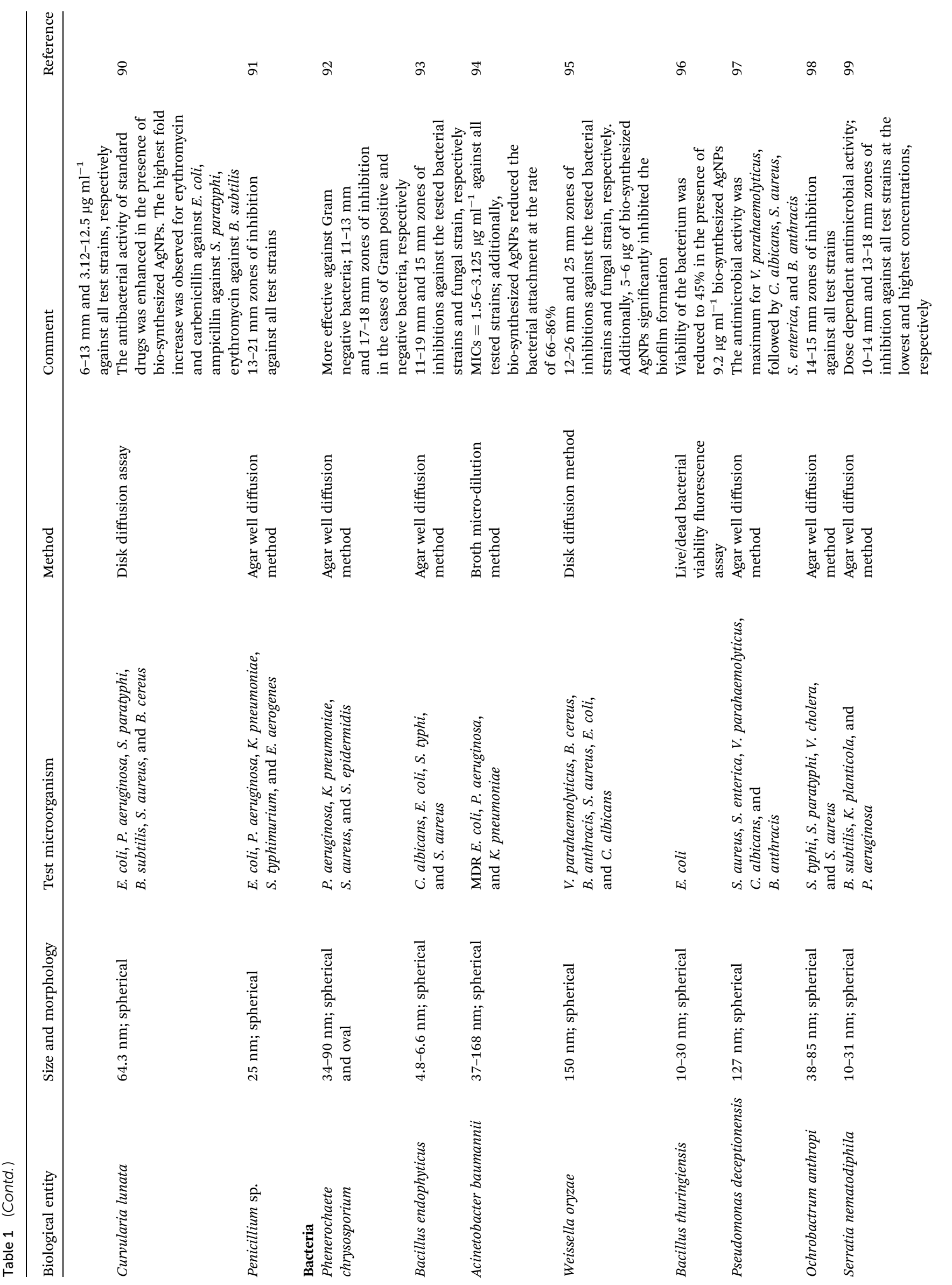




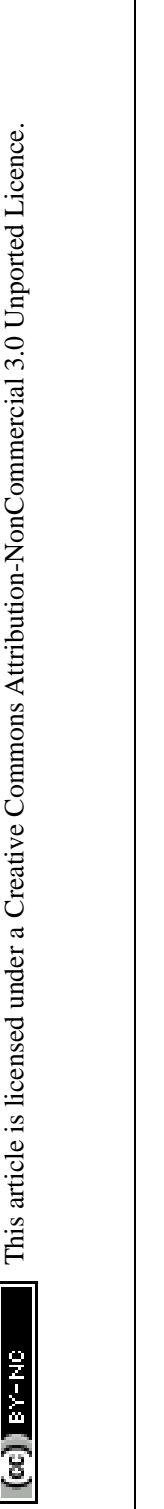

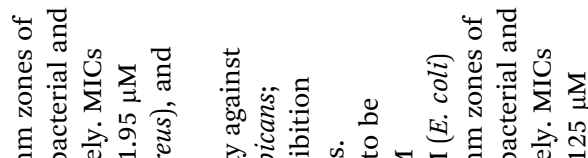

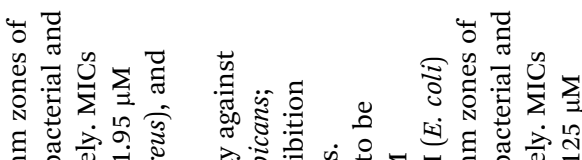

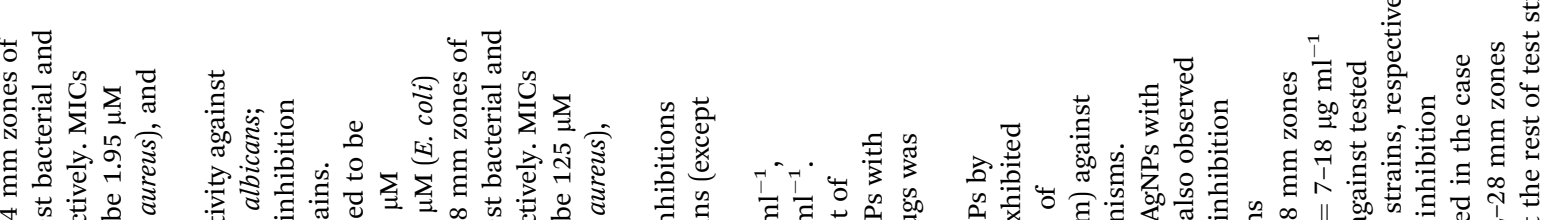

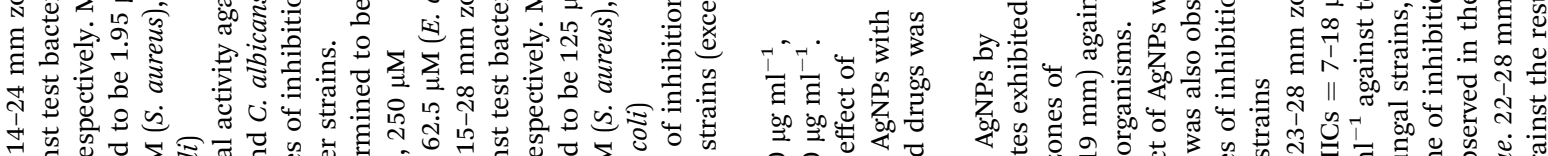

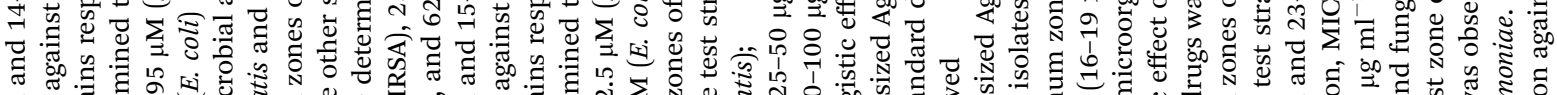

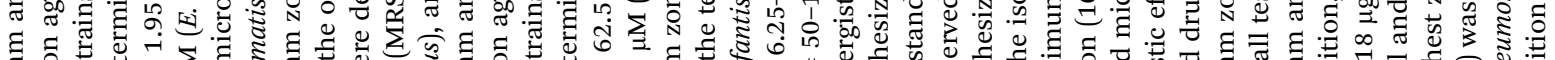

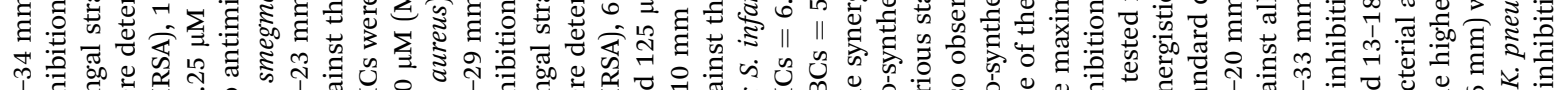

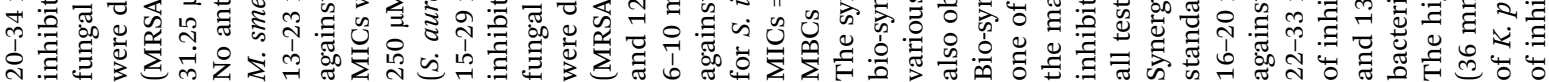
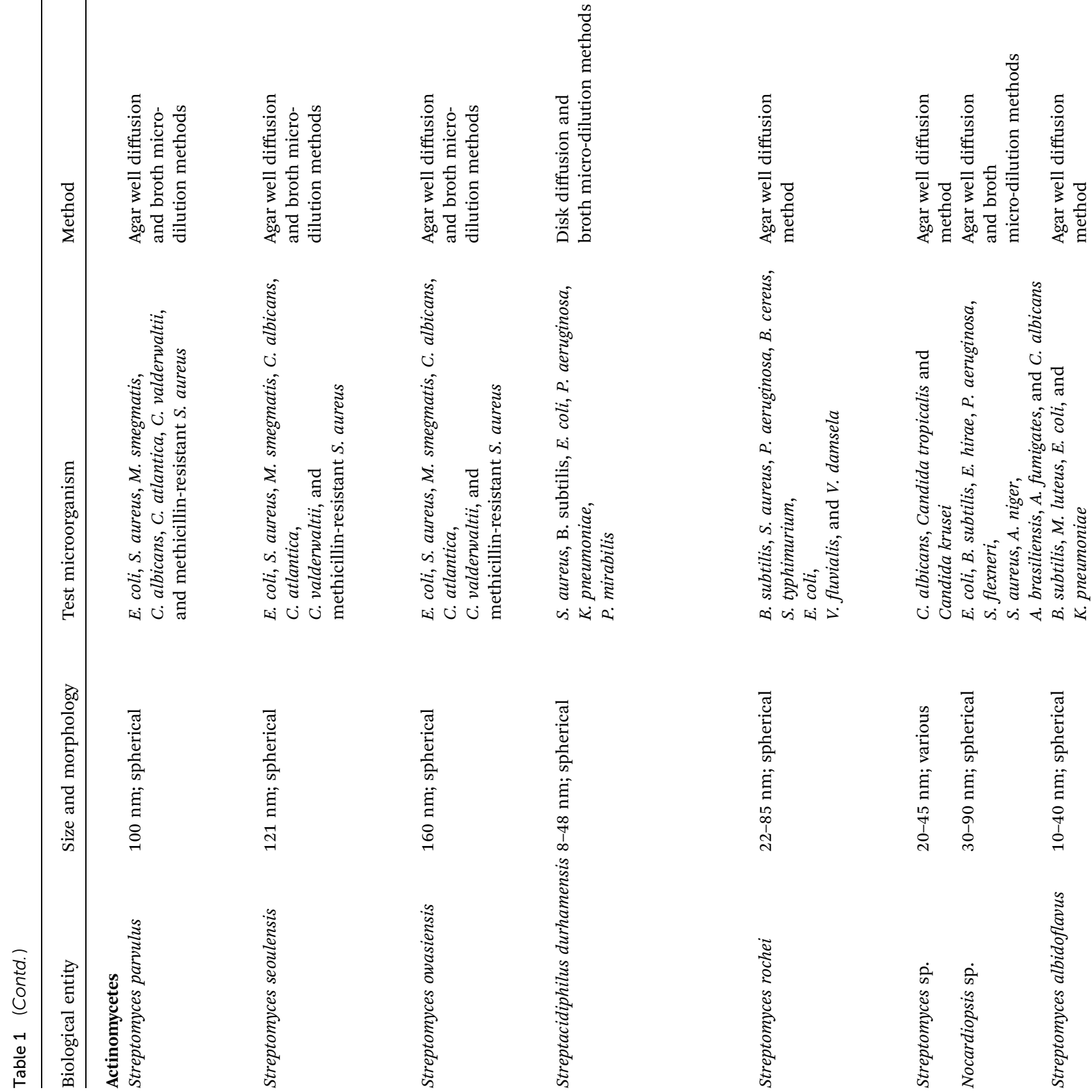

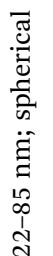
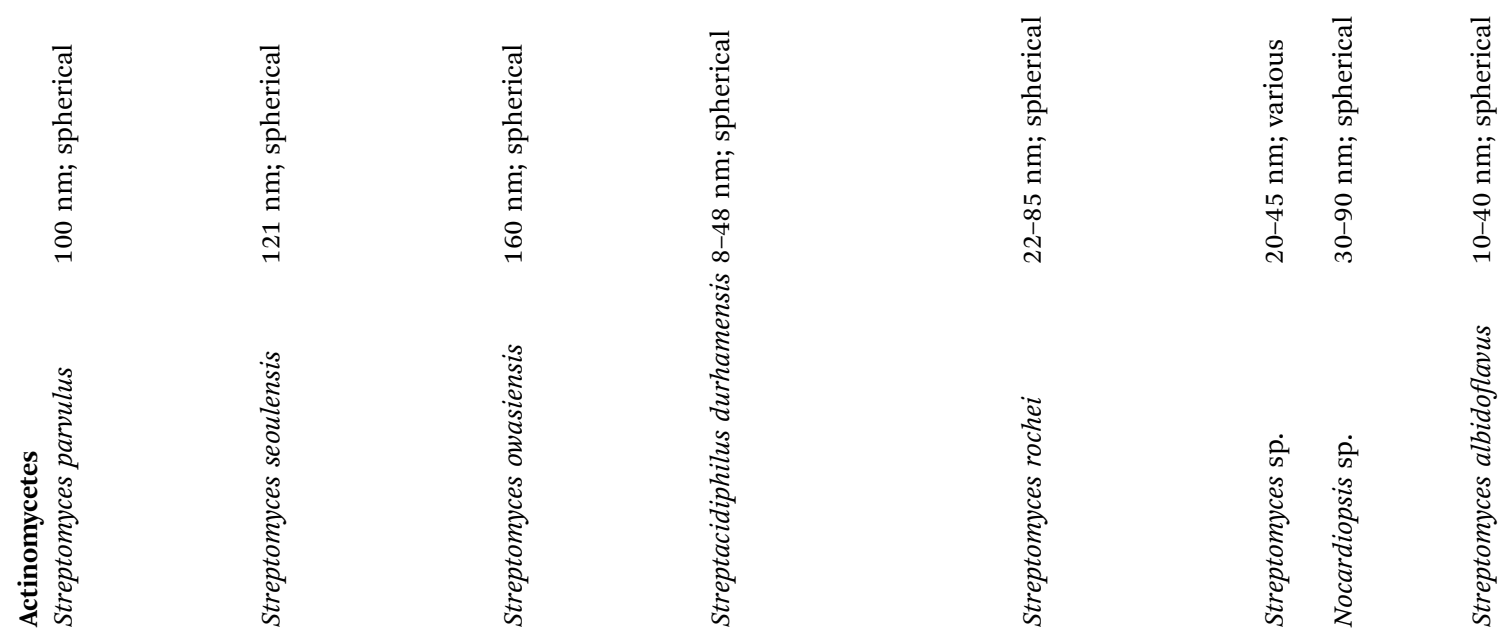

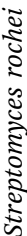

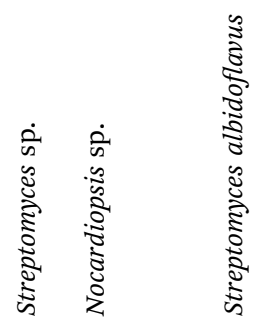


secretes of the bacterial populations are separated and used for the synthesis. Microorganisms generally show resistance to silver ions are generally tend to produce AgNPs effectively. Resistance mechanism of individual microbes also differs with organisms. Bacillus licheniformis use the synthesis of silver nanoparticles at $1 \mathrm{mM}$ concentration without undergoing cell death. Increasing the concentration (crosses the threshold level) to $10 \mathrm{mM}$, the organism undergoes cell death within minutes. ${ }^{107,108,112,113} \mathrm{~A}$ silver resistant bacterium screened from silver mine accumulated AgNPs (size 35-46 nm) in their periplasmic space. ${ }^{109,114}$ Reduction of $\mathrm{Ag}^{+}$ions is proposed to come from the combinations of bio molecules (enzymes/proteins, amino acids, polysaccharides, and vitamins etc.) found in these extracts. But the exact mechanism is not till understood. As shown in Fig. 2, mostly accepted mechanism is based on the presence of enzyme "nitrate reductase". ${ }^{107,109,110,112,115}$ The enzyme converts nitrate $\left(\mathrm{NO}_{3}{ }^{-}\right)$to nitrite $\left(\mathrm{NO}_{2}{ }^{-}\right)$. During this reduction process where $\mathrm{NO}_{3}{ }^{-}$is converted into $\mathrm{NO}_{2}^{-}$, the electron is transferred to the silver ion $\left(\mathrm{Ag}^{+}\right)$which then reduced to metallic silver $\left(\mathrm{Ag}^{0}\right)^{3,114}$ showed direct evidence of it by using purified nitrate reductase from the organism Fusarium oxysporum for synthesizing silver nanoparticles. Besides, functional groups on bacterial cell wall also cause the reduction of $\mathrm{Ag}^{+}$to $\mathrm{Ag}^{0}$ without the presence of nitrate reductase. ${ }^{112}$ Apart from bacteria, fungi can also be used for the synthesis of nanoparticles and have advantageous over productivity due to the huge presence of enzymes, proteins, and reducing components on its cell surface. ${ }^{113,116}$ Fungi can trap $\mathrm{Ag}^{+}$onto their cell surfaces causing subsequent reduction using enzymes (like naphthoquinones and anthraquinones) of fungal systems. ${ }^{14,115,117,118}$ The use of yeast in synthesizing silver nanoparticles did not get success. Although a very few reports are also available. Formation of silver nanoparticles is thought to be due to the combinational effect of bio molecules found in extract. This is also true for the case of algae. Presence of enzymes serves actinomycetes to synthesize silver nanoparticles. Reduction of metal ions is thought to be occurred via intracellular interactions. ${ }^{117,119-122}$

\section{Synthesis of silver nanoparticles by plants}

Slow rate of nanoparticle synthesis using microbes makes plant extracts as preferred choice due to its simplicity, efficiency and viability. The ability of plants to accumulate and detoxify heavymetals is well proved. ${ }^{118,123}$ Generally it is used as bio reductant in the process of synthesizing silver nanoparticles. A plant extract contains a number of metabolites and reductive biomolecules responsible for the reduction of metal ions. This includes terpenoids, flavones, ketones, aldehydes, amides, carboxylic acids, carbohydrates, proteins, and vitamins. ${ }^{124}$ Among many possible natural products, polysaccharides represent an excellent scaffold for this purpose. ${ }^{125}$ The use of polysaccharides like starch and chitosan for the synthesis of AgNPs has been reported in recent years. Hydroxypropyl starch is used for in situ reduction and capping for the synthesis of stable silver nanoparticles of 6 to $8 \mathrm{~nm}$ diameter. No aggregation was observed for more than 6 months due to its effective capping. ${ }^{126,127}$ Diaminopyridinyl (DAP)-derivatized heparin, a linear acidic mammalian polysaccharide has been used in the preparation of AgNPs. ${ }^{128}$ The use of hyaluronic acid, a high molecular weight polysaccharide for the synthesis of AgNPs and gold nanoparticles (AuNPs) was also reported. ${ }^{129}$ Synthesis of AuNPs using $(1 \rightarrow 3)-,,(1 \rightarrow 6)-\alpha, \beta$-D-glucan of an edible mushroom $^{130}$ and a gum polysaccharide of Cochlospermum religiosum (katira gum $)^{131}$ have been reported.

Among the different strategies of green synthesis, plants extracts mediated synthesis has further practical applications. This method is comparatively faster than other biogenic route and the availability of raw material is cheap and sustainable. Apart from this, use of antimicrobial plant extract as in situ reducing and capping agent, helps the development of engineered nanoparticles with enhanced antimicrobial activity. The antimicrobial action of the nanoparticles often depends upon its size. This size is well protected by the action of capping agent. Now interestingly, if the capping agents itself have antimicrobial activity, it might offer enhanced antimicrobial action. Plants with antimicrobial action can be thus successfully used to develop silver nanoparticles with enhanced antimicrobial action.

\section{Factors affecting the antimicrobial activity of silver nanoparticles}

In the recent years, silver nanoparticles have gained much attention due to their unique antimicrobial properties. They are

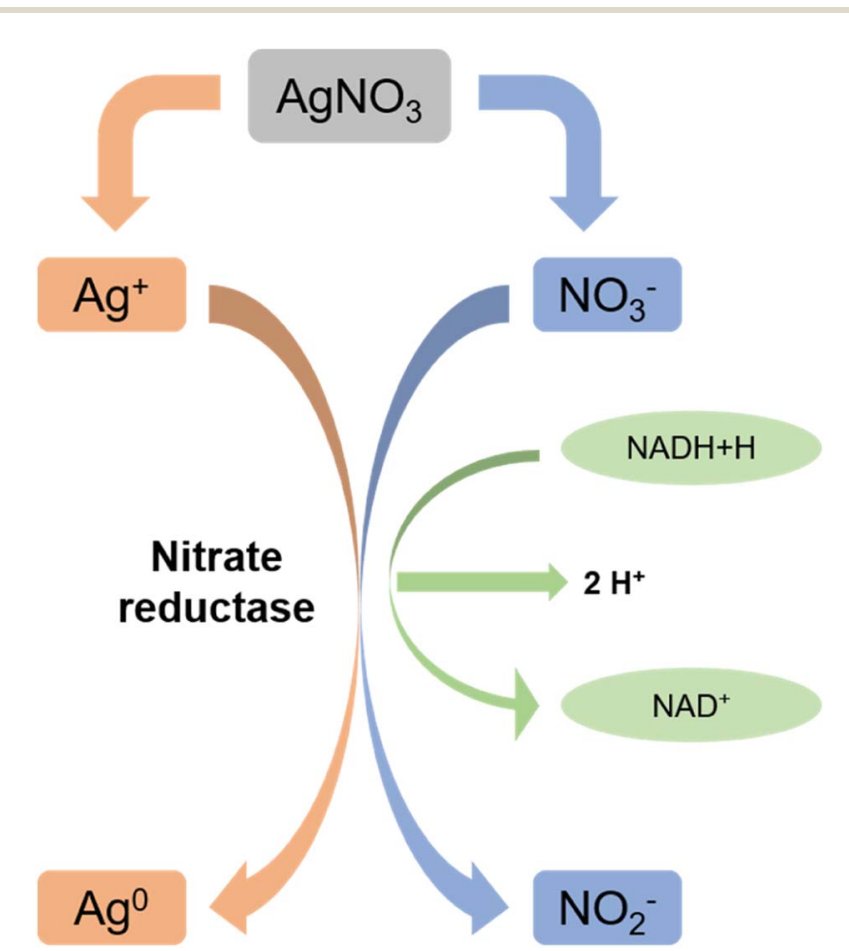

Fig. 2 Nitrate reductase mediated synthesis of AgNPs (this figure has been adapted from ref. 119 with permission from Springer). 
considered as a novel and potential alternative to standard antibiotic drugs since they have a great potential against the increasing multidrug resistance in pathogenic bacteria and fungi. Development and synthesis of these nanomaterials for use as an alternate antibiotic therapy straightly depend on some physical and chemical properties such as their size, shape, concentration and zeta potential. ${ }^{\mathbf{1 3 2 , 1 3 3}}$ Therefore, the properties of nanoparticles should be considered and given more attention when designing antimicrobial AgNPs.

One of the most important physico-chemical properties that affects the antimicrobial activity is the size. Typically, smaller nanoparticles have relatively increased stability and enhanced antimicrobial activity. This is due to the larger surface area of smaller nanoparticles, which provides a higher interaction area and ascendant intracellular penetration..$^{22,134}$ In a broad sense, the size of nanoparticles should be lower than $50 \mathrm{~nm}$ in order to have an effective antimicrobial activity. In particular, nanoparticles in the range of 10-15 $\mathrm{nm}$ sizes have superior antimicrobial activity. ${ }^{\mathbf{1 3 5}}$ Panáček et al. synthesized a wide range of AgNPs with narrow size distributions via reduction of $\mathrm{Ag}\left(\mathrm{NH}_{3}\right)^{2+}$ complex cation by four saccharides, namely glucose, galactose, maltose, and lactose. ${ }^{\mathbf{1 3 6}}$ The colloidal AgNPs synthesized by using maltose and lactose had higher antibacterial and bactericidal activity against tested Gram-positive and Gram-negative bacteria than those synthesized by using glucose and galactose. This might be directly related to nanoparticle sizes, since the AgNP sizes were smaller for disaccharides (maltose and lactose) than monosaccharides (glucose and galactose). AgNPs synthesized by using maltose had the smallest size distribution and the highest antimicrobial activity. In contrast, the largest AgNPs, $50 \mathrm{~nm}$, synthesized by using galactose exhibited the lowest antimicrobial activity. In another study, Li et al. showed that the antibacterial activity of AgNPs decreased with increase of the nanoparticle size. ${ }^{\mathbf{1 3 7}}$ The highest antibacterial effect was observed in the case of smallest nanoparticles, $5 \mathrm{~nm}$, in which attachment of the nanoparticles onto the cell membrane led to membrane damage, increased membrane permeability and finally cell death. To this end, Ivask et al. tested toxic effect AgNPs with different sizes on various types of organisms and cells. ${ }^{138}$ It was concluded that AgNPs in the range of $20-80 \mathrm{~nm}$ were toxic due to release of $\mathrm{Ag}^{+}$ions. On the other hand, $10 \mathrm{~nm}$ and smaller nanoparticles were more toxic due to more efficient cell-particle interaction leading to higher intracellular bioavailability of AgNPs.

Shape is also a crucial physico-chemical property regarding the antimicrobial activity. AgNPs with different shapes have been shown to exhibit different antimicrobial activity due to displaying various degrees of interaction with the cell membrane and hence causing the membrane damage. In this context, the antimicrobial activity of AgNPs with different shapes has been compared. El-Zahry et al. compared the antibacterial activity of spherical, triangular and hexagonal shaped AgNPs against Gram negative bacterium $E$. coli by using conventional disk assay and surface enhanced Raman spectroscopy (SERS). ${ }^{139}$ Both methods demonstrated that hexagonal AgNPs exhibited the highest antibacterial activity whereas triangular AgNPs displayed no activity. Recent research revealed that the antimicrobial activity is highest in the case of truncated triangular AgNPs or similar geometries such as hexagonal and octahedral shapes. ${ }^{\mathbf{1 4 0 - 1 4 4}}$ Conversely, some researchers reported that the shape of AgNPs does not have any effect on the antimicrobial activity. Actis et al. tested spherical, triangular and cubic AgNPs against methicillin-susceptible and -resistant $S$. aureus. Surprisingly, the nanoparticle shape had no significant effect on the antibacterial activity. ${ }^{\mathbf{1 4 5}}$ The bacterial viability was completely reduced at the highest nanoparticle concentration, whereas the difference between different shaped AgNPs at lower concentrations was not remarkable. Despite many studies proposed the shape dependent antimicrobial susceptibility of AgNPs, none of them provided a mechanistic basis, therefore exact mechanism of the shape dependent antimicrobial activity is still unknown.

Another important factor is the nanoparticle concentration. ${ }^{\mathbf{1 4 6 , 1 4 7}}$ This property is directly correlated to microbial species. ${ }^{56,79} \mathrm{Kim}$ et al. reported that the antibacterial activity of AgNPs was more effective against $E$. coli than against $S$. aureus. ${ }^{148}$ The growth of $E$. coli was inhibited at lower nanoparticle concentrations, while the inhibitory effect of same concentration on $S$. aureus was inadequate. Pazos-Ortiz et al. reported the dose-dependent antimicrobial activity of a composite of AgNPs embedded in poly-epsilon-caprolactone nanofibers and tested against both Gram-positive and Gramnegative bacteria. ${ }^{149}$ It was found that beginning from the 12.5 mM nanoparticle concentration, AgNPs gradually displayed a significant antibacterial effect on the different bacterial strains. Similarly, Gurunathan et al. demonstrated the dosedependent bactericidal activity of AgNPs at concentrations ranging from 0.1 to $1.0 \mu \mathrm{g} \mathrm{ml}^{-1}$ against two Gram-negative and two Gram-positive bacterial strains. ${ }^{22}$ Consistently, the cell viability was reduced as the AgNP concentrations increased, and no growth was observed at MIC values for each strain. In the case of Gram-negative bacteria, $0.5-0.6 \mu \mathrm{g} \mathrm{m}{ }^{-1}$ caused nearly $95 \%$ reduction in the bacterial population. However, same concentrations of AgNPs led to only 50\% reduction in the Grampositive bacterial population (Fig. 3). Therefore, the bactericidal concentration is specific for each bacterial strain.

Zeta potential is another physico-chemical property that has an effect on antimicrobial activity since the interaction between nanoparticles and the cell membrane is based on electrostatic adhesion. ${ }^{150-152}$ In their study, El Badawy et al. synthesized AgNPs having various zeta potentials and investigated the antibacterial activity against Bacillus species. ${ }^{153}$ They found a direct correlation between the nanoparticle surface charge and antibacterial activity. Gram-positive Bacillus strains were more susceptible to positive AgNPs, and the more negative AgNPs were the least toxic. Bacterial resistance to the negative AgNPs was estimated to be caused by the repulsion between negatively charged functional groups of biomolecules located on the cell surface and negatively charged nanoparticle surface. Similarly, Ashraf et al. synthesized positively charged and polyhexamethylene biguanide (PHMB) functionalized AgNPs. ${ }^{154}$ The cationic AgNPs exhibited superior bacteriostatic and bactericidal against $E$. coli. The bactericidal activity of PHMB was around $10 \mu \mathrm{g} \mathrm{ml} \mathrm{m}^{-1}$; but when used in combination with 
AgNPs, bacteriostatic and bactericidal activities were lowered down to 0.075 and $0.150 \mu \mathrm{g} \mathrm{ml}^{-1}$, respectively. In this regard, environmental conditions have a significant influence on the nanoparticle activity and stability. ${ }^{155}$ At low $\mathrm{pH}$, the nanoparticle surfaces are positively charged, which favours the interaction between the nanoparticle surface and the negatively charged groups of the bacterial cell surface. ${ }^{156}$ Peretyazhko et al. showed the oxidative dissolution of AgNPs through the interaction of $\mathrm{Ag}^{+}$with dissolved oxygen and protons, and solubility of AgNPs was affected by the environment which was higher in acetic acid than in the neutral water. ${ }^{157}$ Such an alteration in aquatic chemistry might promote release of $\mathrm{Ag}^{+}$from the nanoparticles and hence lead to increased antimicrobial activity. ${ }^{40}$ Additionally, Maillard et al. conducted biophysical analysis including surface pressure, zeta-potential and DLS measurements to study interaction of AgNPs with lipid membranes. ${ }^{158}$ Surprisingly, negatively charged green synthesized AgNPs could have interacted with the membrane via electrostatic attraction with the polar heads of the lipids, and displayed higher antibacterial activity as compared to AgNPs synthesized using citrate. This was presumed to be due to aromatic and hydrophobic moieties of capping agents used during green synthesis procedure, indicating the advantages of green chemistry on the antimicrobial activity of silver nanoparticles.

The reducing and capping materials of the green synthesized AgNPs are derived from the biological extracts containing various naturally occurring compounds and biomolecules such as alkaloids, terpenoids, phenolics, vitamins, co-enzymes, carbohydrates, enzymes and proteins. Therefore, these molecules increase the probability of attachment and action of AgNPs on the microbial cells.

\section{Mechanism of antimicrobial action}

Although antimicrobial activity of AgNPs alone or in combination with standard antibiotic drugs has been proved against a wide range of microorganisms including Gram-negative and Gram-positive bacteria, and fungi, still a little is known about the precise mechanism of their mode of antimicrobial action. Nevertheless, there have been extensive research in order to elucidate their mode of action, and three well-defined mechanisms have been proposed so far: (i) cell wall and membrane damage, (ii) intracellular penetration and damage, and (iii) oxidative stress ${ }^{159-161}$ (Fig. 4).

\section{Cell wall and membrane damage}

Components of the cell wall and membrane exert different adhesion pathways for the nanoparticles. One of the functions of the cell wall and membrane is to protect the microorganism against the environmental threats and to maintain homeostasis while still permitting the transport of nutrients inside the cell. Bacterial classification is based on the differences of cell wall structures; Gram-negative cell wall, also known as cell envelope, contains at least two layers of lipopolysaccharides whereas Gram-positive cell wall is typically thicker and primarily
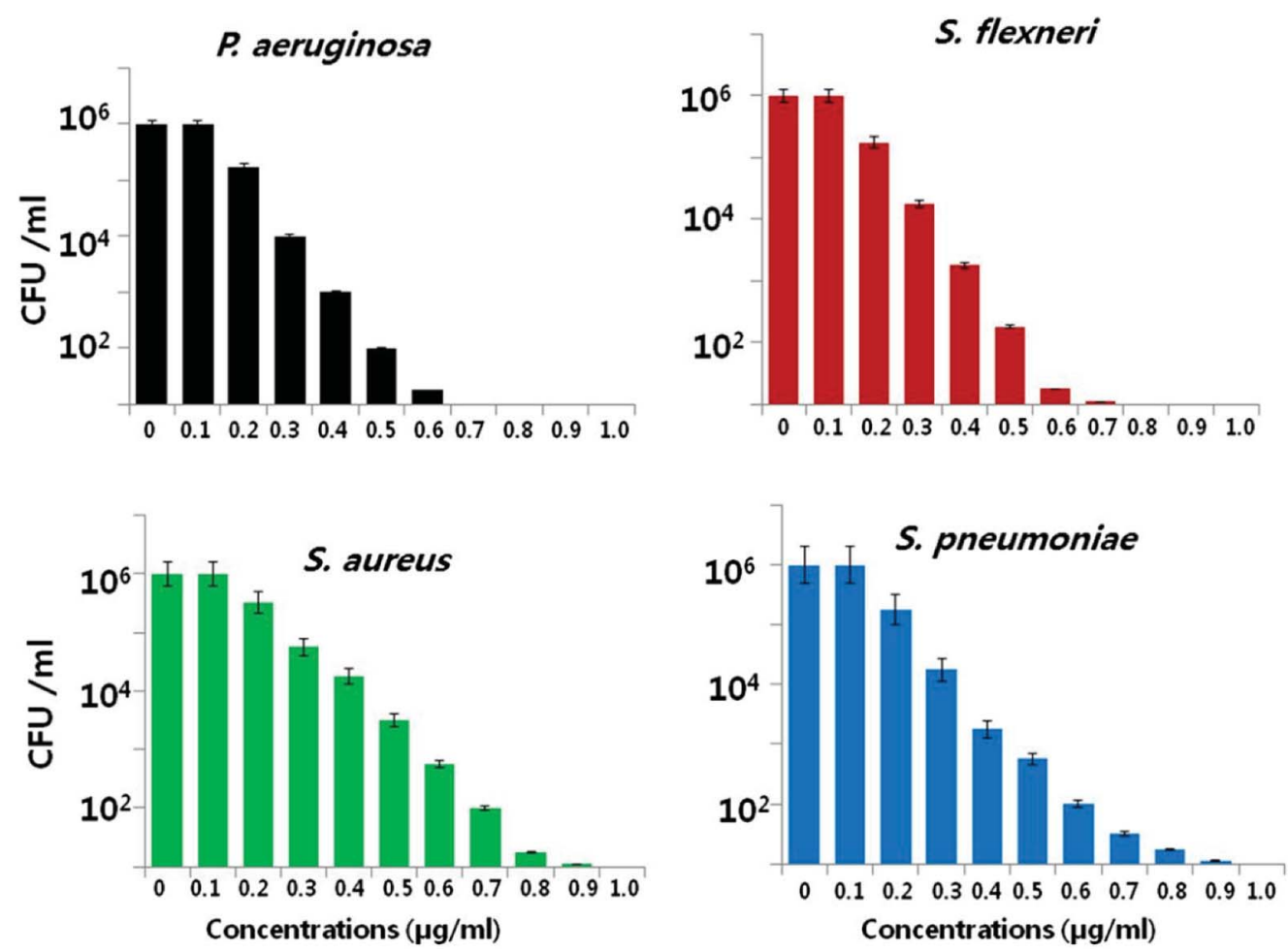

Fig. 3 Bactericidal effect of green synthesized AgNPs on different bacterial strains. Dose-dependent activity of AgNPs synthesized using Allophylus cobbe leaves. The bacterial strains were incubated at various AgNP concentrations ranging from 0.1 to $1.0 \mu \mathrm{g} \mathrm{ml} l^{-1}$ and bacterial rate survival was estimated by colony forming unit (CFU) assay at $4 \mathrm{~h}$ (this figure has been adapted from ref. 22 with permission from Springer). 
composed of a single type of molecule, peptidoglycans. ${ }^{162,163}$ Most of AgNPs exhibit higher antibacterial activity against Gram-negative bacteria than Gram-positive bacteria, since the peptidoglycan layer, made of glycan strands cross-linked by short peptides and anionic glycopolymers called teichoic acid, in the Gram positive bacterial cell wall provides a natural barrier which prevents penetration of the nanoparticles. On the other hand, Gram-negative bacteria have thinner cell wall and less peptidoglycan. Despite the key component of the Gram-negative bacterial cell wall, lipopolysaccharides (LPS), has a significant contribution to durability and integrity of the membrane, its negative charge facilitates adhesion of nanoparticles. ${ }^{7,62,73,143,164-166}$ The interaction between AgNPs and microorganisms starts with adhesion of AgNPs to the microbial cell wall and membrane, which is based on electrostatic attraction between the negatively charged microbial cell membrane and positively or less negatively charged AgNPs. ${ }^{167}$ The interaction of AgNPs with bacterial cells is also shown by a significant decrease in zeta potential of cell surface in both Gram-positive and Gram-negative bacteria. ${ }^{\mathbf{1 4 2 , 1 6 8}}$ Upon such an attraction and interaction, morphological changes in the membrane structure are triggered by the nanoparticle, and thereby leading to disruption of membrane permeability and respiratory functions via membrane depolarization, and finally disruption of the cell integrity and cell death. ${ }^{169-172}$ As a result of the increased membrane permeability and disruption of the cell wall, the cellular content including proteins, enzymes, DNA, ions, metabolites and energy reservoir also leaks into the environment. ${ }^{\mathbf{4 8 , 1 3 7 , 1 4 2 , 1 6 9 , 1 7 3}}$ Therefore, disintegration of the cell wall by the nanoparticle adhesion is assumed to be primary mechanism of the antimicrobial action. ${ }^{\mathbf{1 7 4 , 1 7 5}}$

In addition, AgNPs have been shown to cause irregular pit formations on the cell wall, which allowing the nanoparticles enter the periplasmic space and finally inside the cell ${ }^{\mathbf{1 7 6}}$ (Fig. 5). After a brief contact of AgNPs with bacterial cells, peripheral damages and dense pits on the cell surface can be visualized by advanced imaging techniques such as transmission electron microscopy (TEM), scanning electron microscopy (SEM) and atomic force microscopy (AFM). ${ }^{\mathbf{1 0 1 , 1 6 4 , 1 7 5}}$ Gopinath et al. investigated the structural changes in bacterial cell morphology caused by AgNPs by field emission scanning electron microscopy (FE-SEM). ${ }^{164}$ The untreated bacterial cells showed smooth and undamaged structures (Fig. 6A-D), whereas the cells subjected to 60 min of AgNP treatment were drastically damaged, lost their membrane integrity and the original morphological structures (Fig. 6E-H). They also examined the leakage of intracellular content from the AgNP treated bacterial cells using FITC, a fluorescent dye used as a marker for labelling proteins. Supernatants obtained from AgNP treated bacterial cell cultures and stained with FITC displayed fluorescent signal, indicating the protein leakage from the cell. Similarly, Ansari and Alzohairy evaluated morphological and ultra-structural changes of MRSA cell by SEM and TEM. ${ }^{\mathbf{1 7 4}}$ They found that untreated MRSA cells were round-shaped and had smooth and intact cell walls. However, the cells were wrinkled and damaged upon AgNP treatment, indicating the disruption and disorganization of cell

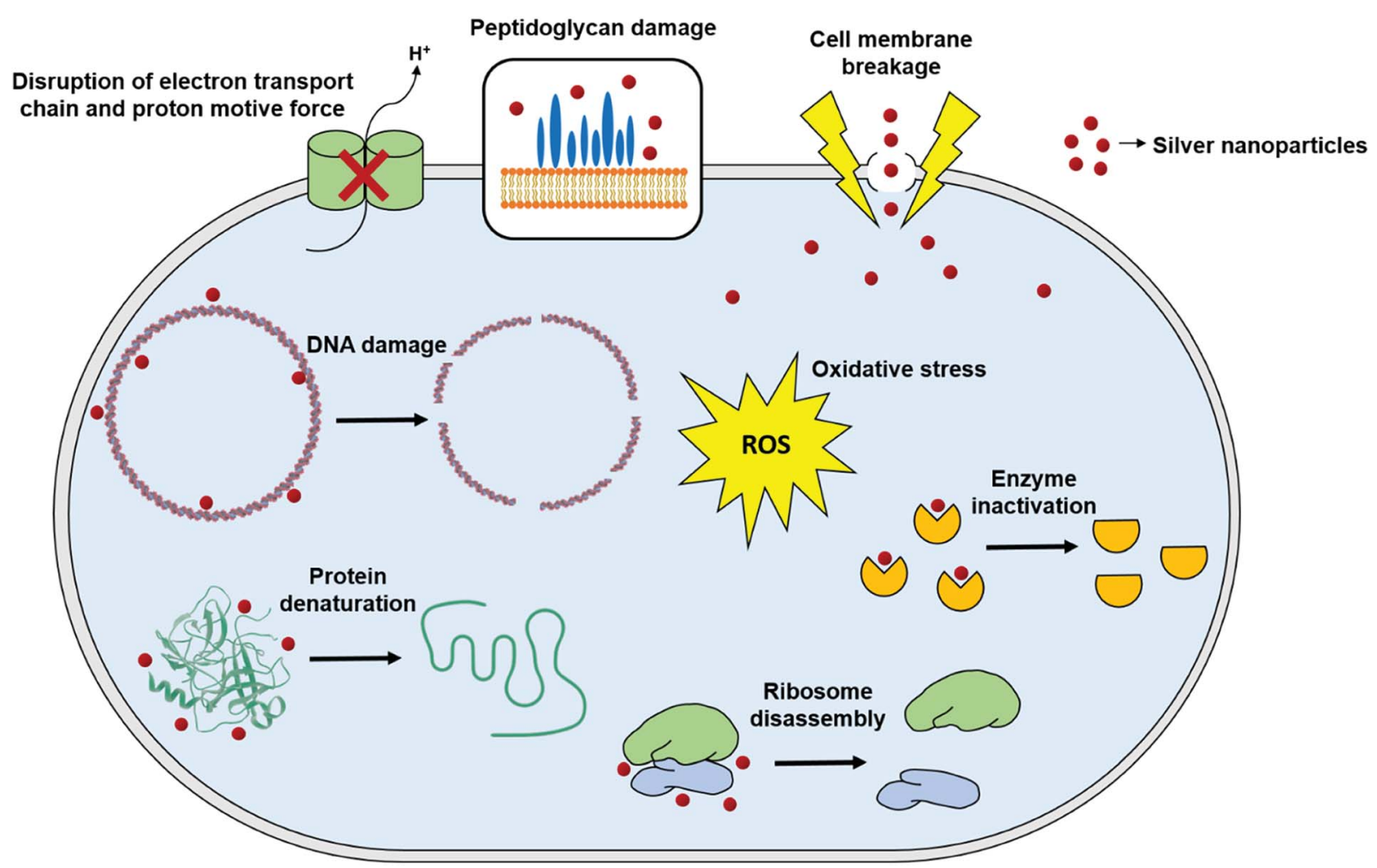

Fig. 4 General mechanisms for antimicrobial mode of action of silver nanoparticles (this figure has been adapted from ref. 159 with permission from Frontiers). 
membrane and wall. TEM imaging further revealed that large translucent zones formed in the cytoplasm caused by local or complete disassociation of the cell membrane and the cell wall. As a result of the leakage of intracellular content, the cell membrane shrink occurred and led to death. Ahmad et al. also showed the physico-chemical and morphological changes in AgNP-treated cells by zeta potential and SEM analyses. ${ }^{\mathbf{1 4 2}}$ Further, they investigated whether the intracellular content of cells would leak into the environment due to the AgNP-induced cell wall and membrane damage. For this, after $4 \mathrm{~h}$ of treatment, the cells were harvested by centrifugation, and leakage of nucleic acids and proteins into the medium was determined by measuring absorbance of the supernatant at 260 and $280 \mathrm{~nm}$. With the increasing concentrations of AgNPs, absorbance at 260 and $280 \mathrm{~nm}$ also increased whereas absorbance of the control cells was zero.

Furthermore, it was proposed that AgNPs could interact with protein parts of the outer membrane, constitute complexes with oxygen, phosphorous, nitrogen or sulphur atom containing electron donors, and cause irreversibly changes in the cell wall structure. ${ }^{177}$ The interaction of protein thiol groups with silver ions and AgNPs is well-defined, and thiol groups in the enzymes of bacterial respiratory chain have been shown to be possible sites for $\mathrm{Ag}^{+}$binding. ${ }^{118,178-180}$ In the proteomic study of Lok et al., it was shown that the interaction of AgNPs with sulphur containing membrane-bound proteins and enzymes led to inactivation of these molecules. ${ }^{\mathbf{1 8 1}}$ Additionally, bacteria started to express a series of envelope proteins, heat shock proteins and periplasmic components responsible for protecting the cell against the entry of foreign substances as a stress response. Gomaa investigated the effect of AgNPs on the enzymatic activity of respiratory chain dehydrogenases of $E$. coli and $S$. aureus cells using a colorimetric method. ${ }^{169}$ Iodonitrotetrazolium chloride (INT) is a colourless compound and reduced by the bacterial respiratory chain dehydrogenases to a dark red water-insoluble iodonitrotetrazolium formazan (INF) under normal conditions. Decrease of the enzymatic activity of respiratory chain dehydrogenases in AgNP-treated cells was
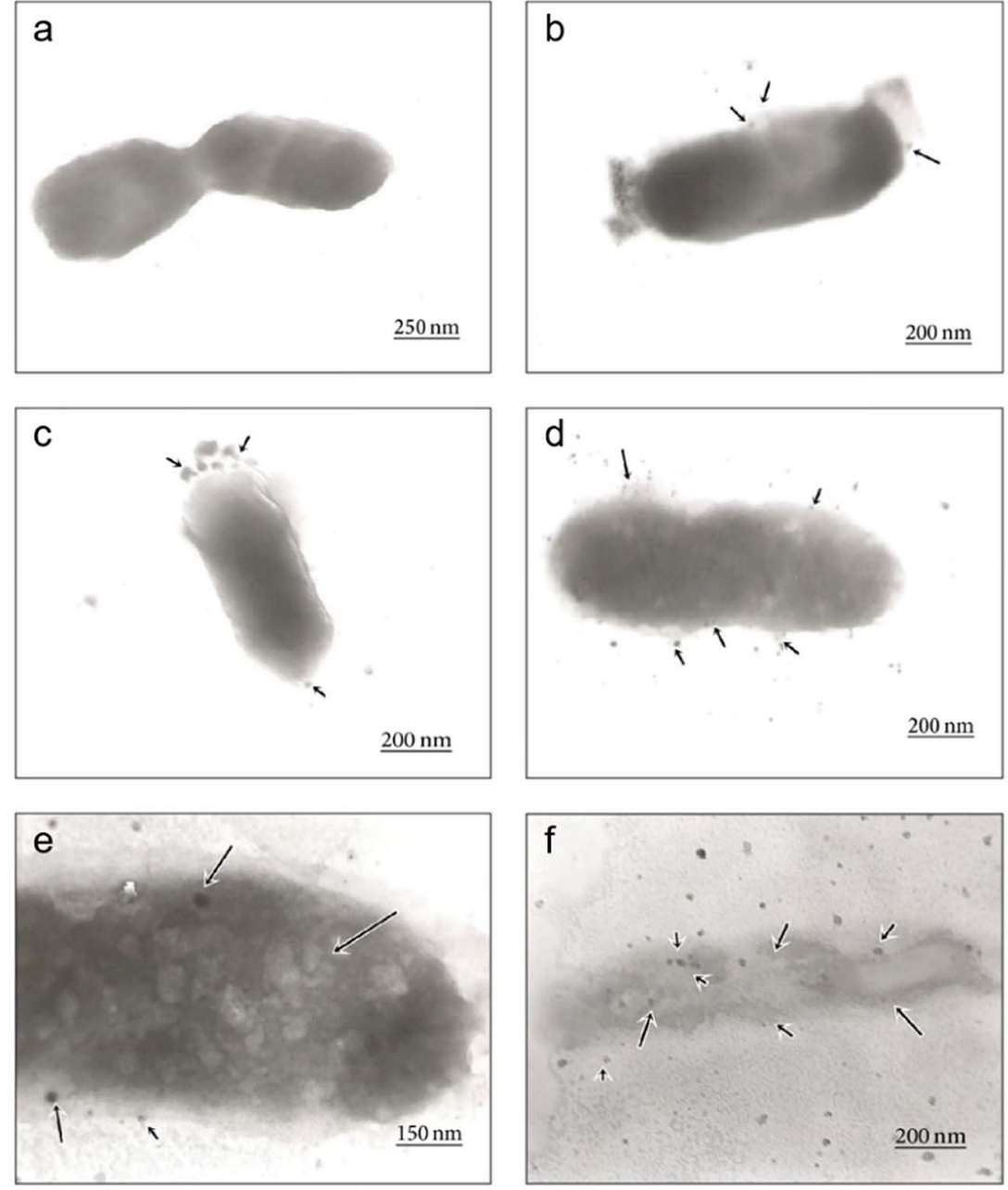

Fig. 5 Time-dependent TEM images of E. coli cells treated with biosynthesized AgNPs using Aspergillus niger extract. (a) The untreated cell; (b) adhesion of AgNPs on the E. coli cell wall at $1 \mathrm{~h}$; (c) disruption of the cell membrane by formation of pits and gaps at $5 \mathrm{~h}$; (d) complete disruption of the cell wall and membrane; (e) penetration of AgNPs into the $E$. coli cell at $8 \mathrm{~h}$; (f) disintegration of the cell and cell lysis at $12 \mathrm{~h}$ (this figure has been adapted from ref. 176 with permission from Hindawi). 
determined by increase of the absorbance of INF at $490 \mathrm{~nm}$, whereas untreated cells increased the activity with time. These results demonstrate that AgNPs drastically damage the cell membrane and peptidoglycan, enter the cell, and inhibit the respiratory chain dehydrogenases leading to cell death. McQuillan and Shaw suggested another possible antimicrobial mechanism in which $\mathrm{Ag}^{+}$released from AgNPs may enter the cell by cation selective membrane transport proteins called porins, and cause damage inside the cell. ${ }^{182}$

\section{Intracellular penetration and damage}

Depending on the degree of membrane damage, AgNPs can penetrate inside the cell and affect crucial and vital functions of the cell by interacting with DNA and proteins. ${ }^{183}$ One of the proposed mechanism for antimicrobial activity of AgNPs is based on silver ion release from the nanoparticles, which has an adverse effect on both DNA and proteins. ${ }^{\mathbf{1 8 4 , 1 8 5}}$ Feng et al. showed that silver ions led to transformation of the bacterial DNA from the natural relaxed state to a condensed state in which the DNA molecule loses its replication ability. ${ }^{\mathbf{1 6 5}}$ Furthermore, Energy Dispersive X-ray Analysis demonstrated the sulphur existence which indicates that silver ions interacted with thiol groups of proteins and led to inactivation of enzymatic activity. Besides the conformational change of DNA, AgNPs and silver ions can also cause degradation and or denaturation of DNA. Vishnupriya et al. studied the interaction of AgNPs with E. coli, and penetration inside the cell and intracellular damage using Raman spectroscopy along with the scattering-based hyperspectral imaging (HSI) at single-cell level. ${ }^{186}$ Time-dependent HSI demonstrated accumulation of AgNPs on the bacterial cell due to high affinity of silver for sulphur and amine groups of proteins located on the outer membrane, and then uptake of AgNPs by the cell. After penetration of AgNPs, DNA degradation was demonstrated by the increase in Raman peak intensities of adenine, guanine and cytosine bases. Researchers also suggested that relatively less increase in the thymine base is due to lack of exocyclic nitrogen in this base, whereas the interaction of AgNPs with adenine, guanine and cytosine is based on the exocyclic nitrogen present in these bases. It has been also shown that silver ions are physically attracted to DNA and interact with nucleoside part of the nucleotide. As a result, the base pairing between the complementary strands is disrupted by breaking the hydrogen bonds. ${ }^{184,187,188}$ Similarly, Chowdhury et al. studied effects of AgNPs on DNA by treating a plasmid DNA with various concentrations of AgNPs. ${ }^{189}$ They showed the dose-dependent AgNP-induced DNA strand breaks. With the increase in AgNP concentration, degradation of the supercoiled plasmid DNA to relaxed circle, linear form and finally to smaller linear fragments was observed by the agarose gel electrophoresis. Small fragments formed as a result of AgNP-induced DNA break were seen as extra lower bands in the gel (Fig. 7).

Radzig et al. compared the AgNP and silver ion susceptibility in $E$. coli wild-type and mutant strains. ${ }^{190}$ They found that E. coli strains carrying mutations in the genes responsible for repair of oxidative damage in the DNA (mutM, mutS, mutT and mutY) and in the genes coding for repair enzymes ( $n t h$ and $x t h A$ ) were more susceptible to AgNPs. Similarly, Dutta et al. conducted gene expression analyses upon AgNP treatment, and reported that genes coding for copper and magnesium transporters, proteins involved in sulfur transport, metal ion influx, antibiotic resistance and antioxidants were up-regulated. ${ }^{191}$ All these findings suggest that DNA damage caused by AgNP treatment might be also mediated by oxidative damage induced by AgNPs and
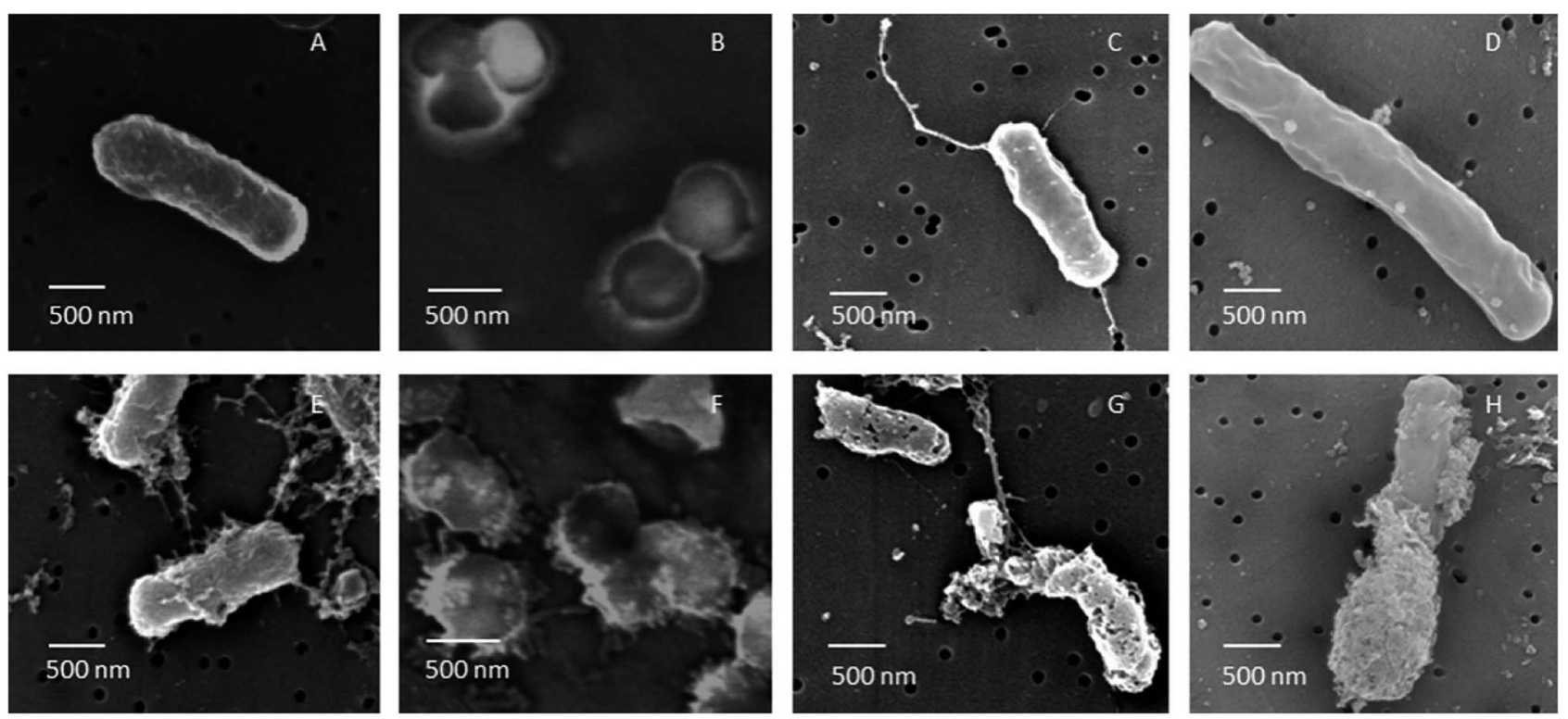

Fig. 6 FE-SEM images of B. cereus, S. aureus, E. coli and P. aeruginosa cells untreated (A-D) and treated (E-H) with AgNPs. After 60 min of treatment with AgNPs biosynthesized using soil derived Pseudomonas putida, all cells were subjected to severe membrane damage (this figure has been adapted from ref. 164 with permission from Elsevier). 
intracellular antioxidant balance have an important role in the antibacterial effect of AgNPs and silver ions.

The intracellular effect of AgNPs is not limited to DNA damage. Recent proteomic studies have demonstrated effects of AgNPs on proteins and protein synthesis as well. ${ }^{181}$ As previously mentioned, AgNPs and $\mathrm{Ag}^{+}$ions released from AgNPs have a tendency to react with thiol groups of proteins. Thiol or thiolate groups are found in the amino acid cysteine as the functional group. Cysteine is one of the least abundant amino acids, but commonly acts as a highly conserved residue within functional sites in proteins. Therefore, it is very important in biological reactions due to its high affinity metal binding property, nucleophilic role in catalytic reactions, and ability to form disulfide bonds which is vital for folding and three-dimensional structure of proteins. ${ }^{192,193}$ Yan et al. found that the expression of many membrane proteins was significantly up-regulated or down-regulated in $P$. aeruginosa as a result of AgNP treatment. ${ }^{194}$ These proteins are essentially responsible for ion binding, transport, flagellum assembly, pore formation, antibiotic resistance, and membrane stabilization. The most notably upregulated proteins were found to function in ATP synthesis, phospholipid synthesis, and transmembrane transport. In addition, a series of metal transporters including copper, iron, zinc and magnesium transporters were repressed, which might assist transport of AgNPs into the cell. Wigginton et al. also conducted a proteomic study to identify interaction between $E$. coli proteins and AgNPs. ${ }^{195}$ Surprisingly, they found that $65 \%$ of E. coli proteins interacted with AgNPs were enzymes such as tryptophanase (TNase) and alcohol dehydrogenase while the rest was non-enzymatic proteins such as membrane porins, chaperonins, periplasmic peptide-binding proteins. Among the enzymatic proteins, TNase exhibited relatively higher affinity for AgNPs. Thereby, interaction of AgNPs with purified TNase was also investigated. TNase was found to be fragmented and lost its catalytic activity upon interaction, which might be due to the fact that the active site of TNase is in the vicinity of binding site of AgNPs. Similarly, Yuan et al. found that AgNPs repressed production of some proteins in nitrifying bacterium Nitrosomonas europaea. ${ }^{196}$ Among these proteins, GroEL, DnaK and ClpB which are chaperon proteins responsible for protein biosynthesis under stress conditions, and elongation factors $\mathrm{Tu}$ and $\mathrm{G}$ which are involved in binding of tRNAs and mRNAs to ribosome for translation, were the most notable proteins. Based on the fact that AgNPs can also repress the production of ammonia monooxygenase and hydroxylamine oxidoreductase which catalyse two critical reactions of nitrification, it can be concluded that AgNPs displayed the antibacterial effect on $N$. europaea by inhibiting protein biosynthesis and nitrification. ${ }^{197}$ The proteomic studies of bacteria-AgNP interaction also revealed that ribosomal subunits were also affected by the nanoparticles, leading to termination of the protein biosynthesis. ${ }^{198}$

\section{Oxidative stress}

Reactive oxygen species (ROS) are oxygen containing molecules having a strong redox potential. Under normal conditions, ROS production and the antioxidant capacity in the cell are

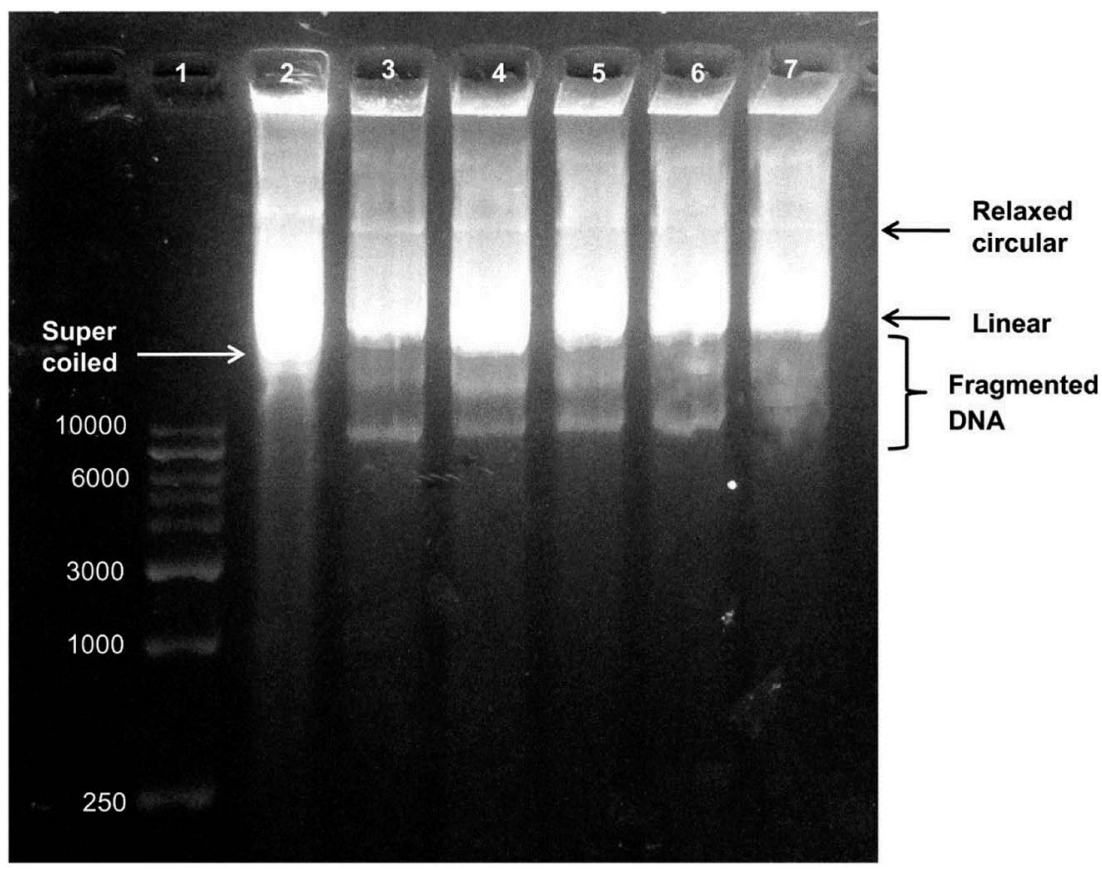

Fig. 7 Agarose gel electrophoresis of biosynthesized AgNP-treated plasmid DNA. Lane 1, DNA marker. Lane 2, untreated plasmid DNA in supercoiled form. Lane 3, plasmid DNA treated with $0.51 \mu \mathrm{g}$ of AgNPs showing a decrease in supercoiled DNA form. Lane 4, plasmid DNA treated with $1.02 \mu \mathrm{g}$ of AgNPs. Lane 5, plasmid DNA treated with $2.55 \mu \mathrm{g}$ of AgNPs. Lane 6 plasmid DNA treated with $0.51 \mu \mathrm{g}$ of AgNPs showing degradation of DNA bands. Lane 7, plasmid DNA treated with $5.1 \mu \mathrm{g}$ of AgNPs showing the highest degree of DNA degradation (this figure has been adapted from ref. 189 with permission from Springer). 
balanced. However, in the case of imbalance between the antioxidant mechanism and excessive production of ROS, the redox balance of the cell favours oxidation, leading to oxidative stress. ${ }^{199}$ Nevertheless, oxidative stress is a normal cellular process involved in many aspects of cellular signalling, though excessive oxidative stress can be harmful. The literature revealed that nanoparticle challenge triggers the cellular oxidative stress..$^{\mathbf{8 , 2 0 0 , 2 0 1}}$ In order to overcome this stress, cells exhibit protective responses which include enzymatic or nonenzymatic defence mechanisms. ${ }^{201-203}$ When the oxidative stress overcomes the defence mechanisms, the cell wall and biomolecules such as proteins, lipids, and DNA are subjected to damage caused by ROS and free radicals such as hypochlorous acid (HOCl), hydrogen peroxide $\left(\mathrm{H}_{2} \mathrm{O}_{2}\right)$, hydroxyl radical $(\cdot \mathrm{OH})$, superoxide anion $\left(\mathrm{O}_{2}{ }^{-}\right)$and singlet oxygen $\left({ }^{1} \mathrm{O}_{2}\right)$. DNA damages include deletions, mutations, single-breaks, double-strand breaks, adduct formation, and cross-linking with proteins. Studies confirmed oxidation-induced DNA fragmentation following exposure to metal oxide nanoparticles. ${ }^{130,161,204}$ In response to DNA insult, cells attempt to repair the damaged DNA. Repair failure may lead to cell death. It is most likely that in the bacterial cell where the antibiotics which were effluxed out from the cell wall of the bacteria could first approach to the bacterial cell membrane with the aid of nanoparticles because of nanoparticle-induced lipid peroxidation, thereby both the nanoparticles and antibiotics could damage the intracellular DNA and proteins. ${ }^{193,205}$ In this respect, Das et al. evaluated the ROS-mediated antibacterial activity of AgNPs against multidrug resistant $E$. coli and $S$. aureus, and found that ROS generation significantly contributed to the antibacterial action. ${ }^{206}$ Elevated ROS levels caused the membrane damage by increasing the permeability, which finally resulted in disruption of electron transport chain and leakage of the cellular content. Gurunathan et al. also tested AgNPs in combination with standard antibiotic drugs against bacteria. ${ }^{22}$ The synergistic effect was not only observed in the antibacterial effect, but also led to enhanced ROS generation capacity. Even though, sub-lethal concentrations of both antibiotic drugs and AgNPs produced low amount of ROS, use of AgNPs combined with antibiotic drugs such as ampicillin and vancomycin resulted in significantly higher production of ROS (Fig. 8). The increased antibacterial activity in the presence of enhanced ROS production demonstrated that AgNP-induced ROS production is vital for antimicrobial activity.

Similarly, Das et al. tested AgNPs against multidrug resistant $P$. aeruginosa cells, and also investigated whether the antimicrobial activity of AgNPs was mediated by ROS formation. For this purpose, they used a fluorescence assay which is based on transformation of non-fluorescent $2^{\prime}, 7^{\prime}$-dichlorofluorescein diacetate $\left(\mathrm{H}_{2}\right.$-DCFDA) to highly fluorescent $2^{\prime}, 7^{\prime}$-dichlorofluorescein (DCF) upon oxidation. AgNP-treated $P$. aeruginosa cells became DCF positive, indicating the intracellular ROS formation. Further, they used a potent ROS inhibitor (NAC) to investigate role of ROS formation in the cell death. It was observed that $P$. aeruginosa cells pre-treated with NAC were resistant to AgNP-induced toxicity and restored the cell viability more than $80 \%$. Ramalingam et al. also used $\mathrm{H}_{2}$-DCFDA assay to investigate AgNP-induced ROS generation in E. coli and $P$. aeruginosa. ${ }^{\mathbf{1 6 8}}$ Although ROS were also generated in the control cells, AgNP-treatment resulted in more intracellular ROS generation (Fig. 9A). The dose-dependent ROS generation was observed in both bacterial strains (Fig. 9B). ROS generation levels were approximately $70-80 \%$ at $2.7-4.5 \mu \mathrm{g} \mathrm{ml} \mathrm{m}^{-1} \mathrm{AgNP}$ concentration interval as compared to the positive control, $1 \mathrm{mM} \mathrm{H} \mathrm{H}_{2} \mathrm{O}_{2}$ treated cells. This result is indicating that even AgNP-induced ROS production plays an important role, it is not effective alone, and some others factors such as cell membrane and wall damage are also involved in cell death. Moreover, they verified the ROS generation by measuring glutathione (GSH) concentration. GSH is a thiol-containing tripeptide and mainly present in a reduced form to protect cells from the deleterious effects of oxidative stress acting as an antioxidant. However, GSH is oxidized to disulfide (GSSG) in the case of oxidative stress, and this oxidation reaction might cause the cell death. Therefore, intracellular GSH concentration was measured to show the AgNP-triggered oxidative stress. As shown in Fig. 9C, GSH concentration significantly reduced in both $E$. coli and $P$. aeruginosa after treatment with 4.5 and $2.7 \mu \mathrm{g} \mathrm{ml}^{-1}$ of AgNPs, respectively. Thereby, GSH depleted cells are subjected to oxidative stress due to imbalance between ROS generation and antioxidant defence systems, leading to the cell death. The cell death was verified by epifluorescence microscopy, as well. For this, cells were stained with SYTO 9 and propidium iodide (PI). Red fluorescent membrane impermeant PI stains only dead cells by penetrating through the disrupted cell membrane, while green fluorescent membrane permeant SYTO 9 s quenched by PI and stains both dead and live cells. Therefore, in a bacterial population, live cells are stained with green fluorescent colour as the dead cells exhibit red fluorescence. Untreated $E$. coli and $P$. aeruginosa samples display only green fluorescent indicating the viable cells. On the other hand, AgNPtreated cells stained red color demonstrating that the cell membrane and damage led to cell death (Fig. 9D). These results suggest that the oxidative stress induced by elevated ROS production plays an important in the antimicrobial potential of AgNPs.

It is also possible that ROS generation mediated by $\mathrm{Ag}^{+}$ions released from AgNPs can cause dysfunction of the bacterial electron transport chain and proton motive force as a result of inhibition of enzymes involved in the reactions. ${ }^{45,207}$ In addition to breakdown of membrane functions, Kim et al. found that AgNP-mediated ROS generation caused protein leakage by increasing the membrane permeability. ${ }^{208}$ Protein leakage from the cells treated with AgNPs finally resulted in cell death. Compared with $S$. aureus membrane, significantly higher amount of protein leakage occurred through the $E$. coli membrane. This result is consistent with the previous reports, and indicating that antibacterial activity is related to cell wall content of the microorganism. Additionally, they showed that activity of lactate dehydrogenase, an important respiratory enzyme, significantly decreased due to AgNP induced oxidative stress, indicating the effect of ROS on respiratory chain activity.

Deleterious effects of oxidative stress is not limited to cell membrane and electron transport chain damage, but it also has adverse effects on proteins, DNA, and other intracellular 
systems. ${ }^{209}$ Quinteros et al. showed that time-dependent ROS generation was induced after AgNP treatment. ${ }^{210}$ Their further analyses revealed that AgNP-induced oxidative stress caused an increase of $60 \%$ in the oxidation of DNA, proteins and lipid in $E$. coli. Thereby, ROS generation might be considered to have an important contribution to the antimicrobial action. Similarly, Yuan et al. confirmed increased ROS generation in bacterial cells upon AgNP treatment. ${ }^{173}$ They also measured the level of malondialdehyde (MDA) that is a product of a lipid peroxidation and serves as an indicator of lipid peroxidation oxidative stress, and found that MDA levels in AgNP-treated bacterial cells significantly increased.

Besides the direct effects on cell wall and components, oxidative stress also alters the gene expression. In Pseudomonas cells treated with AgNPs, translation of ribosomal proteins S2 and L9, keto-hydroxyglutarate aldolase (KHGA), alkyl hydroperoxide reductase $\mathrm{C}$ (AhpC) and thiol-specific antioxidant (TSA) was found to be up-regulated. In addition to their structural functions, the ribosomal proteins S2 and L9 are also involved in the regulation of protein biosynthesis. AhpC and TSA are members of an antioxidant family of enzymes called peroxiredoxins that protect the cell from oxidative stress by regulating the intracellular peroxide levels. KHGA is involved in sugar metabolism by metabolizing sugar acids, hexonates, and hexuronates to pyruvate and glyceraldehyde-3-phosphate, thereby prevents the accumulation of toxic intermediates. All together, the up-regulation of these proteins demonstrates a cellular response to AgNP-induced oxidative stress. ${ }^{211}$

It has been also found that AgNPs can act on bacterial cell signaling and signal transduction systems which continuously monitor the changing environmental and intracellular conditions and mediate the adaptive responses to changes in these conditions. ${ }^{212}$ Although various modification systems such as glycosylation, methylation and acetylation are involved in cell signalling, the bacterial signal transduction is mainly mediated by phosphorylation. ${ }^{213}$ The phosphorylation and dephosphorylation cycle of proteins has an important role on bacterial growth, metabolism, and cellular activities including cell cycle and DNA replication. In the case of inhibition of this cycle, all enzymatic activities would end up and lead to inhibition of the bacterial growth. Based on this fact, Shrivastava et al. investigated the phosphotyrosine profile of $S$. aureus and E. coli proteins to reveal the effect of AgNPs on bacterial signal transduction pathways. ${ }^{214}$ They found that AgNPs modulated the signal transduction by causing dephosphorylation of tyrosine residues on bacterial protein substrates which finally resulted in inhibition of the bacterial growth. There was no change in the profile of tyrosine phosphorylated proteins in $S$. aureus, whereas dephosphorylation of two peptides of $E$. coli and Salmonella typhi significantly changed. However, these are the initial findings, and proteomic characterization of the dephosphorylated peptide substrates and further research should be performed to elucidate the precise effect of AgNPs on signal transduction.

\section{Option to decode bacterial lipopolysaccharide Achilles}

Metal nanoparticles are thought to pose antimicrobial activity due to its small structures. Most important antimicrobial silver nanoparticles interacts with peptidoglycan cell wall ${ }^{215,216}$ and the plasma membrane; ${ }^{217}$ bacterial (cytoplasmic) DNA; ${ }^{218}$ and bacterial proteins, ${ }^{\mathbf{2 1 4 , 2 1 6}}$ especially enzymes involved in vital cellular processes such as the electron transport chain. But in green synthesis method have advantageous for surface functionalization of AgNPs as the green constituents acts as both reducing and capping agent. These constituents can be effectively passed as an adjacent molecule coated over the

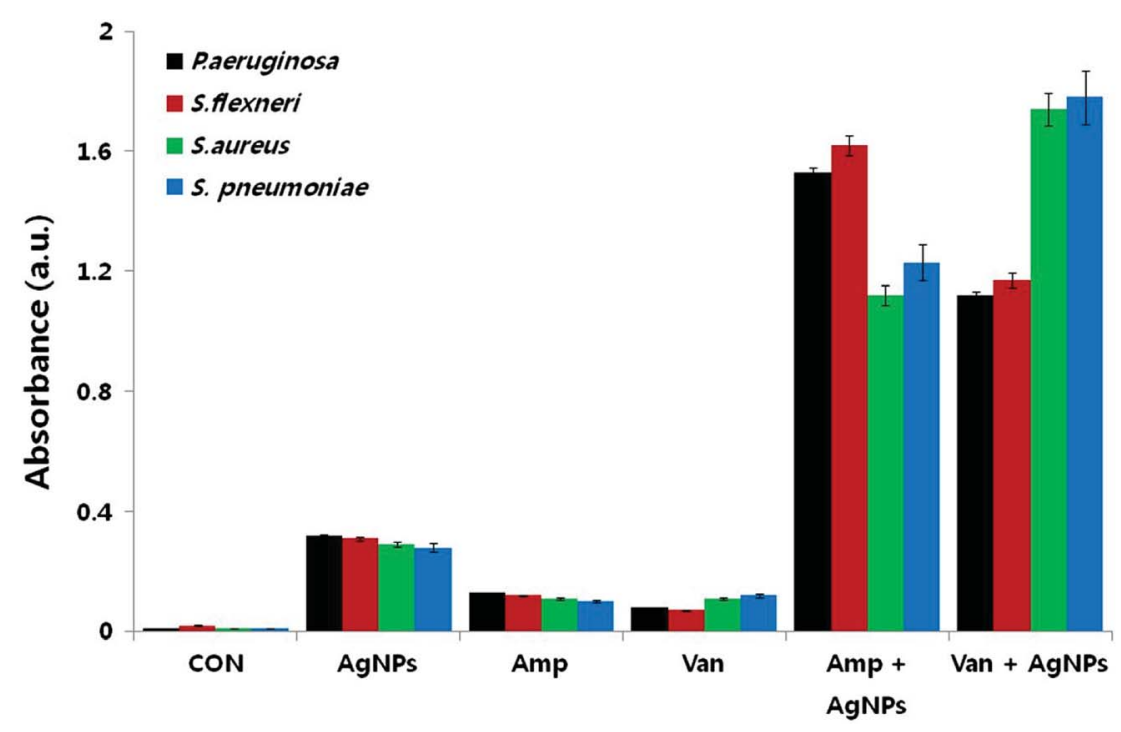

Fig. 8 Synergistic effect of biosynthesized AgNPs and standard antibiotic drugs on ROS generation. Results of ROS measurement after $12 \mathrm{~h}$ treatment of the bacterial cells with AgNPs alone, antibiotics alone, and combinations of AgNPs with antibiotics (this figure has been adapted from ref. 22 with permission from Springer). 

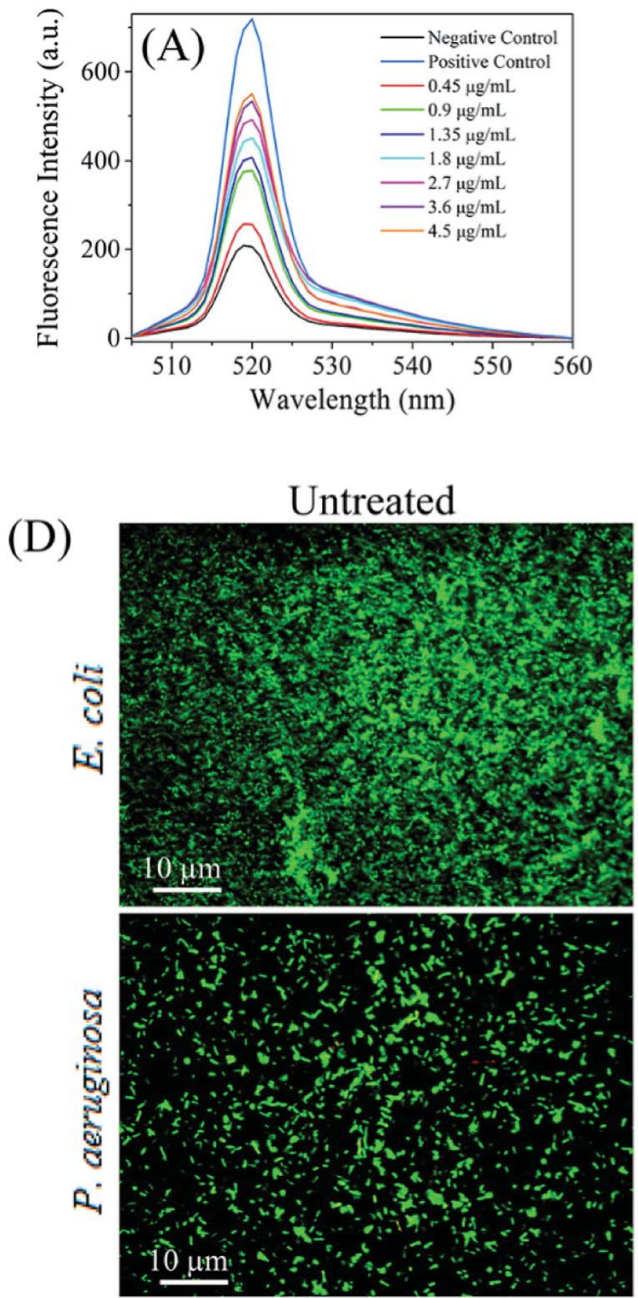

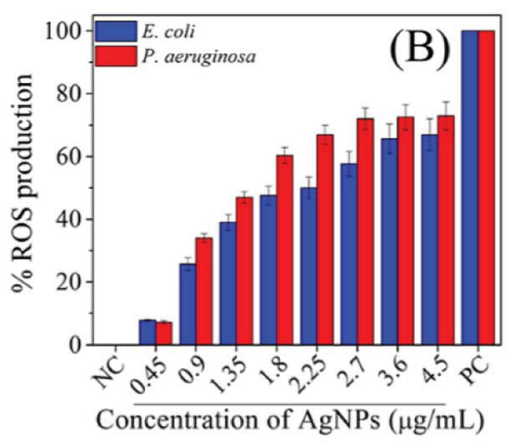

AgNPs treated
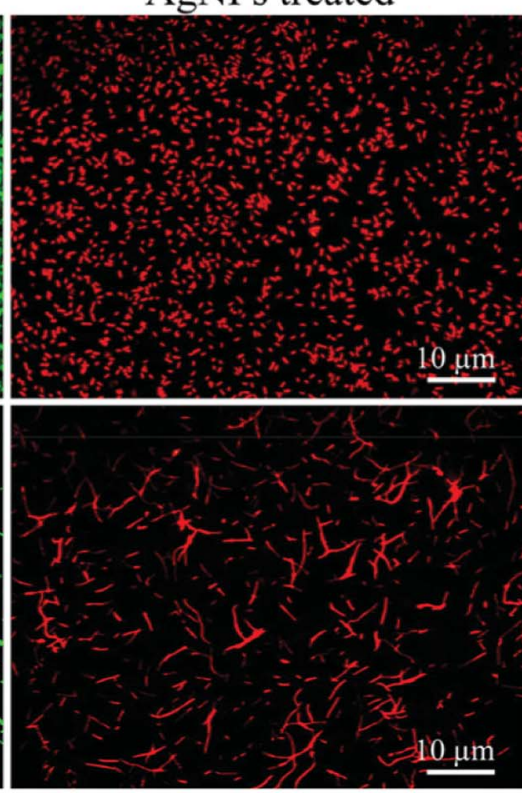

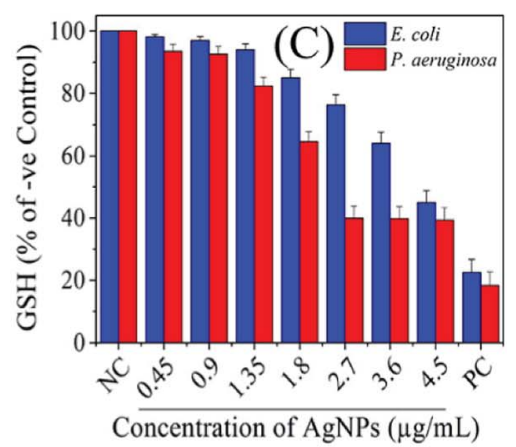

Antibiotic treated

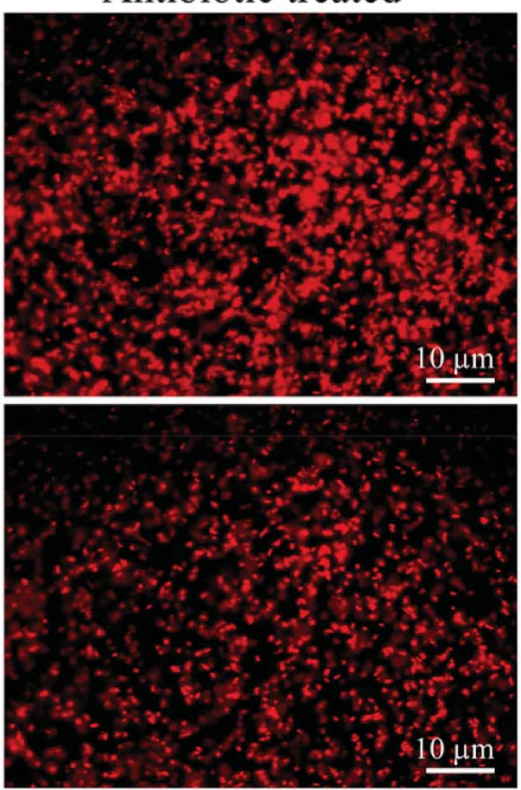

Fig. 9 (A) $\mathrm{H}_{2}$-DCFDA assay for investigation biosynthesized AgNP-induced intracellular ROS generation; (B) the dose-dependent ROS generation in AgNP-treated in E. coli and P. aeruginosa; (C) relative GSH concentration in the treated cells as compared to positive control (PC), $1 \mathrm{mM}$ $\mathrm{H}_{2} \mathrm{O}_{2}$; (D) fluorescence microscopy images of untreated, AgNP-treated, and gentamicin-treated E. coli and P. aeruginosa cells. SYTO 9 (green fluorescent) stained cells are intact and live, while PI (red fluorescent) stained cells are dead due to disruption of the cell membrane. As control, gentamicin, a standard antibiotic drug known to cause cell membrane damage, treated cell also displayed red fluorescent colour (this figure has been adapted from ref. 168 with permission from American Chemical Society).

nanoparticle. The uniqueness of nanoparticles is that it acts first at the defensive walls rather than attacking the bacteria itself. Once the damages complete, it can now interact with bacterial (cytoplasmic) DNA, bacterial proteins and enzymes.

A recent finding reports the crystal structure of the unique integral membrane LPS translocon LptD-LptE complex in Gram negative bacteria. According to this report, LptD forms a novel 26 -stranded largest $\beta$-barrel and LptE adopts a roll-like structure located inside the barrel of LptD to form an unprecedented twoprotein 'barrel and plug' architecture. ${ }^{219}$ This bacterial molecular bricks is the key behind the antimicrobial resistance.

Hydrophilic O-antigen and the core oligosaccharide of the LPS may pass through the barrel and the lipid A of the LPS may be inserted into the outer leaflet of the outer membrane through a lateral opening between strands $\beta 1$ and $\beta 26$ of LptD.

Keeping this in view and the prevalence report of potential effects of AgNPs against multidrug susceptible as well as multidrug sensitive strains like Pseudomonas aeruginosa, ampicillin-resistant Escherichia coli, erythromycin-resistant Streptococcus pyogenes, methicillin-resistant Staphylococcus aureus (MRSA) and vancomycin-resistant Staphylococcus aureus (VRSA) suggests evidences of bacterial defensive architecture breakdown. Thus, green synthesis of silver nanoparticles using a strong antimicrobial agent as both reducing and capping agent may have synergistic effect. Nanoparticles can breakdown the defensive barrier and helps to insert attached drug molecule over the surfaces.

Besides, target nanoparticle surfaces can be charged that also provide ease attachment of nanoparticles over the defensive brick architecture. But to get the optimum results research should be focused over the antimicrobial pure bio compound based synthesis. Even biological core-shell may also prove advantageous where single metal in core and dual drug on the surface can be easily prepared. In that case the drugs and the metal should follow an ascending order of reduction potential. 


\section{Green synthesized silver nanoparticles controlling antifungal activity}

Apart from bacterial pathogenesis, high rates of morbidity and mortality caused by fungal infections is also a severe concern to mankind. The problems is ever increasing as a limited new antifungal targets are explored and fungi are also developing resistance mechanism through mutation arch. In such scenario, silver nanoparticles which already been proved to exert antibacterial action are often tried against fungal infections. Due to limited antifungal arsenal, nanoparticles thought to serve as a carriers of antifungal. More interestingly, the if the reducing agent itself serves antifungal action and deposits over the nanoparticle surface as capping agent, it would offer synergistic antifungal action. Antifungal drug molecules can also be successfully adsorbed on the surface of biogenic silver thus can offer a efficient strategy for antifungal drug delivery. ${ }^{220}$

This strategy was successfully implemented by Kumar and co-workers. ${ }^{221}$ They initially synthesized spherical and monodispersed silver nanoparticles of $9.8 \mathrm{~nm}$ size using the cell free supernatant of Delftia sp. strain KCM-006. This AgNPs also exhibited antifungal activity. Further they conjugated antifungal drug miconazole to biogenic silver nanoparticles surface. This strategy exhibited significant fungicidal activity, inhibited of ergosterol biosynthesis and biofilm inhibition by increasing ROS levels.

Similar strategy was followed by Tutaj and co-workers. ${ }^{222}$ They proceeded their synthesis in an alkaline environment using Amphotericin B (AmB) as reducing and coating agent. This alkaline environment prevented aggregation of AmB itself and promotes to develop a monodisperse, AmB-coated silver nanoparticles (AmB-AgNPs) with the diameter $\sim 7 \mathrm{~nm}$. Similarly, Ahmad et al. who successfully developed a amphotericin B-conjugated biogenic silver nanoparticles with size of 424$433 \mathrm{~nm}$. They have successfully used amphotericin B as in situ reducing and capping agent for silver nanoparticles. Amphotericin B-conjugated biogenic silver nanoparticles offered synergistic antifungal activity against selected fungal strains i.e. C. albicans and C. tropicalis. ${ }^{223}$

Apart from such drug delivery example, green synthesized AgNPs are also reported to exhibits antifungal activity due to its bio-coating in combination with its size. Ishida et al., reported antifungal activity green synthesized AgNPs from the fungus Fusarium oxysporum. Green synthesized AgNPs showed a high level of antifungal activity against Candida and Cryptococcus, with minimum inhibitory concentration values $\leq 1.68 \mu \mathrm{g} \mathrm{ml}^{-1}$ for both genera. ${ }^{224}$ It has been investigated using disc diffusion method that colloidal silver has strong antifungal activity against three species of Candida like C. albicans, C. glabrata and C. tropicalis. ${ }^{225}$ Silver nanoparticles synthesized from Pilimelia columellifera subsp. pallida SL19 strain demonstrated antifungal activity against fungi causing superficial mycoses viz., $C$. albicans and M. furfur. The lowest MIC of AgNPs was noticed against $M$. furfur $\left(16 \mu \mathrm{g} \mathrm{ml}{ }^{-1}\right) \cdot{ }^{226}$ Mentha pulegium aqueous extract mediated synthesized AgNPs also showed considerable antifungal activity against fluconazole resistant Candida albicans. ${ }^{227}$ It has been established by food poisoning technique that the growth of following fungi like Bipolaris spicifera, Fusarium oxysporum, Aspergillus niger and Curvularia lunata is inhibited by NPs. ${ }^{228}$ Therefore AgNPs may be used as good antifungal drug to control several pathogenic fungi.

Green synthesized silver nanoparticles are found to effective against plant pathogenic fungi. The colonies of plant pathogenic fungi Bipolaris sorokiniana and Magnaporthe grisea are inhibited by applying nanosilver and ionic silver in vitro condition. ${ }^{229}$ Green synthesized AgNPs are much effective as broad spectrum fungicide against Alternaria alternata and Botrytis cinerea. The hyphae and conidia of these fungi are damaged by applying the NPs. ${ }^{230}$ The NPs also have strong synergistic activity with other fungicides against several plant pathogenic fungi like Fusarium graminearum (cause head blight of wheat), Fusarium oxysporum (cause tomato wilt), Fusarium solani (cause potato rot), and Penicillium expansum (cause apple rot). ${ }^{231}$ Elgorban et al. showed that nano silver has strong inhibitory effect on the growth of Rhizoctonia solani. ${ }^{232}$ The growth of some wood degrading fungi like Gloeophyllum abietinum, G. trabeum, Chaetomium globosum, and Phanerochaete sordida is inhibited by biogenic synthesized AgNPs. ${ }^{116}$ Thus apart from the bacterial control, green synthesized silver nanoparticles can be used in fungal control.

\section{Green synthesized silver nanoparticles against Leishmania}

Leishmaniasis, disease caused by parasites of the Leishmania type, is an emerging and uncontrollable disease, characterized as a category-1 disease by WHO. ${ }^{233}$ After malaria, it is the most prevalent infectious disease in terms of fatality and geographical distribution. ${ }^{234}$ The most common forms of leishmaniasis are cutaneous, characterized by skin sores, and visceral leishmaniasis which affects several internal organs like spleen, liver etc. Limited availability of antileishmanial drugs, its high cost and continuum resistance over the available drugs makes the situation fatal. To overcome such, green synthesis based drug delivery strategy is seen to open a newer avenue of treatment. The parasite is very much sensitive to AgNPs for the generation of ROS. It is reported that NPs have synergistic antiprotozoal activity against Leishmania tropica under UV light. ${ }^{235}$ As mentioned in the earlier section, the reducing and coating or stabilizing agent can also impart functional activity to AgNPs. Additionally, this coated surface of the biogenic nanoparticles can also act as a active site for the targeted drug for drug delivery option.

Ahmad et al. used this strategy and they initially synthesized spherical AgNPs (10-20 nm) using aqueous extract of Isatis tinctoria as reducing and capping agents. Later they have successfully adsorbed amphotericin B over the previously formed biogenic AgNPs surface. ${ }^{234}$ They observed a enhanced parasites activity of amphotericin B adsorbed silver nanoparticle $\left(\mathrm{IC}_{50}\right.$ value $\left.2.43 \mu \mathrm{g} \mathrm{ml}^{-1}\right)$ than biogenic nanoparticle $\left(\mathrm{IC}_{50}\right.$ value of $4.2 \mu \mathrm{g} \mathrm{ml}^{-1}$ ) against Leishmania tropica ${ }^{234}$ at promastigotes stage. Kalangi et al. has explored that miltefosine 
doped green synthesized AgNPs offer enhanced antileishmanial effect. They concluded their finding by reporting that green synthesized spherical AgNPs of $35 \mathrm{~nm}$ size at a concentration of $(50 \mu \mathrm{M})$ didn't show antileishmanial effect on promastigote stage of Leishmania parasite. But after applying in combination with miltefosine $(12.5 \mu \mathrm{M}$ and $25 \mu \mathrm{M}), 2$ fold magnification in antileishmanial effect was observed. ${ }^{236}$ Spherical AgNPs with a size of $12.82 \pm 2.5 \mathrm{~nm}$ was synthesized using aqueous leaf extract of Euphorbia prostrata. This biogenic nanoparticles offered parasitic activity against Leishmania donovani with a $\mathrm{IC}_{50}$ value of 3.89 and $14.94 \mu \mathrm{g} \mathrm{ml}^{-1}$ in amastigotes and promastigotes stage. ${ }^{237}$ Similar study by Ahmad et al. reported promising antileishmanial activity ( $\mathrm{IC}_{50}$ value 4.37 ) of green synthesized spherical AgNPs (3-8 nm) using phytochemicals from Sargentodoxa cuneata. ${ }^{238}$ Lopes et al. reported that green synthesized AgNPs using tannic acid (TA) officered antileishmanial activity. ${ }^{239}$ El-khadragy et al. reported clinical efficacy of biosynthesize AgNPs against Leishmania in in vivo rat model study. Biosynthesized spherical silver nanoparticle (116 nm) using Moringa oleifera extract resulted in a significant reduction in the average size of leishmaniasis cutaneous lesions compared with untreated mice. ${ }^{240}$ Green synthesized spherical Ag-NPs of $26 \mathrm{~nm}$ using Olax nana Wall. ex Benth. (family: Olacaceae) aqueous extract offered activity against Leishmania tropica (KMH23) promastigotes $\left(\mathrm{IC}_{50}=12.56\right.$ and $21.52 \mu \mathrm{g} \mathrm{ml}{ }^{-1}$ ) and amastigotes (17.44 and $\left.42.20 \mu \mathrm{g} \mathrm{ml}{ }^{-1}\right) .{ }^{241}$ Another study on green synthesized silver nanoparticle from Fusarium oxysporum exhibited strong activity against Leishmania amazonensis promastigote and amastigote forms. ${ }^{242}$ Ullah et al. showed that biogenic AgNPs are able to produce high level of nitric oxide (NO) in L. infantum infected macrophage cell. The production of NO radical is able to reduce the pathogenicity by killing the parasite. ${ }^{243}$ So green synthesized silver nanoparticle could be milestone in disease management of Leishmaniasis.

\section{Cytotoxicity of AgNPs}

Conversion of metal to its nanoform brings risk of toxicity. This is also true for the case of silver and depends upon the sizes, ${ }^{244}$ shapes $^{\mathbf{2 4 5}}$ and density of the AgNPs. ${ }^{\mathbf{1 1 0}}$ The toxicity concern of silver nanoparticles is suitably reduced with green synthesis method. The primary reason behind the nominal toxicity lies upon its coating which are generally biocompatible in nature. Although the primary role of the coating is to stabilize the nanoparticle and prevent agglomeration; but the biocompatible behaviour of coating makes green synthesized AgNPs suitable in different bio medicinal applications.

Early report suggests that stabilization of AgNPs by different polymers reduce the toxicity of AgNPs tested against mouse skin fibroblasts (L929), human hepatocarcinoma cells (HepG2), and mouse monocyte macrophages (J774A1). Polymer coated AgNPs at a concentration $1.5 \mathrm{ppm}$ exhibited hemocompatible nature. It can be noted that materials with a hemolysis ratio less than $5 \%$ were regarded as hemocompatible. ${ }^{246} \mathrm{~A}$ number of reports reveals that coating over the silver nanoparticle reduces its toxicity. ${ }^{247-250}$
In green synthesis, reduction and stabilization of the silver nanoparticles are achieved by the biocompatible material and hence the toxicity concern is reduced in most of the cases. Green synthesis using biopolymer i.e. glucan gave a glucan capped spherical AgNPs of $2.445 \pm 1.08 \mathrm{~nm}$. This nanoparticles exhibited only $0.68 \%$ hemolysis to human RBCs at its $\mathrm{LD}_{50}$ dosage. ${ }^{130}$ Thus, AgNPs-glucan conjugates were found to be compatible with human $\mathrm{RBCs}$ at its $\mathrm{LD}_{50}$ dosage. In an another study, polysaccharide capped AgNPs of $2.78 \pm 1.47 \mathrm{~nm}$ were synthesized from a hetero polysaccharide isolated from Lentinus squarrosulus (Mont.). This nanoparticles also gave compatible nature with human $\mathrm{RBCs}$ at its $\mathrm{LD}_{50}$ dosage. ${ }^{131}$ Similarly phytoconstituents also gave similar results of toxicity tested on human cell. AgNPs prepared using Croton bonplandianum leaves extract at its MIC dosage showed only $0.02 \%$ hemolysis. $^{251}$ AgNPs (spherical, $9.8 \mathrm{~mm}$ size) from cell free supernatant of Delftia sp. strain KCM-006 which was further used as a carrier of antifungal drug exhibited non-toxic nature up to a concentration of $20 \mu \mathrm{M}$. Biocompatibility level was assessed determining cell viability and immunocytochemistry analysis against different normal cell lines including Chinese hamster ovary cells (CHO), human lung cell line (MRC5) and human vascular endothelial cells (HUVEC). ${ }^{221}$ Silver nanoparticles synthesized from Anethum graveolens leaf extract also confer biocompatible nature. ${ }^{236}$ Aqueous extract of Rosa damascena mediated silver nanoparticle of 15-27 nm size also exhibited compatibility against erythrocytes. ${ }^{252}$ In another study, phytosynthesized AgNPs from aqueous extract of Salacia chinensis (SC) bark offer full biocompatibility when treated against normal human fibroblasts and blood erythrocytes. ${ }^{253}$ Thus the biocompatibility achieved through green synthesis suggests its possible use in varying field of biomedical application.

\section{Conclusion}

Based upon the previous discussion it can be said that the synthesis of nanoparticles may serve as a future direction in biomedical nanotechnology in developing antimicrobial compounds. The previously used metal antimicrobial may come with lots of possibilities with the advancement of green nanotechnology in combating multidrug resistance. Nanoparticles are seen to have ability to cross and disrupt the membrane. Thus loading drugs on the nanoparticle surface may increase the efficiency of biocidal motion by additional effect than disrupting the membrane. Thus it can have the future option to decode bacterial lipopolysaccharide Achilles. Toxicity of silver nanoparticles is also a major issue. Although biomolecular capping in green synthesis process reduces the toxicity, but it is imperative to develop more efficient capping and reducing agents for particular uses. The current trend of research is mainly carried out using the whole plant extracts as reducing and capping agents. This serves as a drawback regarding not clearly understanding the role of isolated pure bio molecules in synthesis and activity of nanoparticles. Synthesis using pure compound in an optimized condition may additionally give solution regarding the poly disparity of green nanoparticle synthesis. Thus studies using pure compounds 
would be carried out for better understanding the science behind the green synthesis. In near future new opportunities may also come with new problem solutions. From the previous discussion it can be concluded that this is the beginning of green nanoparticle synthesis. Green synthesis may serve many medicinal applications in near future.

\section{Conflicts of interest}

There are no conflicts to declare.

\section{Acknowledgements}

O. B. and M. D. Y. wish to thank Konya Food and Agriculture University (KFAU) and KFAU Research and Development Center for Diagnostic Kits (KIT-ARGEM) for their support.

\section{References}

1 A. Roy, O. L. Franco and S. M. Mandal, Curr. Protein Pept. Sci., 2013, 14, 580-587.

2 S. M. Mandal, A. Roy, A. K. Ghosh, T. K. Hazra, A. Basak and O. L. Franco, Front. Pharmacol., 2014, 5, 105.

3 A. Roy, K. Khanra, A. Mishra and N. Bhattacharyya, Int. J. Adv. Res., 2013, 1, 193-198.

4 S. M. Mandal, A. Roy, D. Mahata, L. Migliolo, D. O. Nolasco and O. L. Franco, J. Antibiot., 2014, 67, 771-775.

5 I. K. Sen, A. K. Mandal, R. Chakraborty, B. Behera, K. K. Yadav, T. K. Maiti and S. S. Islam, Carbohydr. Polym., 2014, 101, 188-195.

6 D. M. Livermore, M. Blaser, O. Carrs, G. Cassell, N. Fishman, R. Guidos, S. Levy, J. Powers, R. Norrby, G. Tillotson, R. Davies, S. Projan, M. Dawson, D. Monnet, M. Keogh-Brown, K. Hand, S. Garner, D. Findlay, C. Morel, R. Wise, R. Bax, F. Burke, I. Chopra, L. Czaplewski, R. Finch, D. Livermore, L. J. V. Piddock and T. White, J. Antimicrob. Chemother., 2011, 66, 19411944.

7 M. K. Rai, S. D. Deshmukh, A. P. Ingle and A. K. Gade, J. Appl. Microbiol., 2012, 112, 841-852.

8 J. A. Lemire, J. J. Harrison and R. J. Turner, Nat. Rev. Microbiol., 2013, 11, 371-384.

9 J. W. Alexander, Surg. Infect., 2009, 10, 289-292.

10 G. Borkow and J. Gabbay, Curr. Chem. Biol., 2009, 3, 272278.

11 L.-J. Ming, Med. Res. Rev., 2003, 23, 697-762.

12 Z. H. Chohan, C. T. Supuran and A. Scozzafava, J. Enzyme Inhib. Med. Chem., 2005, 20, 303-307.

13 S. Moharrer, B. Mohammadi, R. A. Gharamohammadi, Yargoli and M. Yargoli, Indian J. Sci. Technol., 2012, 5, 2443-2444.

14 H.-J. Lee, J. Y. Song and B. S. Kim, J. Chem. Technol. Biotechnol., 2013, 88, 1971-1977.

15 S. Azizi, M. B. Ahmad, F. Namvar and R. Mohamad, Mater. Lett., 2014, 116, 275-277.
16 P. S. Schabes-Retchkiman, G. Canizal, R. Herrera-Becerra, C. Zorrilla, H. B. Liu and J. A. Ascencio, Opt. Mater., 2006, 29, 95-99.

17 R. Raliya and J. C. Tarafdar, Agric. Res., 2013, 2, 48-57.

18 H. Gu, P. L. Ho, E. Tong, L. Wang and B. Xu, Nano Lett., 2003, 3, 1261-1263.

19 J. R. Morones-Ramirez, J. A. Winkler, C. S. Spina and J. J. Collins, Sci. Transl. Med., 2013, 5, 190 ra81.

20 M. Zhou, M. Lin, L. Chen, Y. Wang, X. Guo, L. Peng, X. Guo and W. Ding, Chem. Commun., 2015, 51, 5116-5119.

21 M. Rai, A. Yadav and A. Gade, Biotechnol. Adv., 2009, 27, 7683.

22 S. Gurunathan, J. W. Han, D.-N. Kwon and J.-H. Kim, Nanoscale Res. Lett., 2014, 9, 373.

23 P. Gong, H. Li, X. He, K. Wang, J. Hu, W. Tan, S. Zhang and X. Yang, Nanotechnology, 2007, 18, 285604.

24 P. Jain and T. Pradeep, Biotechnol. Bioeng., 2005, 90, 59-63. 25 I. Sawada, R. Fachrul, T. Ito, Y. Ohmukai, T. Maruyama and H. Matsuyama, J. Membr. Sci., 2012, 387-388, 1-6.

26 I. Sawada, R. Fachrul, T. Ito, Y. Ohmukai, T. Maruyama and H. Matsuyama, J. Membr. Sci., 2012, 387-388, 1-6.

27 A. Das, A. Kumar, N. B. Patil, C. Viswanathan and D. Ghosh, Carbohydr. Polym., 2015, 130, 254-261.

28 M. Shah, D. Fawcett, S. Sharma, S. Tripathy, G. Poinern, M. Shah, D. Fawcett, S. Sharma, S. K. Tripathy and G. E. J. Poinern, Materials, 2015, 8, 7278-7308.

29 S. F. Adil, M. E. Assal, M. Khan, A. Al-Warthan, M. R. H. Siddiqui and L. M. Liz-Marzán, Dalton Trans., 2015, 44, 9709-9717.

30 J. Virkutyte and R. S. Varma, Sustainable Preparation of Metal Nanoparticles, Royal Society of Chemistry, Cambridge, 2012.

31 P. Christian, F. Von der Kammer, M. Baalousha and T. Hofmann, Ecotoxicology, 2008, 17, 326-343.

32 A. K. Mittal, Y. Chisti and U. C. Banerjee, Biotechnol. Adv., 2013, 31, 346-356.

33 A. D. Dwivedi and K. Gopal, Colloids Surf., A, 2010, 369, 2733.

34 A. Rai, A. Prabhune and C. C. Perry, J. Mater. Chem., 2010, 20, 6789 .

35 M. Demurtas and C. C. Perry, Gold Bull., 2013, 47, 103-107. 36 S. Francis, S. Joseph, E. P. Koshy and B. Mathew, Artif. Cells, Nanomed., Biotechnol., 2018, 46, 795-804.

37 M. A. Asghar, E. Zahir, S. M. Shahid, M. N. Khan, M. A. Asghar, J. Iqbal and G. Walker, Lebensm.-Wiss. -Technol., 2018, 90, 98-107.

38 B. Ajitha, Y. A. K. Reddy, H.-J. Jeon and C. W. Ahn, Adv. Powder Technol., 2018, 29, 86-93.

39 M. Baghayeri, B. Mahdavi, Z. Hosseinpor-Mohsen Abadi and S. Farhadi, Appl. Organomet. Chem., 2018, 32, e4057.

40 L. Wang, C. Hu and L. Shao, Int. J. Nanomed., 2017, 12, 1227-1249.

41 Y. He, F. Wei, Z. Ma, H. Zhang, Q. Yang, B. Yao, Z. Huang, J. Li, C. Zeng and Q. Zhang, RSC Adv., 2017, 7, 39842-39851.

42 Y. He, X. Li, Y. Zheng, Z. Wang, Z. Ma, Q. Yang, B. Yao, Y. Zhao and H. Zhang, New J. Chem., 2018, 42, 2882-2888. 
43 S. Hamedi, S. A. Shojaosadati and A. Mohammadi, J. Photochem. Photobiol., B, 2017, 167, 36-44.

44 Y. K. Mohanta, S. K. Panda, R. Jayabalan, N. Sharma, A. K. Bastia and T. K. Mohanta, Front. Mol. Biosci., 2017, 4, 14.

45 N. Jain, A. Bhargava, M. Rathi, R. V. Dilip and J. Panwar, PLoS One, 2015, 10, e0134337.

46 M. N. Gallucci, J. C. Fraire, A. P. V. Ferreyra Maillard, P. L. Páez, I. M. Aiassa Martínez, E. V. Pannunzio Miner, E. A. Coronado and P. R. Dalmasso, Mater. Lett., 2017, 197, 98-101.

47 A. R. Allafchian, S. Z. Mirahmadi-Zare, S. A. H. Jalali, S. S. Hashemi and M. R. Vahabi, J. Nanostruct. Chem., 2016, 6, 129-135.

48 A. Ravichandran, P. Subramanian, V. Manoharan, T. Muthu, R. Periyannan, M. Thangapandi, K. Ponnuchamy, B. Pandi and P. N. Marimuthu, J. Photochem. Photobiol., B, 2018, 185, 117-125.

49 K. Anandalakshmi, J. Venugobal and V. Ramasamy, Appl. Nanosci., 2016, 6, 399-408.

50 P. S. Ramesh, T. Kokila and D. Geetha, Spectrochim. Acta, Part A, 2015, 142, 339-343.

51 K. Ali, B. Ahmed, S. Dwivedi, Q. Saquib, A. A. Al-Khedhairy and J. Musarrat, PLoS One, 2015, 10, e0131178.

52 H. M. M. Ibrahim, J. Radiat. Res. Appl. Sci., 2015, 8, 265-275.

53 N. Muniyappan and N. S. Nagarajan, Process Biochem., 2014, 49, 1054-1061.

54 P. Kumar, S. Senthamil Selvi and M. Govindaraju, Appl. Nanosci., 2013, 3, 495-500.

55 K. Paulkumar, G. Gnanajobitha, M. Vanaja, S. Rajeshkumar, C. Malarkodi, K. Pandian and G. Annadurai, Sci. World J., 2014, 2014, 829894.

56 P. Prakash, P. Gnanaprakasam, R. Emmanuel, S. Arokiyaraj and M. Saravanan, Colloids Surf., B, 2013, 108, 255-259.

57 F. T. Minhas, G. Arslan, I. H. Gubbuk, C. Akkoz, B. Y. Ozturk, B. Asıkkutlu, U. Arslan and M. Ersoz, Int. J. Biol. Macromol., 2018, 107, 157-165.

58 E. F. Aboelfetoh, R. A. El-Shenody and M. M. Ghobara, Environ. Monit. Assess., 2017, 189, 349.

59 V. S. Ramkumar, A. Pugazhendhi, K. Gopalakrishnan, P. Sivagurunathan, G. D. Saratale, T. N. B. Dung and E. Kannapiran, Biotechnol. Rep., 2017, 14, 1-7.

60 Z. Salari, F. Danafar, S. Dabaghi and S. A. Ataei, J. Saudi Chem. Soc., 2016, 20, 459-464.

61 T. Kathiraven, A. Sundaramanickam, N. Shanmugam and T. Balasubramanian, Appl. Nanosci., 2015, 5, 499-504.

62 N. Aziz, M. Faraz, R. Pandey, M. Shakir, T. Fatma, A. Varma, I. Barman and R. Prasad, Langmuir, 2015, 31, 11605-11612.

63 M. Yousefzadi, Z. Rahimi and V. Ghafori, Mater. Lett., 2014, 137, 1-4.

64 S. P. Sivagnanam, A. T. Getachew, J. H. Choi, Y. B. Park, H. C. Woo and B. S. Chun, Green Process. Synth., 2016, 6, 147-160.

65 D. Inbakandan, R. Venkatesan and S. Ajmal Khan, Colloids Surf., B, 2010, 81, 634-639.

66 T. Kathiraven, A. Sundaramanickam, N. Shanmugam and T. Balasubramanian, Appl. Nanosci., 2015, 5, 499-504.
67 H. M. El-Rafie, M. H. El-Rafie and M. K. Zahran, Carbohydr. Polym., 2013, 96, 403-410.

68 P. Kumar, S. S. Selvi, A. L. Prabha, K. P. Kumar, R. S. Ganeshkumar and M. Govindaraju, Nano Biomed. Eng., 2013, 52, 562-566.

69 A. Pugazhendhi, D. Prabakar, J. M. Jacob, I. Karuppusamy and R. G. Saratale, Microb. Pathog., 2018, 114, 41-45.

70 S. Murugesan, S. Bhuvaneswari and V. Sivamurugan, Int. J. Pharm. Pharm. Sci., 2017, 9, 192-197.

71 A. P. de Aragão, T. M. de Oliveira, P. V. Quelemes, M. L. G. Perfeito, M. C. Araújo, J. de A. S. Santiago, V. S. Cardoso, P. Quaresma, J. R. de Souza de Almeida Leite and D. A. da Silva, Arabian J. Chem., DOI: 10.1016/ J.ARABJC.2016.04.014.

72 F. WA, A. E. BEE, S. WF and F. WA, J. Nanomed. Nanotechnol., 2016, 07, 1-4.

73 V. Lavakumar, K. Masilamani, V. Ravichandiran, N. Venkateshan, D. V. R. Saigopal, C. K. Ashok Kumar and C. Sowmya, Chem. Cent. J., 2015, 9, 42.

74 H. M. El-Rafie, M. H. El-Rafie and M. K. Zahran, Carbohydr. Polym., 2013, 96, 403-410.

75 V. Venkatpurwar and V. Pokharkar, Mater. Lett., 2011, 65, 999-1002.

76 A. S. Sonker, Richa, J. Pathak, Rajneesh, V. K. Kannaujiya and R. P. Sinha, Can. J. Biotechnol., 2017, 1, 26-37.

77 N. O. San Keskin, N. Koçberber Kılıç, G. Dönmez and T. Tekinay, J. Nano Res., 2016, 40, 120-127.

78 V. Patel, D. Berthold, P. Puranik and M. Gantar, Biotechnol. Rep., 2015, 5, 112-119.

79 G. Singh, P. K. Babele, S. K. Shahi, R. P. Sinha, M. B. Tyagi and A. Kumar, J. Microbiol. Biotechnol., 2014, 24, 1354-1367.

80 F. M. Morsy, N. A. Nafady, M. H. Abd-Alla and D. A. Elhady, Univers. J. Microbiol. Res., 2014, 2, 36-43.

81 S. Neethu, S. J. Midhun, E. K. Radhakrishnan and M. Jyothis, Microb. Pathog., 2018, 116, 263-272.

82 T. Singh, K. Jyoti, A. Patnaik, A. Singh, R. Chauhan and S. S. Chandel, J. Genet. Eng. Biotechnol., 2017, 15, 31-39.

83 L. Ma, W. Su, J.-X. Liu, X.-X. Zeng, Z. Huang, W. Li, Z.-C. Liu and J.-X. Tang, Mater. Sci. Eng., C, 2017, 77, 963-971.

84 R. Al-Bahrani, J. Raman, H. Lakshmanan, A. A. Hassan and V. Sabaratnam, Mater. Lett., 2017, 186, 21-25.

85 M. Eugenio, N. Müller, S. Frasés, R. Almeida-Paes, L. M. T. R. Lima, L. Lemgruber, M. Farina, W. de Souza and C. Sant'Anna, RSC Adv., 2016, 6, 9893-9904.

86 J. G. Fernández, M. A. Fernández-Baldo, E. Berni, G. Camí, N. Durán, J. Raba and M. I. Sanz, Process Biochem., 2016, 51, 1306-1313.

87 B. Xue, D. He, S. Gao, D. Wang, K. Yokoyama and L. Wang, Int. J. Nanomed., 2016, 11, 1899-1906.

88 S. K. Singdevsachan, U. K. Parida, H. Bae, Y. K. Mohanta, T. K. Mohanta and S. K. Panda, IET Nanobiotechnol., 2016, 10, 184-189.

89 F. Niknejad, M. Nabili, R. Daie Ghazvini and M. Moazeni, Curr. Med. Mycol., 2015, 1, 17-24.

90 P. Ramalingmam, S. Muthukrishnan and P. Thangaraj, Journal of Nanoscience and Nanoengineering, 2015, 1, 241247. 
91 D. Singh, V. Rathod, S. Ninganagouda, J. Herimath and P. Kulkarni, J. Pharm. Res., 2013, 7, 448-453.

92 M. Saravanan, S. Arokiyaraj, T. Lakshmi and A. Pugazhendhi, Microb. Pathog., 2018, 117, 68-72.

93 L. Gan, S. Zhang, Y. Zhang, S. He and Y. Tian, Prep. Biochem. Biotechnol., 2018, 1-7.

94 M. A. Shaker and M. I. Shaaban, J. Taibah Univ. Med. Sci., 2017, 12, 291-297.

95 P. Singh, Y. J. Kim, C. Wang, R. Mathiyalagan and D. C. Yang, Artif. Cells, Nanomed., Biotechnol., 2016, 44, 1569-1575.

96 P. S. Nayak, M. Arakha, A. Kumar, S. Asthana, B. C. Mallick and S. Jha, RSC Adv., 2016, 6, 8232-8242.

97 J. H. Jo, P. Singh, Y. J. Kim, C. Wang, R. Mathiyalagan, C.-G. Jin and D. C. Yang, Artif. Cells, Nanomed., Biotechnol., 2016, 44, 1576-1581.

98 R. Thomas, A. Janardhanan, R. T. Varghese, E. V Soniya, J. Mathew and E. K. Radhakrishnan, Braz. J. Microbiol., 2014, 45, 1221-1227.

99 C. Malarkodi, S. Rajeshkumar, K. Paulkumar, M. Vanaja, G. D. G. Jobitha and G. Annadurai, Drug Invent. Today, 2013, 5, 119-125.

100 M. S.-V. Nélly, E. D. C. Nelson, d. A. S. Taciana, V. Q. Patrick, R. d. A. Alyne, C. M. d. M. Ana, L. d. S. C. Ana, P. F. L. João, B. A. Ricardo, A. d. S. Durcilene, R. d. S. d. A. L. José and F. S. T. Maria, Afr. J. Biotechnol., 2017, 16, 2072-2082.

101 B. Buszewski, V. Railean-Plugaru, P. Pomastowski, K. Rafińska, M. Szultka-Mlynska, P. Golinska, M. Wypij, D. Laskowski and H. Dahm, J. Microbiol., Immunol. Infect., 2018, 51, 45-54.

102 H. M. Abd-Elnaby, G. M. Abo-Elala, U. M. Abdel-Raouf and M. M. Hamed, Egypt. J. Aquat. Res., 2016, 42, 301-312.

103 P. Sanjenbam, J. V. Gopal and K. Kannabiran, J. Mycol. Med., 2014, 24, 211-219.

104 P. Manivasagan, J. Venkatesan, K. Senthilkumar, K. Sivakumar and S.-K. Kim, BioMed Res. Int., 2013, 2013, 287638.

105 R. S. Prakasham, S. K. Buddana, S. K. Yannam and G. S. Guntuku, J. Microbiol. Biotechnol., 2012, 22, 614-621.

106 K. Khanra, A. Roy and N. Bhattacharyya, J. Nanosci. Nanotechnol., 2013, 1, 1-6.

107 S. Ahmed, M. Ahmad, B. L. Swami and S. Ikram, J. Adv. Res., 2016, 7, 17-28.

108 M. Rai, A. Yadav and A. Gade, Crit. Rev. Biotechnol., 2008, 28, 277-284.

109 P. Mohanpuria, N. K. Rana and S. K. Yadav, J. Nanopart. Res., 2008, 10, 507-517.

110 N. Roy, A. Gaur, A. Jain, S. Bhattacharya and V. Rani, Environ. Toxicol. Pharmacol., 2013, 36, 807-812.

111 V. L. Das, R. Thomas, R. T. Varghese, E. V Soniya, J. Mathew and E. K. Radhakrishnan, 3 Biotech, 2014, 4, 121-126.

112 K. Kalimuthu, R. Suresh Babu, D. Venkataraman, M. Bilal and S. Gurunathan, Colloids Surf., B, 2008, 65, 150-153.

113 S. R. Kumar Pandian, V. Deepak, K. Kalishwaralal, P. Viswanathan and S. Gurunathan, Braz. J. Microbiol., 2010, 41, 805-809.
114 S. Anil Kumar, M. K. Abyaneh, S. W. Gosavi, S. K. Kulkarni, R. Pasricha, A. Ahmad and M. I. Khan, Biotechnol. Lett., 2007, 29, 439-445.

115 R. M. Slawson, M. I. Van Dyke, H. Lee and J. T. Trevors, Plasmid, 1992, 27, 72-79.

116 K. B. Narayanan and H. H. Park, Eur. J. Plant Pathol., 2014, 140, 185-192.

117 P. Mukherjee, A. Ahmad, D. Mandal, S. Senapati, S. R. Sainkar, M. I. Khan, R. Parishcha, P. V. Ajaykumar, M. Alam, R. Kumar and M. Sastry, Nano Lett., 2001, 1, 515-519.

118 A. M. Fayaz, K. Balaji, M. Girilal, R. Yadav, P. T. Kalaichelvan and R. Venketesan, Nanomedicine, 2010, 6, 103-109.

119 M. Rai and N. E. Duran, Metal nanoparticles in microbiology, Springer, 2011.

120 K. B. Narayanan and N. Sakthivel, J. Hazard. Mater., 2011, 189, 519-525.

121 A. Ahmad, S. Senapati, M. I. Khan, R. Kumar, R. Ramani, V. Srinivas and M. Sastry, Nanotechnology, 2003, 14, 824828.

122 D. Inbakandan, R. Venkatesan and S. Ajmal Khan, Colloids Surf., B, 2010, 81, 634-639.

123 S. Iravani, Green Chem., 2011, 13, 2638.

124 A. K. Jha, K. Prasad, K. Prasad and A. R. Kulkarni, Colloids Surf., B, 2009, 73, 219-223.

125 Y. Park, Y. N. Hong, A. Weyers, Y. S. Kim and R. J. Linhardt, IET Nanobiotechnol., 2011, 5, 69-78.

126 M. H. El-Rafie, M. E. El-Naggar, M. A. Ramadan, M. M. G. Fouda, S. S. Al-Deyab and A. Hebeish, Carbohydr. Polym., 2011, 86, 630-635.

127 X. Gao, L. Wei, H. Yan and B. Xu, Mater. Lett., 2011, 65, 2963-2965.

128 M. M. Kemp, A. Kumar, S. Mousa, E. Dyskin, M. Yalcin, P. Ajayan, R. J. Linhardt and S. A. Mousa, Nanotechnology, 2009, 20, 455104.

129 J. Koller, Drugs Exp. Clin. Res., 2004, 30, 183-190.

130 I. K. Sen, A. K. Mandal, S. Chakraborti, B. Dey, R. Chakraborty and S. S. Islam, Int. J. Biol. Macromol., 2013, 62, 439-449.

131 D. K. Manna, A. K. Mandal, I. K. Sen, P. K. Maji, S. Chakraborti, R. Chakraborty and S. S. Islam, Int. J. Biol. Macromol., 2015, 80, 455-459.

132 Z. Lu, K. Rong, J. Li, H. Yang and R. Chen, J. Mater. Sci.: Mater. Med., 2013, 24, 1465-1471.

133 S. Pal, Y. K. Tak and J. M. Song, Appl. Environ. Microbiol., 2007, 73, 1712-1720.

134 M. A. Raza, Z. Kanwal, A. Rauf, A. N. Sabri, S. Riaz and S. Naseem, Nanomaterials, 2016, 6, 74.

135 M. J. Yacamán, J. A. Ascencio, H. B. Liu and J. GardeaTorresdey, J. Vac. Sci. Technol., B: Microelectron. Nanometer Struct., 2001, 19, 1091.

136 A. Panáček, L. Kvítek, R. Prucek, M. Kolář, R. Večeřová, N. Pizúrová, V. K. Sharma, T. Nevěčná and R. Zbořil, J. Phys. Chem. B, 2006, 110, 16248-16253.

137 J. Li, K. Rong, H. Zhao, F. Li, Z. Lu and R. Chen, J. Nanosci. Nanotechnol., 2013, 13, 6806-6813. 
138 A. Ivask, I. Kurvet, K. Kasemets, I. Blinova, V. Aruoja, S. Suppi, H. Vija, A. Käkinen, T. Titma, M. Heinlaan, M. Visnapuu, D. Koller, V. Kisand and A. Kahru, PLoS One, 2014, 9, e102108.

139 M. R. El-Zahry, A. Mahmoud, I. H. Refaat, H. A. Mohamed, H. Bohlmann and B. Lendl, Talanta, 2015, 138, 183-189.

140 A. Alshareef, K. Laird and R. B. M. Cross, Appl. Surf. Sci., 2017, 424, 310-315.

141 P. Van Dong, C. H. Ha, L. T. Binh and J. Kasbohm, Int. Nano Lett., 2012, 2, 9.

142 A. Ahmad, Y. Wei, F. Syed, K. Tahir, A. U. Rehman, A. Khan, S. Ullah and Q. Yuan, Microb. Pathog., 2017, 102, 133-142.

143 S. Pal, Y. K. Tak and J. M. Song, Appl. Environ. Microbiol., 2007, 73, 1712-1720.

144 S. Chen and D. L. Carroll, Nano Lett., 2002, 2, 1003-1007.

145 L. Actis, A. Srinivasan, J. L. Lopez-Ribot, A. K. Ramasubramanian and J. L. Ong, J. Mater. Sci.: Mater. Med., 2015, 26, 215.

146 A. Parveen, M. S. Yalagatti, V. Abbaraju and R. Deshpande, J. Drug Delivery, 2018, 2018, 1-10.

147 P. Van Viet, T. T. Sang, N. H. N. Bich and C. M. Thi, J. Photochem. Photobiol., B, 2018, 182, 108-114.

148 J. S. Kim, E. Kuk, K. N. Yu, J.-H. Kim, S. J. Park, H. J. Lee, S. H. Kim, Y. K. Park, Y. H. Park, C.-Y. Hwang, Y.-K. Kim, Y.-S. Lee, D. H. Jeong and M.-H. Cho, Nanomedicine, 2007, 3, 95-101.

149 E. Pazos-Ortiz, J. H. Roque-Ruiz, E. A. Hinojos-Márquez, J. López-Esparza, A. Donohué-Cornejo, J. C. CuevasGonzález, L. F. Espinosa-Cristóbal and S. Y. Reyes-López, J. Nanomater., 2017, 2017, 1-9.

150 D. Mandal, S. Kumar Dash, B. Das, S. Chattopadhyay, T. Ghosh, D. Das and S. Roy, Biomed. Pharmacother., 2016, 83, 548-558.

151 K. Shameli, M. Bin Ahmad, E. A. Jaffar Al-Mulla, N. A. Ibrahim, P. Shabanzadeh, A. Rustaiyan, Y. Abdollahi, S. Bagheri, S. Abdolmohammadi, M. S. Usman and M. Zidan, Molecules, 2012, 17, 8506-8517. 152 P. Phanjom and G. Ahmed, Adv. Nat. Sci.: Nanosci. Nanotechnol., 2017, 8, 045016.

153 A. M. El Badawy, R. G. Silva, B. Morris, K. G. Scheckel, M. T. Suidan and T. M. Tolaymat, Environ. Sci. Technol., 2011, 45, 283-287.

154 S. Ashraf, N. Akhtar, M. Ghauri, M. Rajoka, Z. M. Khalid and I. Hussain, Nanoscale Res. Lett., 2012, 7, 267.

155 K. Chitra and G. Annadurai, BioMed Res. Int., 2014, 2014, 16.

156 H. Mu, J. Tang, Q. Liu, C. Sun, T. Wang and J. Duan, Sci. Rep., 2016, 6, 18877.

157 T. S. Peretyazhko, Q. Zhang and V. L. Colvin, Environ. Sci. Technol., 2014, 48, 11954-11961.

158 A. P. V. Ferreyra Maillard, P. R. Dalmasso, B. A. López de Mishima and A. Hollmann, Colloids Surf., B, 2018, 171, 320-326.

159 T. C. Dakal, A. Kumar, R. S. Majumdar and V. Yadav, Front. Microbiol., 2016, 7, 1831.
160 N. Durán, M. Durán, M. B. de Jesus, A. B. Seabra, W. J. Fávaro and G. Nakazato, Nanomedicine, 2016, 12, 789-799.

161 Y. N. Slavin, J. Asnis, U. O. Häfeli and H. Bach, J. Nanobiotechnol., 2017, 15, 65.

162 M. T. Madigan, J. M. Martinko, K. Bender, D. P. Buckley and D. A. Stahl, Brock Biology of Microorganisms Plus Masteringmicrobiology With Etext, Benjamin-Cummings Pub Co, 2014.

163 T. J. Silhavy, D. Kahne and S. Walker, Cold Spring Harbor Perspect. Biol., 2010, 2, a000414.

164 V. Gopinath, S. Priyadarshini, M. F. Loke, J. Arunkumar, E. Marsili, D. MubarakAli, P. Velusamy and J. Vadivelu, Arabian J. Chem., 2017, 10, 1107-1117.

165 Q. Feng, J. Wu and G. Chen, J. Biomed. Mater. Res., 2000, 52, 662-668.

166 T. J. Beveridge, J. Bacteriol., 1999, 181, 4725-4733.

167 A. Abbaszadegan, Y. Ghahramani, A. Gholami, B. Hemmateenejad, S. Dorostkar, M. Nabavizadeh and H. Sharghi, J. Nanomater., 2015, 2015, 1-8.

168 B. Ramalingam, T. Parandhaman and S. K. Das, ACS Appl. Mater. Interfaces, 2016, 8, 4963-4976.

169 E. Z. Gomaa, J. Gen. Appl. Microbiol., 2017, 63, 36-43.

170 B. Das, S. Dash, D. Mandal, J. Adhikary, S. Chattopadhyay, S. Tripathy, A. Dey, S. Manna, S. Dey, D. Das and S. Roy, BLDE Univ. J. Health Sci., 2016, 1, 89.

171 C. Krishnaraj, E. G. Jagan, S. Rajasekar, P. Selvakumar, P. T. Kalaichelvan and N. Mohan, Colloids Surf., B, 2010, 76, 50-56.

172 T. A. Abalkhil, S. A. Alharbi, S. H. Salmen and M. Wainwright, Biotechnol. Biotechnol. Equip., 2017, 31, 411-417.

173 Y.-G. Yuan, Q.-L. Peng and S. Gurunathan, Int. J. Mol. Sci., 2017, 18, 569.

174 M. A. Ansari and M. A. Alzohairy, Evid.-Based Complementary Altern. Med., 2018, 2018, 1-9.

175 J. S. McQuillan, H. Groenaga Infante, E. Stokes and A. M. Shaw, Nanotoxicology, 2012, 6, 857-866.

176 S. Ninganagouda, V. Rathod, D. Singh, J. Hiremath, A. K. Singh, J. Mathew and M. ul-Haq, BioMed Res. Int., 2014, 2014, 753419.

177 B. Chopade, S. Ghosh, M. Patil, R. Ahire, S. Kitture, K. Jabgunde, S. S. Kale, J. Pardesi, D. D. Cameotra, A. Bellare and B. A. Dhavale, Int. J. Nanomed., 2012, 7, 483.

178 S. Y. Liau, D. C. Read, W. J. Pugh, J. R. Furr and A. D. Russell, Lett. Appl. Microbiol., 1997, 25, 279-283.

179 K. B. Holt and A. J. Bard, Biochemistry, 2005, 44, 1321413223.

180 H. S. Toh, C. Batchelor-McAuley, K. Tschulik and R. G. Compton, Sci. China: Chem., 2014, 57, 1199-1210.

181 C.-N. Lok, C.-M. Ho, R. Chen, Q.-Y. He, W.-Y. Yu, H. Sun, P. K.-H. Tam, J.-F. Chiu and C.-M. Che, J. Proteome Res., 2006, 5, 916-924.

182 J. S. McQuillan and A. M. Shaw, Nanotoxicology, 2014, 8, 177-184.

183 S. K. Gogoi, P. Gopinath, A. Paul, A. Ramesh, S. S. Ghosh and A. Chattopadhyay, Langmuir, 2006, 22, 9322-9328. 
184 Y.-H. Hsueh, K.-S. Lin, W.-J. Ke, C.-T. Hsieh, C.-L. Chiang, D.-Y. Tzou and S.-T. Liu, PLoS One, 2015, 10, e0144306.

185 O. Bondarenko, A. Ivask, A. Käkinen, I. Kurvet and A. Kahru, PLoS One, 2013, 8, e64060.

186 S. Vishnupriya, K. Chaudhari, R. Jagannathan and T. Pradeep, Part. Part. Syst. Charact., 2013, 30, 1056-1062.

187 M. Rahban, A. Divsalar, A. A. Saboury and A. Golestani, J. Phys. Chem. C, 2010, 114, 5798-5803.

188 S. Pramanik, S. Chatterjee, A. Saha, P. S. Devi and G. Suresh Kumar, J. Phys. Chem. B, 2016, 120, 5313-5324.

189 S. Chowdhury, A. Basu and S. Kundu, Nanoscale Res. Lett., 2014, 9, 365.

190 M. A. Radzig, V. A. Nadtochenko, O. A. Koksharova, J. Kiwi, V. A. Lipasova and I. A. Khmel, Colloids Surf., B, 2013, 102, 300-306.

191 P. Dutta, A. Harrison, S. Sabbani, R. S. Munson, P. K. Dutta and W. J. Waldman, Int. J. Nanomed., 2011, 6, 1833.

192 K. Siriwardana, A. Wang, M. Gadogbe, W. E. Collier, N. C. Fitzkee and D. Zhang, J. Phys. Chem. C, 2015, 119, 2910-2916.

193 K. Poole, Efflux-mediated antimicrobial resistance, 2005, vol. 56.

194 X. Yan, B. He, L. Liu, G. Qu, J. Shi, L. Hu and G. Jiang, Metallomics, 2018, 10, 557-564.

195 N. S. Wigginton, A. de Titta, F. Piccapietra, J. Dobias, V. J. Nesatyy, M. J. F. Suter and R. Bernier-Latmani, Environ. Sci. Technol., 2010, 44, 2163-2168.

196 Z. Yuan, J. Li, L. Cui, B. Xu, H. Zhang and C.-P. Yu, Chemosphere, 2013, 90, 1404-1411.

197 T. S. Radniecki, D. P. Stankus, A. Neigh, J. A. Nason and L. Semprini, Chemosphere, 2011, 85, 43-49.

198 M. Yamanaka, K. Hara and J. Kudo, Appl. Environ. Microbiol, 2005, 71, 7589-7593.

199 M. Schieber and N. S. Chandel, Curr. Biol., 2014, 24, R453$\mathrm{R} 462$.

200 S. K. Verma, E. Jha, B. Sahoo, P. K. Panda, A. Thirumurugan, S. K. S. Parashar and M. Suar, RSC Adv., 2017, 7, 40034-40045.

201 H. Fu, J. Yuan and H. Gao, Arch. Biochem. Biophys., 2015, 584, 28-35.

202 S. B. Farr and T. Kogoma, Microbiol. Rev., 1991, 55, 561-585.

203 Y. Zhang, D. Meng, Z. Wang, H. Guo and Y. Wang, FEMS Microbiol. Lett., 2012, 334, 95-101.

204 W. Yang, C. Shen, Q. Ji, H. An, J. Wang, Q. Liu and Z. Zhang, Nanotechnology, 2009, 20, 085102.

205 L. Zou, J. Wang, Y. Gao, X. Ren, M. E. Rottenberg, J. Lu and A. Holmgren, Sci. Rep., 2018, 8, 11131.

206 B. Das, S. K. Dash, D. Mandal, T. Ghosh, S. Chattopadhyay, S. Tripathy, S. Das, S. K. Dey, D. Das and S. Roy, Arabian J. Chem., 2017, 10, 862-876.

207 S. Belluco, C. Losasso, I. Patuzzi, L. Rigo, D. Conficoni, F. Gallocchio, V. Cibin, P. Catellani, S. Segato and A. Ricci, Front. Microbiol., 2016, 7, 307.

208 K. Soo-Hwan, H. Seon Lee, D. Seon Ryu, S. Jae Choi and D. Seok Lee, Korean J. Microbiol. Biotechnol., 2011, 39, 7785.
209 P. Korshed, L. Li, Z. Liu and T. Wang, PLoS One, 2016, 11, e0160078.

210 M. A. Quinteros, V. Cano Aristizábal, P. R. Dalmasso, M. G. Paraje and P. L. Páez, Toxicol. In Vitro, 2016, 36, 216-223.

211 D. Soni, A. Bafana, D. Gandhi, S. Sivanesan and R. A. Pandey, Environ. Toxicol. Chem., 2014, 33, 2126-2132.

212 M. Y. Galperin, Environ. Microbiol., 2004, 6, 552-567.

213 A. Kobir, L. Shi, A. Boskovic, C. Grangeasse, D. Franjevic and I. Mijakovic, Biochim. Biophys. Acta, Gen. Subj., 2011, 1810, 989-994.

214 S. Shrivastava, T. Bera, A. Roy, G. Singh, P. Ramachandrarao and D. Dash, Nanotechnology, 2007, 18, 225103.

215 A. Roy, S. L. Shrivastava, S. M. Mandal, S. K. Roy and S. K. Srivastava, Adv. Sci., Eng. Med., 2015, 7, 465-472.

216 M. Yamanaka, K. Hara and J. Kudo, Appl. Environ. Microbiol., 2005, 71, 7589-7593.

217 W. K. Jung, H. C. Koo, K. W. Kim, S. Shin, S. H. Kim and Y. H. Park, Appl. Environ. Microbiol., 2008, 74, 2171-2178.

218 D. P. Li, Z. Zheng, Y. Lei, F. L. Yang, S. X. Ge, Y. D. Zhang, B. J. Huang, Y. H. Gao, K. W. Wong and W. M. Lau, Chem.Eur. J., 2011, 17, 7694-7700.

219 H. Dong, Q. Xiang, Y. Gu, Z. Wang, N. G. Paterson, P. J. Stansfeld, C. He, Y. Zhang, W. Wang and C. Dong, Nature, 2014, 511, 52-56.

220 L. Scorzoni, A. C. A. de Paula e Silva, C. M. Marcos, P. A. Assato, W. C. M. A. de Melo, H. C. de Oliveira, C. B. Costa-Orlandi, M. J. S. Mendes-Giannini and A. M. Fusco-Almeida, Front. Microbiol., 2017, 08, 36.

221 C. G. Kumar and Y. Poornachandra, Colloids Surf., B, 2015, 125, 110-119.

222 K. Tutaj, R. Szlazak, K. Szalapata, J. Starzyk, R. Luchowski, W. Grudzinski, M. Osinska-Jaroszuk, A. Jarosz-Wilkolazka, A. Szuster-Ciesielska and W. I. Gruszecki, Nanomedicine, 2016, 12, 1095-1103.

223 A. Ahmad, Y. Wei, F. Syed, K. Tahir, R. Taj, A. U. Khan, M. U. Hameed and Q. Yuan, Microb. Pathog., 2016, 99, 271-281.

224 K. Ishida, T. F. Cipriano, G. M. Rocha, G. Weissmüller, F. Gomes, K. Miranda and S. Rozental, Mem. Inst. Oswaldo Cruz, 2014, 109, 220-228.

225 N. T. Khan and M. Mushtaq, Biol. Med., 2017, 09, 1-4.

226 M. Wypij, J. Czarnecka, H. Dahm, M. Rai and P. Golinska, J. Basic Microbiol., 2017, 57, 793-800.

227 A. H. A. Kelkawi, A. Abbasi Kajani and A.-K. Bordbar, IET Nanobiotechnol., 2017, 11, 370-376.

228 M. Bhagat, R. Anand, R. Datt, V. Gupta and S. Arya, J. Inorg. Organomet. Polym. Mater., 2018, 1-9.

229 Y.-K. Jo, B. H. Kim and G. Jung, Plant Dis., 2009, 93, 10371043.

230 S. M. Ouda, Res. J. Microbiol., 2014, 9, 34-42.

231 S. M. Ali, N. M. H. Yousef and N. A. Nafady, J. Nanomater., 2015, 2015, 1-10.

232 A. M. Elgorban, A. E.-R. M. El-Samawaty, M. A. Yassin, S. R. Sayed, S. F. Adil, K. M. Elhindi, M. Bakri and M. Khan, Biotechnol. Biotechnol. Equip., 2016, 30, 56-62. 
233 H. J. C. de Vries, S. H. Reedijk and H. D. F. H. Schallig, Am. J. Clin. Dermatol., 2015, 16, 99-109.

234 A. Ahmad, Y. Wei, F. Syed, S. Khan, G. M. Khan, K. Tahir, A. U. Khan, M. Raza, F. U. Khan and Q. Yuan, J. Photochem. Photobiol., B, 2016, 161, 17-24.

235 A. Allahverdiyev, E. Ş. Abamor, M. Bagirova, C. B. Ustundag, C. Kaya, F. Kaya and M. Rafailovich, Int. J. Nanomed., 2011, 6, 2705.

236 S. K. Kalangi, A. Dayakar, D. Gangappa, R. Sathyavathi, R. S. Maurya and D. Narayana Rao, Exp. Parasitol., 2016, 170, 184-192.

237 A. A. Zahir, I. S. Chauhan, A. Bagavan, C. Kamaraj, G. Elango, J. Shankar, N. Arjaria, S. M. Roopan, A. A. Rahuman and N. Singh, Antimicrob. Agents Chemother., 2015, 59, 4782-4799.

238 A. Ahmad, F. Syed, A. Shah, Z. Khan, K. Tahir, A. U. Khan and Q. Yuan, RSC Adv., 2015, 5, 73793-73806.

239 L. C. S. Lopes, L. M. Brito, T. T. Bezerra, K. N. Gomes, F. A. D. A. Carvalho, M. H. Chaves and W. Cantanhêde, An. Acad. Bras. Cienc., 2018, 90, 2679-2689.

240 M. El-khadragy, E. Alolayan, D. Metwally, M. El-Din, S. Alobud, N. Alsultan, S. Alsaif, M. Awad and A. Abdel Moneim, Int. J. Environ. Res. Public Health, 2018, 15, 1037.

241 M. Ovais, A. T. Khalil, A. Raza, N. U. Islam, M. Ayaz, M. Saravanan, M. Ali, I. Ahmad, M. Shahid and Z. K. Shinwari, Appl. Microbiol. Biotechnol., 2018, 102, 4393-4408.

242 J. R. Fanti, F. Tomiotto-Pellissier, M. M. Miranda-Sapla, A. H. D. Cataneo, C. G. T. de J. Andrade, C. Panis, J. H. da S. Rodrigues, P. F. Wowk, D. Kuczera, I. N. Costa,
C. V. Nakamura, G. Nakazato, N. Durán, W. R. Pavanelli and I. Conchon-Costa, Acta Trop., 2018, 178, 46-54.

243 I. Ullah, G. Cosar, E. S. Abamor, M. Bagirova, Z. K. Shinwari and A. M. Allahverdiyev, 3 Biotech, 2018, 8, 98.

244 J. S. Kim, T.-J. Yoon, K. N. Yu, B. G. Kim, S. J. Park, H. W. Kim, K. H. Lee, S. B. Park, J.-K. Lee and M. H. Cho, Toxicol. Sci., 2006, 89, 338-347.

245 D. E. Gorka, J. S. Osterberg, C. A. Gwin, B. P. Colman, J. N. Meyer, E. S. Bernhardt, C. K. Gunsch, R. T. DiGulio and J. Liu, Environ. Sci. Technol., 2015, 49, 10093-10098.

246 J.-J. Lin, W.-C. Lin, R.-X. Dong and S. Hsu, Nanotechnology, 2012, 23, 065102.

247 K. C. Nguyen, V. L. Seligy, A. Massarsky, T. W. Moon, P. Rippstein, J. Tan and A. F. Tayabali, J. Phys.: Conf. Ser., 2013, 429, 012025.

248 Y. Cheng, L. Yin, S. Lin, M. Wiesner, E. Bernhardt and J. Liu, J. Phys. Chem. C, 2011, 115, 4425-4432.

249 I. M. Pongrac, L. B. Ahmed, H. Mlinarić, D. D. Jurašin, I. Pavičić, A. M. Marjanović Čermak, M. Milić, S. Gajović and I. Vinković Vrček, J. Trace Elem. Med. Biol., 2018, 50, 684-692.

250 L. Brkić Ahmed, M. Milić, I. M. Pongrac, A. M. Marjanović, H. Mlinarić, I. Pavičić, S. Gajović and I. Vinković Vrček, Food Chem. Toxicol., 2017, 107, 349-361.

251 M. Beg, A. Maji, A. K. Mandal, S. Das, M. N. Aktara, P. K. Jha and M. Hossain, J. Mol. Recognit., 2017, 30, e2565.

252 B. Venkatesan, V. Subramanian, A. Tumala and E. Vellaichamy, Asian Pac. J. Trop. Med., 2014, 7, S294-S300.

253 K. Jadhav, S. Deore, D. Dhamecha, H. R. Rajeshwari, S. Jagwani, S. Jalalpure and R. Bohara, ACS Biomater. Sci. Eng., 2018, 4, 892-899. 